OAK RIDGE

NATIONAL LABORATORY

MANAGED BY UT-BATTELLE

FOR THE DEPARTMENT OF ENERGY

\title{
Ground-Source Integrated Heat Pump for Net-Zero-Energy Houses: Technology Status Report
}

\author{
R. W. Murphy \\ C. K. Rice \\ V. D. Baxter \\ W. G. Craddick
}

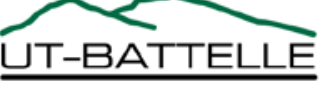




\section{DOCUMENT AVAILABILITY}

Reports produced after January 1, 1996, are generally available free via the

U.S. Department of Energy (DOE) Information Bridge:

Web site: http://www.osti.gov/bridge

Reports produced before January 1, 1996, may be purchased by members of the public from the following source:

National Technical Information Service

5285 Port Royal Road

Springfield, VA 22161

Telephone: 703-605-6000 (1-800-553-6847)

TDD: $703-487-4639$

Fax: 703-605-6900

E-mail: info@ntis.fedworld.gov

Web site: http://www.ntis.gov/support/ordernowabout.htm

Reports are available to DOE employees, DOE contractors, Energy Technology Data

Exchange (ETDE) representatives, and International Nuclear Information System

(INIS) representatives from the following source:

Office of Scientific and Technical Information

P.O. Box 62

Oak Ridge, TN 37831

Telephone: 865-576-8401

Fax: 865-576-5728

E-mail: reports@adonis.osti.gov

Web site: http://www.osti.gov/contact.html

This report was prepared as an account of work sponsored by an agency of the United States Government. Neither the United States government nor any agency thereof, nor any of their employees, makes any warranty, express or implied, or assumes any legal liability or responsibility for the accuracy, completeness, or usefulness of any information, apparatus, product, or process disclosed, or represents that its use would not infringe privately owned rights. Reference herein to any specific commercial product, process, or service by trade name, trademark, manufacturer, or otherwise, does not necessarily constitute or imply its endorsement, recommendation, or favoring by the United States Government or any agency thereof. The views and opinions of authors expressed herein do not necessarily state or reflect those of the United States Government or any agency thereof. 


\title{
Engineering Science and Technology Division
}

\section{Ground-Source Integrated Heat Pump for Net-Zero-Energy Houses: Technology Status Report}

\author{
R. W. Murphy \\ C. K. Rice \\ V. D. Baxter \\ W. G. Craddick \\ Oak Ridge National Laboratory
}

\section{December 2007}

\section{Prepared by}

Oak Ridge National Laboratory

P.O. Box 2008, Oak Ridge, Tennessee 37831-6285, managed by UT-Battelle, LLC

for the

U.S. Department of Energy under contract DE-AC05-00OR22725 


\section{CONTENTS}

List of Tables .............................................................................................. viii

EXECUTIVE SUMMARY .............................................................. 1



1.1 Prior Experience.......................................................................................... 3

1.1.1 Carrier/EPRI HydroTech 2000 ……………………............................... 4

1.1.2 Nordyne/EPRI Powermiser ………………………………………….... 5

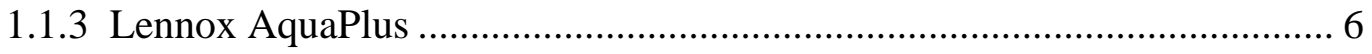

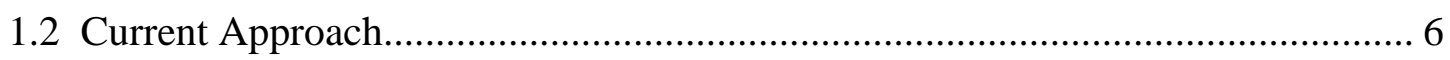

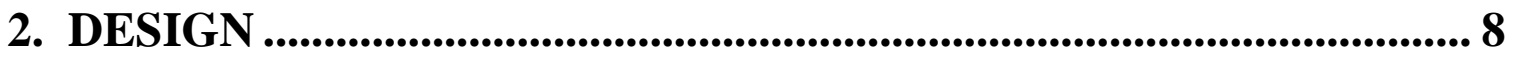

2.1 Refrigerant Compressor .............................................................................. 9

2.2 Domestic Hot Water Interface Heat Exchanger..................................................... 9

2.3 Ground Coil Interface Heat Exchanger............................................................ 9

2.4 Refrigerant Expansion Devices..................................................................... 9

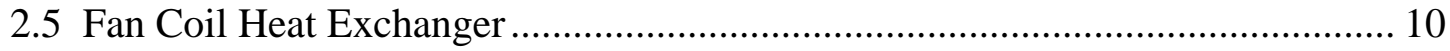

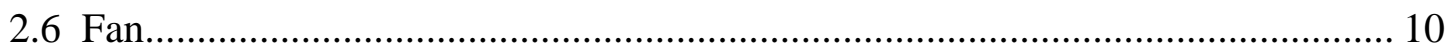

2.7 Domestic Hot Water Loop Pump.............................................................. 10

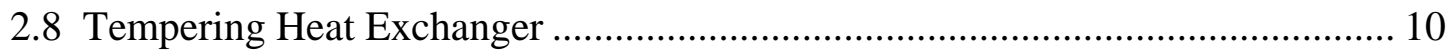

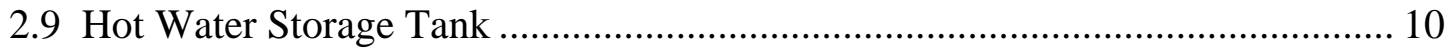



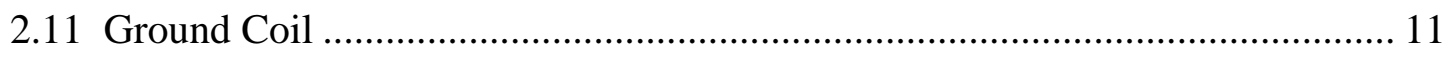

2.12 Ground Coil Loop Pump.......................................................................... 11

2.13 Bypass Water Valves ....................................................................................... 11

2.14 Development of R-410A GS-IHP Design Using the ORNL HPDM................. 11

3. OPERATIONAL MODES AND CONTROLS.................................. 14

3.1 Primary Functions ........................................................................................... 14

3.2 System Components and Control Types............................................................ 14

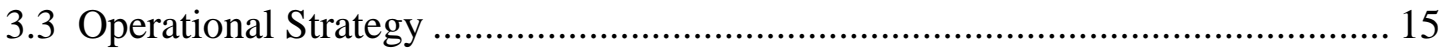

3.4 Inputs to the Control System ………….......................................................... 16

3.5 Operating Modes............................................................................................. 17

3.5.1 Space Cooling (AC) ............................................................................... 18

3.5.2 Space Cooling With Enhanced Dehumidification (ACEAD) .................... 18

3.5.3 Space Cooling Plus “On-Demand” Water Heating (ACWH) .................... 18

3.5.4 Space Cooling With Enhanced Dehumidification Plus "On-Demand"

Water Heating (ACEADWH) ................................................................. 19

3.5.5 Space Heating (AH) .............................................................................. 19 
3.5.6 Space Heating Plus “On-Demand” Water Heating (AHWH) .................... 19

3.5.7 Demand Water Heating (WH) ................................................................... 20

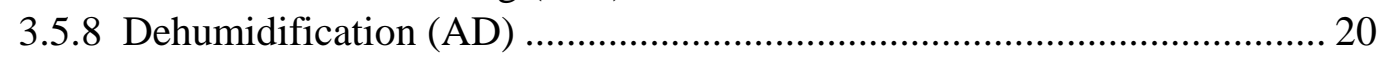

3.5.9 Space Dehumidification Plus Water Heating (ADWH) .............................. 21

3.5.10 Ventilation (AV)............................................................................... 21

3.5.11 Ventilation With Ventilation Air Dehumidification (AVVAD) .............. 21

3.6 GS-IHP System Speed Control Relationships .................................................... 22

3.6.1 Compressor Speed Ratio vs. Ambient in Cooling and Heating Modes .... 22

3.6.2 Control Parameters vs. Compressor Speed Ratio in the Space Cooling and Heating Modes ..................................................................................... 23

3.6.3 Control Parameters vs. Compressor Speed Ratio in the Dedicated and Heat Recovery Water Heating Modes............................................................. 25

3.6.4 Target Speed Ratios and Refrigerant Flow Control vs. Ambient in Space Cooling and Heating Modes ........................................................................ 27

3.6.5 Target Compressor Speed Ratios For Space Heating, Space Cooling, Water Heating, and Ventilation Cooling Modes vs. Ambient................... 29

\section{PREDICTED PERFORMANCE AND ENERGY SAVINGS FOR} ZEHs........................................................................................... 31

4.1 GS-IHP System Target Performance .................................................................... 31

4.1.1 Target GS-IHP Space Heating and Cooling Performance With Proposed Control Relationships for Load Tracking ................................................ 31

4.1.2 GS-IHP vs. AS-IHP Space Heating and Cooling Performance for Equivalent Ambients.

4.1.3 Target GS-IHP Water Heating Performance With Proposed Control Relationships.

4.1.4 Target ground-source IHP ventilation cooling performance vs. ambient with proposed control relationships.......................................................... 37

4.2 Development of Time-Series-Based Energy Use Calculations for IHPs.............. 39

4.2.1 Direct HPDM Call Implementation........................................................... 39

4.2.2 Map-Based IHP Modeling Implementation ................................................. 41

4.2.3 Aids for IHP Operation and Controls Assessment from TRNSYS Results

4.3 Applied Annual Sub-Hourly Performance Analyses Using R-410A …………... 43

4.3.1 Baseline HVAC/WH/DH/H System........................................................ 43

4.3.2 Ground-Source Integrated Heat Pump (GS-IHP) ...................................... 46

4.3.3 Analysis Approach and Results................................................................... 47

\section{UPDATED GS-IHP BUSINESS CASE ASSESSMENT .................. 52}

5.1 Baseline System Estimated Costs ..................................................................... 52



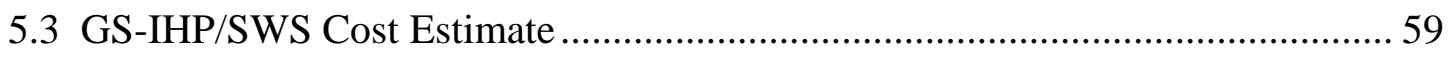

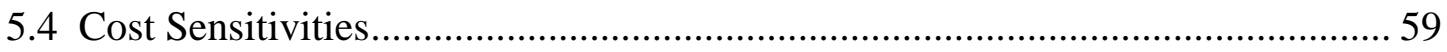


6. CONCLUSIONS AND RECOMMENDATIONS .............................. 63

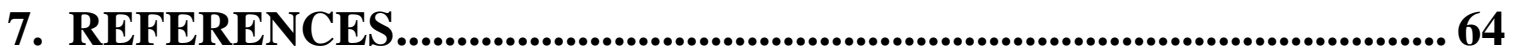




\section{List of Figures}

Figure 1.1 Conceptual installation of the residential ground-source integrated heat pump ......7

Figure 2.1 Schematic of ground-source integrated heat pump concept (space cooling plus on-

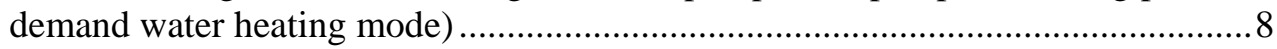

Figure 3.1 Target compressor speed ratios vs. ambient in the space cooling mode ...............23

Figure 3.2 Target compressor speed ratios vs. ambient in the space heating mode ...............23

Figure 3.3 Control parameters versus compressor speed ratio in the space cooling mode .....24

Figure 3.4 Control parameters versus compressor speed ratio in the space heating mode......25

Figure 3.5 Control parameters versus compressor speed ratio in the dedicated water heating

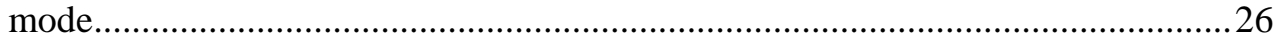

Figure 3.6 Control parameters versus compressor speed ratio in the space cooling/recovery

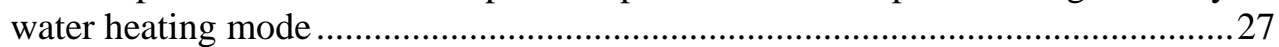

Figure 3.7 Target speed ratios and refrigerant flow control vs. ambient in the space cooling

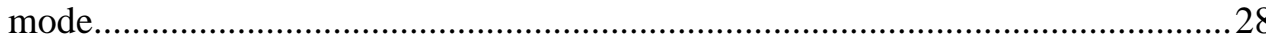

Figure 3.8 Target speed ratios and refrigerant flow control vs. ambient in the space heating

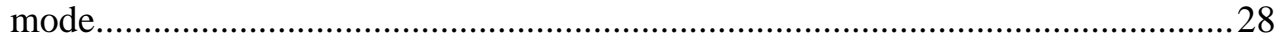

Figure 3.9 Target compressor speed ratios for various operating modes vs. ambient (DDH = dedicated dehumidification; $\mathrm{RH}=$ relative humidity)

Figure 4.1 Target GS-IHP space heating and cooling performance vs. ambient with proposed control relationships for load tracking.

Figure 4.2 Target GS-IHP space heating and cooling performance vs. EWT with proposed control relationships for load tracking

Figure 4.3 Comparison of target GS- and AS-IHP space heating and cooling performances as a function of equivalent ambients

Figure 4.4 Target GS-IHP water heating performance vs. ambient for shoulder season operation with the proposed control relationships ................................................ 35

Figure 4.5 Target GS-IHP water heating performance vs. ambient for heating season operation with the proposed control relationships 36

Figure 4.6 Relationship of ground-loop entering water temperatures to ambient for the GSIHP applied to a ZEH in Atlanta

Figure 4.7 Target GS-IHP ventilation cooling performance vs. ambient with proposed control relationships

Figure 4.8 Target GS-IHP sensible heat ratio (SHR) vs. ambient with proposed control relationships 39

Figure 4.9 Representative humidifier installation 
Figure 5.1 Average 2006 selling prices for 13-SEER, split-system heat pumps. (Source: www.smarterwayinc.com, 11/13/2006.)

Figure 5.2 GS-IHP schematic. Dedicated dehumidification and water heating mode is shown (with modifications resulting from elimination of desuperheating and changes in water-to-air HX operation) .....................................................................................55

Figure 5.3 Suggested arrangement for coaxial fitting for domestic hot water tank in IHP

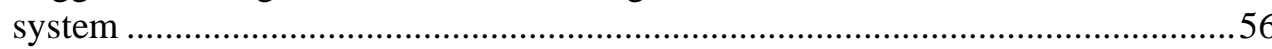




\section{LIST OF TABLES}

Table $3.1 \quad$ Major energy-consuming components for heat pumping..................................14

Table $3.2 \quad$ Minor energy-consuming components for heat pumping ...................................14

Table 3.3 Secondary energy-consuming components …...................................................15

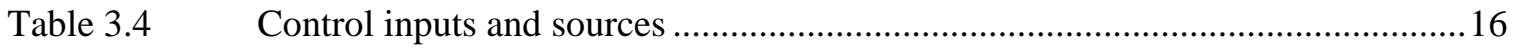

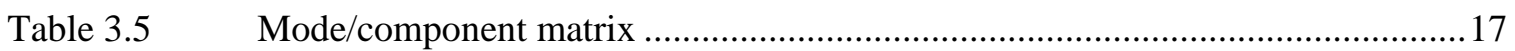

Table 4.1 Daily hot water draw schedule assumed for analyses .........................................46

Table 4.2 Annual site HVAC/WH system energy use and peak for 1800- $\mathrm{ft}^{2}$ ZEH with baseline HVAC/WH system..........................................................................49

Table 4.3 Estimated annual site HVAC/WH system energy use and peak for $1800-\mathrm{ft}^{2} \mathrm{ZEH}$ with GS-IHP system (winter humidification active) ..........................................49

Table 4.4 IHP performance vs. baseline system in ZEH (with humidifier) .........................50

Table 4.5 Comparison of GS-IHP performance vs. baseline HVAC/WH system with and without use of desuperheating for water heating................................................51

Table 5.1 Estimated installed costs for ZEH baseline HVAC/WH system (2006 dollars) ..54

Table 5.2 Estimated total bore lengths and installed costs for vertical ground heat exchangers in the five study locations............................................................5

Table 5.3 Estimated installed costs for ZEH GS-IHP system with humidifier (2006 dollars), assuming vertical-bore ground HX .........................................58

Table 5.4 Estimated installed costs for ZEH AS-IHP system (2006 dollars).......................58

Table 5.5 Estimated installed costs for ZEH SWS-enhanced GS-IHP system (2006 dollars)

Table 5.6 Sensitivity of AS-IHP and GS-IHP system payback vs. baseline system to assumed tax credits and TOU/demand electricity pricing.... 60

Table 5.7 Postulated TOU + demand rate structure used for IHP simple payback sensitivity assessment. 


\section{LIST OF ABBREVIATED TERMS}

AC

ACEAD

ACEADWH

ACWH

$\mathrm{AD}$

ADWH

$\mathrm{AH}$

AHWH

ARI

AS-IHP

AV

AVVAD

$\mathrm{C}$

COP

CPI

$\mathrm{DH}^{\top}$

DHW

DOE

DS

EER

$\mathrm{EF}$

$\mathrm{EF}_{\mathrm{d}}$

EPRI

EVI

EVO

EWT

FI

GC

GHX

GS-IHP

$\mathrm{H}$

HP

HPDM

HSPF

HVAC

HX
Space cooling (operating mode)

Space cooling with enhanced dehumidification (operating mode)

Space cooling with enhanced space dehumidification plus water heating (operating mode)

Space cooling plus water heating (operating mode)

Dehumidification (operating mode)

Dehumidification plus water heating (operating mode)

Space heating (operating mode)

Space heating plus water heating (operating mode)

Air-Conditioning and Refrigeration Institute

Air-source heat pump

Ventilation (operating mode)

Ventilation with ventilation air dehumidification (operating mode)

Compressor

Coefficient of performance

Department of Labor's Consumer Price Index

Dehumidifier

Domestic hot water

U.S. Department of Energy

Desuperheating

Energy efficiency ratio

Energy factor

Dehumidifier energy factor

Electric Power Research Institute

Refrigerant expansion valve for fan coil

Refrigerant expansion valve for ground coil interface

Entering water temperature

Variable-speed fan

Ground-coil loop

Ground heat exchanger

Ground-source heat pump

Humidification

Heat pump

DOE/ORNL Mark VI Heat Pump Design Model

Heating season performance factor

Heating, ventilating, and air conditioning (system)

Heat exchanger 
HXRAI Refrigerant-to-air heat exchanger, fan coil

HXRWI Refrigerant-to-water heat exchanger at domestic hot water interface

HXRWO Refrigerant-to-water heat exchanger at ground coil interface

HXWA Water-to-air heat exchanger, tempering

IHP Integrated heat pump

OEM Original equipment manufacturer

PI Single-speed pump

PID Proportional/integral/differential

PO Multi-speed pump

$\mathrm{RH} \quad$ Relative humidity

R\&D Research and development

RV Reversing valve

SEER Seasonal energy efficiency ratio

SHR Sensible heat ratio

SOM Standard outdoor module

SWS Solid water sorbent

TOU Time of use

TSD Technical Support Document

WH Water heater

WH Water heating (operating mode)

WT Hot water tank

ZEH Zero-energy home 


\section{EXECUTIVE SUMMARY}

The energy service needs of a net-zero-energy house (ZEH) include space heating and cooling, water heating, ventilation, dehumidification, and humidification, depending on the requirements of the specific location. These requirements differ in significant ways from those of current housing. For instance, the most recent DOE buildings energy data (DOE/BED 2007) indicate that on average $\sim 43 \%$ of residential buildings' primary energy use is for space heating and cooling, vs. $\sim 12 \%$ for water heating (about a 3.6:1 ratio). In contrast, for the particular prototype ZEH structures used in the analyses in this report, that ratio ranges from about 0.3:1 to 1.6:1 depending on location. The high-performance envelope of a ZEH results in much lower space heating and cooling loads relative to current housing and also makes the house sufficiently air-tight to require mechanical ventilation for indoor air quality. These envelope characteristics mean that the space conditioning load will be closer in size to the water heating load, which depends on occupant behavior and thus is not expected to drop by any significant amount because of an improved envelope. In some locations such as the Gulf Coast area, additional dehumidification will almost certainly be required during the shoulder and cooling seasons. In locales with heavy space heating needs, supplemental humidification may be needed because of health concerns or may be desired for improved occupant comfort. The U.S. Department of Energy (DOE) has determined that achieving their ZEH goal will require energy service equipment that can meet these needs while using $50 \%$ less energy than current equipment. One promising approach to meeting this requirement is through an integrated heat pump (IHP) - a single system based on heat pumping technology. The energy benefits of an IHP stem from the ability to utilize otherwise wasted energy; for example, heat rejected by the space cooling operation can be used for water heating. With the greater energy savings the cost of the more energy efficient components required for the IHP can be recovered more quickly than if they were applied to individual pieces of equipment to meet each individual energy service need. An IHP can be designed to use either outdoor air or geothermal resources (e.g., ground, ground water, surface water) as the environmental energy source/sink.

Based on a scoping study of a wide variety of possible approaches to meeting the energy service needs for a ZEH, DOE selected the IHP concept as the most promising and has supported research directed toward the development of both air- and ground-source versions. This report describes the ground-source IHP (GS-IHP) design and includes the lessons learned and best practices revealed by the research and development $(\mathrm{R} \& D)$ effort throughout.

Salient features of the GS-IHP include a variable-speed rotary compressor incorporating a brushless direct current permanent magnet motor which provides all refrigerant compression, a variable-speed fan for the indoor section, a multiple-speed ground coil circuit pump, and a singlespeed pump for water heating operation. Laboratory IHP testing has thus far used R-22 because of the availability of the needed components that use this refrigerant. It is expected that HFC R410A will be used for any products arising from the IHP concept. Data for a variable-speed compressor that uses R-410A has been incorporated into the DOE/ORNL Mark VI Heat Pump Design Model (HPDM). HPDM was then linked to TRNSYS, a time-series-dependent simulation model capable of determining the energy use of building cooling and heating equipment as applied to a defined house on a sub-hourly basis. This provided a highly flexible design analysis capability for advanced heat pump equipment; however, the program also took a relatively long time to run. This approach was used with the initial prototype design reported in Murphy et al. (2007a) and in the business case analysis of Baxter (2007). 
A revised approach was developed as described by Murphy et al. (2007b) that allows faster run time while maintaining essentially the same accuracy by using HPDM to generate an IHP performance map that is interrogated by TRNSYS using multi-parameter interpolation. A single multi-parameter performance map can be used to analyze different climates, houses, and control strategies, though it must be regenerated if significant changes are made to the IHP design.

The revised simulation approach was used to calculate the yearly performance of a GS-IHP design optimized for R-410A in five major cities representing the main climate zones in the United States: Atlanta (mixed-humid), Houston (hot-humid), Phoenix (hot-dry), San Francisco (marine), and Chicago (cold). The calculations extended for a full year using 3-minute time steps. The results showed greater than 50\% energy savings for all locations, with greater than $60 \%$ savings in Atlanta, Houston, and San Francisco.

This report provides design specifications based on the R\&D done by ORNL to date, along with a recommended control strategy. It should be noted that all R\&D conducted thus far for the GS-IHP has been aimed at the ZEH. However, modifications to these recommendations will be needed to produce a product optimized to achieve penetration in the current housing market, in which houses differ from the ultimate ZEH goal. These modifications may include eliminating some functions and substituting components to produce a simpler, less-expensive product for initial market penetration. Work in the future with a manufacturing partner (or partners) toward this latter goal is planned.

This report documents the development of a GS-IHP through the fourth quarter of FY2007 and along with another report (Integrated Heat Pump HVAC Systems for Near-Zero-Energy Homes Business Case Assessment, ORNL/TM-2007/064, Baxter), forms the basis for evaluating the GSIHP against DOE's Technology Development Stage-Gate management criteria for Gate 3, for transition from Stage 2, Exploratory Development, to Stage 3, Advanced Development. This report describes the technical development of the GS-IHP, including the most current design, updated analyses reflecting the use of R-410A, and proposed control strategy. The results obtained so far continue to support the GS-IHP being a promising candidate to meet the energy service needs for a ZEH in support of DOE's goal of ZEH-ready residential building designs by the year 2020. 


\section{INTRODUCTION}

The pursuit of net-ZEH residences brings new requirements for meeting space cooling, space heating, water heating, ventilation, and humidity loads. First, the tighter, less conductive envelopes characteristic of ZEH designs result in reduced space cooling and heating demands and, therefore, smaller required equipment capacities than are customary in today's homes. Second, as houses become tighter, there is less natural air infiltration, and mechanical ventilation is generally necessary to meet accepted air quality standards for residences. Moreover, bringing moist ventilation air to space neutral conditions increases the need for latent cooling. And third, although the space conditioning loads are smaller with a tighter building envelope, the water heating load, which depends largely on the number of occupants in the dwelling and their life styles, remains essentially unchanged. Consequently, the water heating load will become a larger portion of the overall energy service demands to be met by building equipment in the house.

Mechanical ventilation combined with reduced space conditioning loads and an unchanged hot water demand suggest that an integrated load-following system would be an effective way to meet the energy service needs of a net-ZEH. Such a system based on the demonstrated high efficiency of vapor compression technology, and denoted as the "integrated heat pump" (IHP) here, would provide in a single appliance for the ZEH space conditioning, ventilation, dehumidification, and water heating requirements.

Systems with the ability to follow load and control supply air sensible heat ratio (SHR) typically employ variable-speed components. Such capabilities also suggest long (near continuous) equipment runtimes, reflecting duty cycles that are well suited to conditioning a supply flow of ventilation air (typically small relative to the air circulation rates of conventional non-variablespeed heat pumps) and to the efficient production of domestic hot water (DHW) using heat pumping. Load following can also reduce on/off cycling and provide more consistent space temperature and humidity control, all leading to improved occupant comfort.

Variable-speed technologies are growing in use and in efficiency. Newsletters (such as International Institute of Refrigeration 2005) indicate that many Japanese heating, ventilation, and air conditioning (HVAC) equipment manufacturers have shifted their attention to variable refrigerant flow systems based on variable-speed technologies (e.g., brushless direct current motors, etc.) with attendant inverter drive systems. Although still more costly than conventional induction motors typically used in single-speed HVAC systems, variable-speed drives and motors have continued to drop in cost, as have most electronic components for equipment, especially for the production volumes in Asian markets. The remaining cost premium can be significantly offset through HVAC designs and control strategies that apply variable-speed technologies to perform the additional functions of dehumidification and water heating.

\subsection{Prior Experience}

While no residential GS-IHP has been attempted to date, at least three prior efforts have been made in the United States (Thorne 1998) to develop and successfully commercialize an air-source heat pump system with both space conditioning and water heating capability: the HydroTech 2000, the Powermiser, and the AquaPlus. 


\subsubsection{Carrier/EPRI HydroTech 2000}

The result of a cooperative effort between the Electric Power Research Institute (EPRI) and the Carrier Corporation, the HydroTech 2000 (38QE/40QE) was a residential system with five primary modes of operation: space cooling, space cooling plus water heating, space heating, space heating with water heating, and water heating only (Dunshee 1995). A novel defrost auxiliary mode used hot water from the storage tank as the heat source to evaporate refrigerant entering the compressor on its way to heat the outdoor coil, thereby removing ice buildup. Other auxiliary modes available for user selection included emergency heat, cooling plus humidity control, and heating plus humidity control. Separate ventilation and dedicated dehumidification (dehumidification only) modes were not incorporated in this system.

Based on development work started in 1982, four early prototypes were fabricated for testing in the laboratory and in a Carrier employee's home in 1985. In 1987-1988 ten improved prototypes were installed as the initial field trial in homes across the continental United States. Commercial production and sales of the systems began in 1989, with two versions offered: 2- and 3-ton nominal cooling capacities. These had Air-Conditioning and Refrigeration Institute (ARI) certified cooling capacities of 24,000 and 36,800 Btu/hr, heating capacities of 25,800 and 35,400 $\mathrm{Btu} / \mathrm{hr}$, and ratings of 13.35 and 14.05 seasonal energy efficiency ratio (SEER) and 8.75 and 9.05 heating season performance factor (HSPF), respectively. For the field demonstration phase, 31 sites in 16 states were selected in cooperation with participating utilities. Twenty-three of the 3ton and eight of the 2-ton instrumented production systems were installed at these locations, of which 27 (21 of the 3-ton systems and 6 of the 2-ton systems) produced useful first-year data and 14 (11 of the 3-ton systems and 3 of the 2-ton systems) produced useful second-year data. A separate field monitoring exercise was conducted at a single house in Maryland by the National Institute of Standards and Technology during the same period (Fanney 1993).

Relative to this unit, the EPRI perspective was: "The HydroTech 2000 represents the first fully integrated, variable-speed heat pump space-conditioning and water-heating system. Its field performance was excellent, and all field test participants noted its comfort and energy efficiency. However, the high first-cost of variable-speed equipment resulted in an expensive unit, which, in turn, resulted in low sales volume and finally, removal as a commercial product. Successful future marketing of similar systems will require adequate consumer understanding of the benefits and costs" (Dunshee 1995). Production and distribution of the HydroTech 2000 was terminated in 1992. Total sales over the three-year period were estimated to be a few hundred units.

This system employed a "triple-split" configuration, chosen to facilitate locating water-containing components indoors to avoid freezing situations. The configuration consisted of three separate parts provided by Carrier: a compressor section, an indoor fan-coil section, and an outdoor fancoil section. The compressor section was connected in the standard configuration to a conventional electric water heater (with resistance elements retained for back-up or emergency water-heating) to complete the arrangement required to provide the integrated functions of space conditioning and water heating. The refrigerant employed was R-22 (9.6 and $12.0 \mathrm{lb}_{\mathrm{m}}$ standard charge, respectively).

The compressor section was located indoors and contained the compressor with accumulator, drive, refrigerant control valves, refrigerant-to-water heat exchanger (HX), water pump, control box, and two temperature sensors. The compressor was a two-cylinder, reciprocating type driven by a variable-speed (1800 to $5400 \mathrm{rpm}$ ), electronically commutated motor with a permanent magnet rotor and three-phase stator. The refrigerant expansion/metering function was accomplished with a single bi-directional pulsing solenoid valve (with pulse-width modulation to follow system load), which also served to block flow through the refrigerant-to-air HX during 
defrost cycles and to prevent refrigerant migration during off cycles. Conventional reversing and defrost valves were employed. The copper tube-in-tube refrigerant-to-water HX surrounded the compressor and was sized to handle the full heat rejection of the heat pump. It consisted of four double-walled and vented inner tubes carrying refrigerant and a surrounding water-carrying annular space enclosed by an outer tube. Two of the inner tubes served as a desuperheater/condenser for the water heating modes, and the other two served as an evaporator for the water-source defrost function. The stainless steel water pump was a single-speed centrifugal type sized for $3 \mathrm{gpm}$. The control box in this section contained a standard outdoor module (SOM) plus a relay module and related power components. The SOM served as the microprocessor-based master control for the system, determining the various operating modes, conducting diagnostic functions, and maintaining bus communications with the indoor fan-coil section. The temperature sensors in this section were $10 \mathrm{k} \Omega$ thermistors located on the suction side of the accumulator (for freeze protection during water-source defrost) and on the discharge side of the compressor (for high-temperature protection).

The indoor fan-coil section contained a refrigerant-to-air HX, a fan with drive, a control box, and two temperature sensors. The refrigerant-to-air HX (3.16 and $5.00 \mathrm{ft}^{2}$ face area, respectively) was constructed using internally enhanced copper tubes and augmented aluminum external fins. Special circuiting was employed to optimize performance and assure proper oil return to the compressor over the full range of variable-load operation. The fan was a direct-drive centrifugal type with a variable-speed (250 to $1500 \mathrm{rpm}$ ) integral control motor similar in type to that associated with the compressor. The control box in this section contained a Standard Indoor Module (SIM) plus power components. The temperature sensors in this section were $10 \mathrm{k} \Omega$ thermistors located on the indoor refrigerant liquid tube (for coil freeze protection) and in the return air (for emergency heat over-temperature protection).

The outdoor fan-coil section contained a refrigerant-to-air HX, a fan, and some control elements. The refrigerant-to-air HX (15.0 and $20.5 \mathrm{ft}^{2}$ face area, respectively) was constructed using internally enhanced copper tubes and augmented aluminum external fins. As with the indoor HX, it was specially circuited to optimize performance and assure proper compressor oil return over the full range of variable-load operation. The fan was a direct-drive type using a multi-bladed propeller with a single-speed induction motor. The temperature sensors in this section were $10 \mathrm{k} \Omega$ thermistors located in the outdoor air (for mode, compressor, and electronic expansion valve control) and on the outdoor refrigerant liquid tube (for defrost control).

The system was controlled by three separate microprocessor-based modules associated with the compressor section, the indoor section, and the thermostat. As described above, six temperature sensors were located in the various sections. One additional temperature sensor (a $10 \mathrm{k} \Omega$ thermistor) was located in the bottom fitting of the water tank (for water heating modes control). Together, these seven temperature sensors provided inputs necessary for the control system to determine, at any given time, which of the components (compressor, indoor fan, outdoor fan, reversing valve, expansion valve, water pump, and resistance heating elements) should be operating and at what rate the compressor, indoor fan, and expansion valve should be operating.

\subsubsection{Nordyne/EPRI Powermiser}

EPRI also co-sponsored a more recent effort with Nordyne, Inc., to develop a lower-cost unit with combined space-conditioning and water-heating capabilities. The Powermiser (Nordyne), introduced in 1992, was marketed under the Miller brand name in 2-, 3-, and 4-ton nominal capacities. SEER 10 (HSPF 7.0) versions of these systems had rated cooling capacities of 22,600, 34,600 , and 45,000 Btu/hr and heating capacities of 21,000, 34,600, and 45,000 Btu/hr, respectively. SEER 12 (HSPF 7.6) versions employed next-nominal-size indoor coils to boost 
both efficiency and capacity, having rated cooling capacities of 24,000, 36,000, and 48,000

$\mathrm{Btu} / \mathrm{hr}$ and heating capacities of 24,000, 36,000, and 48,000 Btu/hr, respectively. Production was halted after several years on the market and estimated total sales were a few thousand units.

The Powermiser had many design similarities to the HydroTech: each was a "triple-split" system with three sections, each employed R-22 as the refrigerant (standard charge 9.9, 13.0, and 16.8 $\mathrm{lb}_{\mathrm{m}}$, respectively, for the Powermiser), and each had a similar list of available operating modes. However, major differences in the Powermiser included the use of only single-speed compressor and fan components, the use of electromechanical controls, the use of two fixed-orifice (0.071-, 0.082-, and 0.093-in. indoor, respectively, and 0.059-, 0.063-, and 0.061-in. outdoor, respectively) expansion devices with sliding check valve functions, the use of air-source defrosting, and the implementation of a charge management system.

\subsubsection{Lennox AquaPlus}

A still more recent product was the Lennox AquaPlus (introduced in mid-1997). Based on concepts initially reported (Gilles 1994) and patented (United States Patent 1994) by Lennox, this unit was essentially a heat pump water-heating unit that was added to a conventional heat pump system. The main module (Lennox 1997) was based on R-22 as the refrigerant (standard charge $2.4 \mathrm{lb}_{\mathrm{m}}$ ) and had a list of components similar in nature to, but different in flexibility from, the HydroTech 2000's compressor section. These encompassed a compressor (single-speed rotary type for the AquaPlus) with accumulator, refrigerant-to-water HX, water pump (single-speed, 3.6 gpm), and controls. However, in the AquaPlus case, this module was solely controlled by demand for hot water. An entirely separate conventional compressor, condenser, expansion valve, and evaporator heat pump system responded to calls for space cooling or heating.

The AquaPlus employed its own refrigerant evaporator coil (with expansion valve) in the return duct to the conventional indoor fan coil to remove heat from the air stream before it encountered the conventional indoor coil. The indoor fan was controlled so as to operate at a low speed when there was only water-heating demand and at high speed when there was any space-conditioning demand. As in the HydroTech 2000 and Powermiser cases, water was pumped from a conventional electrical resistance water-heating tank through the AquaPlus refrigerant-to-water HX and returned to the tank. The water flowed through spiral double-walled copper inner tubes of the helical coaxial tube-in-tube exchanger, receiving heat from the refrigerant condensing between the inner surface of the surrounding steel outer tube and the exterior of the inner tubes.

When there was demand for hot water, the AquaPlus operated, producing hot water efficiently while removing heat from the return air stream, and thereby reducing by approximately 1 ton the cooling load to be accommodated by the conventional space conditioning heat pump.

\subsection{Current Approach}

The current IHP approach (Tomlinson et al. 2005, Murphy et al. 2007a and 2007b) builds on earlier experience garnered from the product development efforts outlined above. At the same time, it recognizes important changes in the residential housing environment that may affect system appeal. As described above, if the marketplace moves toward ZEH-type residences, smaller, more efficient space-conditioning and water-heating systems that can accommodate not only customary loads, but also new active ventilation and dehumidification requirements, will be needed. The relatively large number of current two-story houses with multiple smaller heat pumps might provide a nearer-term market that could induce manufacturers to produce such "futuristic" equipment, especially for "early adopters." If these trends intersect with international component cost reduction trends observed in variable-speed, high-efficiency equipment, and with 
the increasing cost, capacity, and emissions pressures associated with the world energy production markets, the residential GS-IHP, illustrated conceptually in Fig. 1.1, may fill a substantial and valuable niche in the energy-efficiency arsenal. However, the costs and benefits of the GS-IHP system will be weighed in the marketplace against competing suites of individual components that can meet the same imposed loads.

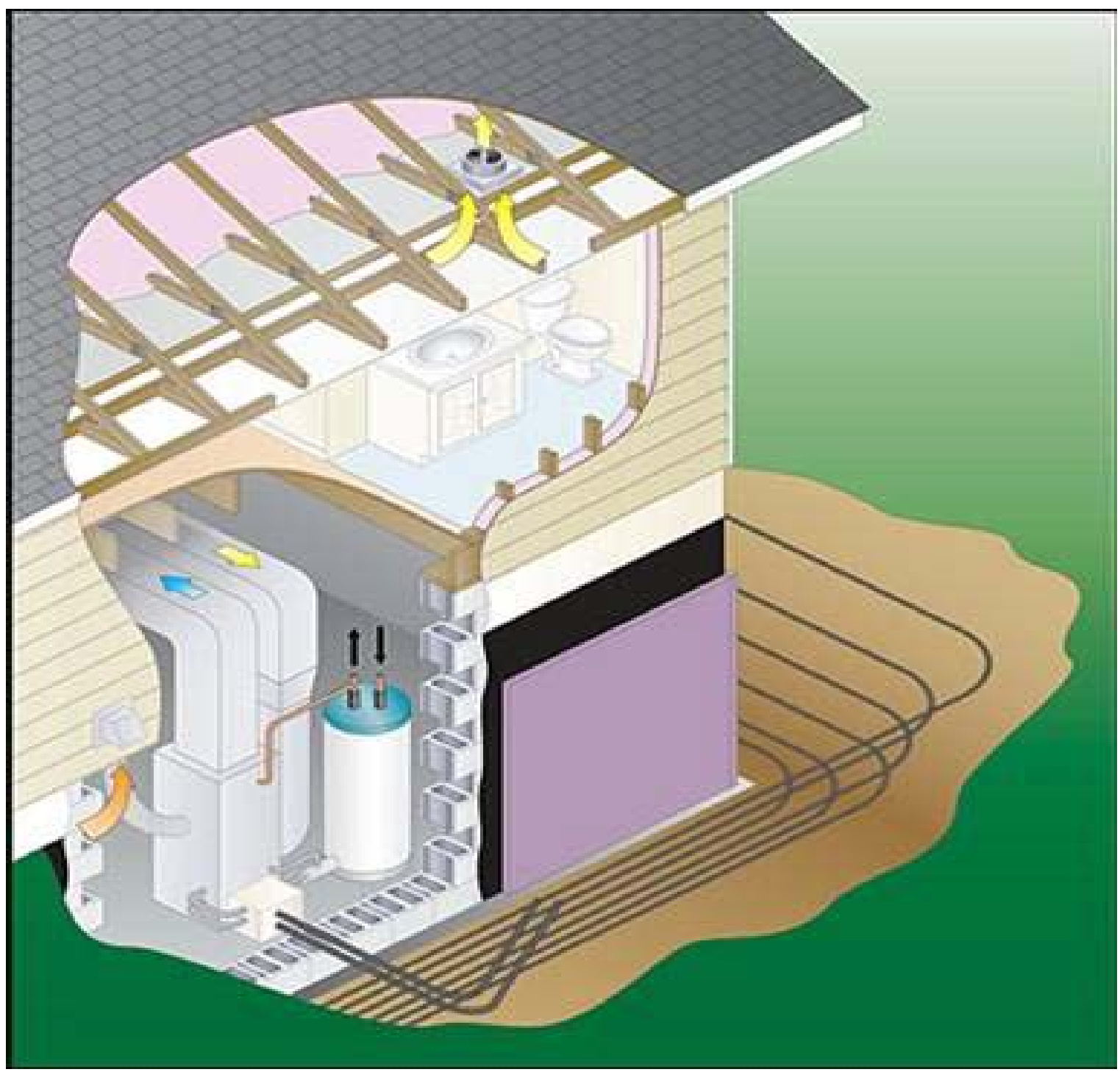

Fig. 1.1. Conceptual installation of the residential ground-source integrated heat pump. 


\section{DESIGN}

The conceptual design for the GS-IHP is based on prior assessments of various concepts. As indicated schematically in Fig. 2.1, the current arrangement incorporates three separate but interactive loops, one refrigerant, one domestic hot water, and one ground coil water (or an antifreeze/water mixture for cold climates), that employ several major electrical-energyconsuming components for heat pumping operation, including one variable-speed compressor (C), one variable-speed fan (FI), and two pumps - one single-speed pump (PI) for the domestic hot water loop and one multiple-speed pump (PO) for the ground coil loop (GC). The remaining major components include a reversing valve (RV), two refrigerant expansion valves [one for the fan coil (EVI) and one for the ground coil interface (EVO)], and four HXs to meet the space conditioning and water heating loads: one refrigerant-to-air (fan coil, HXRAI), one water-to-air (tempering, HXWA), and two refrigerant-to-water [domestic hot water interface (HXRWI) and ground coil interface (HXRWO]. The water-to-air HX uses hot water generated by heat recovery in the cooling and the dehumidification modes and stored in the hot water tank (WT) to temper the ventilation air, as needed, to meet space neutral temperature requirements. Modulation of compressor speed and indoor fan speed can be used to control both supply air humidity and temperature as required. With this arrangement, water heating and air tempering can be accomplished simultaneously. Selection of appropriate specific components and their incorporation in a logical fashion provide flexibility that allows operation over a wide range of modes and parameter ranges.

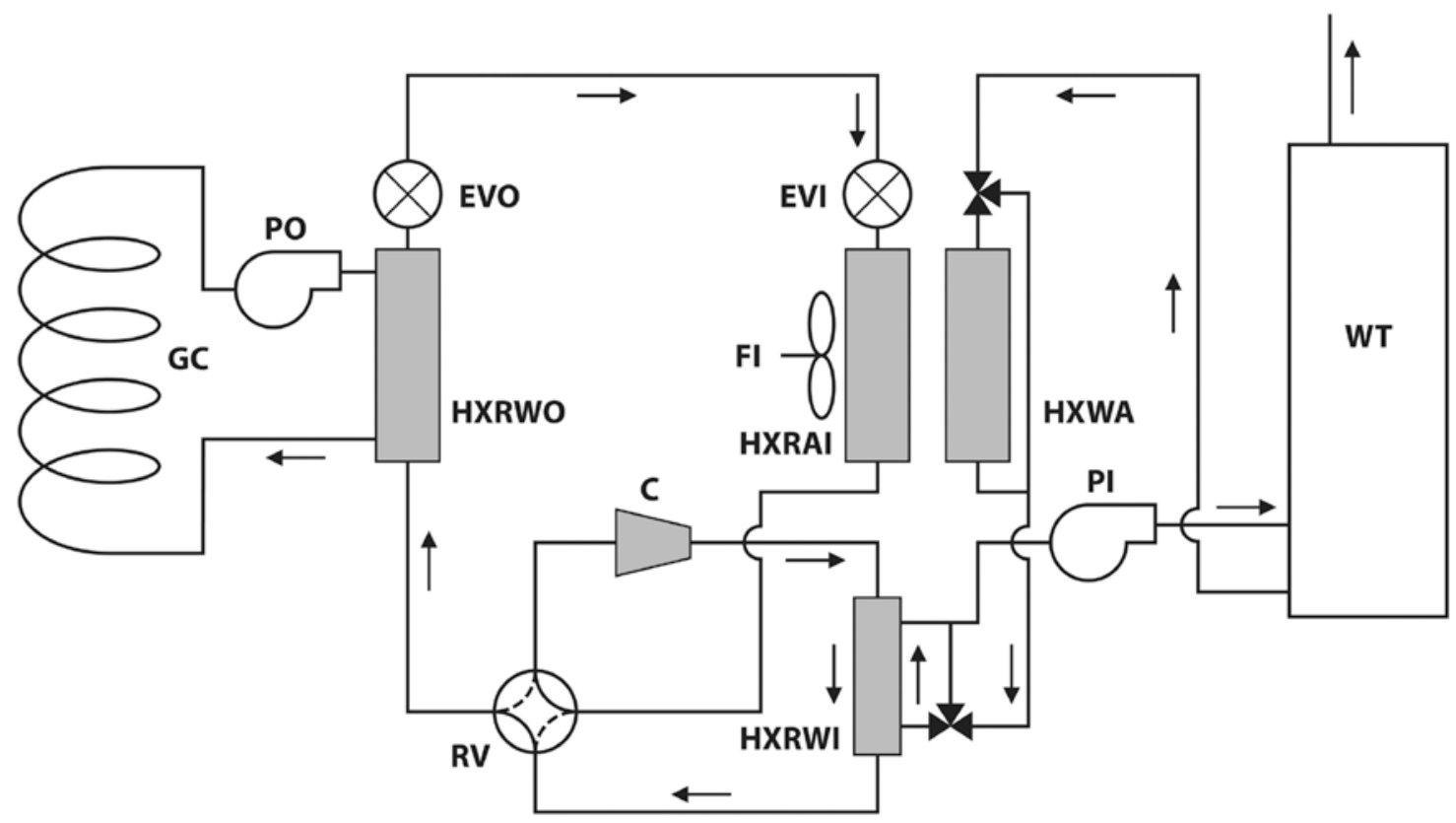

Fig. 2.1. Schematic of ground-source integrated heat pump concept (space cooling plus on-demand water heating mode). 


\subsection{Refrigerant Compressor}

The concept requires a high-efficiency, hermetic, variable-speed motor/compressor (shown as C in Fig. 2.1) for operation with R-410A as the refrigerant. This devices draws cool low-pressure refrigerant vapor from whichever $\mathrm{HX}$ is acting as the evaporator, compresses it to provide hot, high-pressure refrigerant to whichever $\mathrm{HX}$ is acting as the condenser, from which it flows to the relevant expansion device, to return to the evaporator. To meet these requirements, a rotary compressor with an electronically commutated, brushless, direct-current drive, variable-speed motor with a permanent magnet rotor is employed.

\subsection{Domestic Hot Water Interface Heat Exchanger}

The domestic hot water interface HX is a refrigerant-to-water unit (HXRWI in Fig. 2.1) that transfers heat from refrigerant heated in the compression process to potable water circulated from the hot water storage tank. This device is intended to take the full refrigerant condensing load of the system. To meet these demands, a counter-flow arrangement of a tube-in-tube helical HX is used. This HX consists of an inner vented double-wall fluted copper tube surrounded by an outer smooth steel tube. Potable water flows inside the inner wall of the double-wall tube while refrigerant passes through the annulus formed between the outside of the outer wall of the doublewall copper tube and the inside of the steel tube. Counter-flow is employed to provide the closest thermal profile matching and most uniform heat transfer from the refrigerant to the water for lowest condensing temperatures and highest cycle efficiency. The double wall isolates the two fluids to prevent contamination of the water in case of a refrigerant leak. Double-wall protection is a requirement of the International Association of Plumbing and Mechanical Officials for refrigerant-based water heating systems.

\subsection{Ground Coil Interface Heat Exchanger}

The ground coil interface $\mathrm{HX}$ is a refrigerant-to-water (or an antifreeze/water mixture) unit (HXRWO in Fig. 2.1) that transfers heat between the refrigerant loop and the ground coil loop. When the ground is being used as a heat sink (space cooling mode, for example), heat is transferred from condensing refrigerant to the ground loop fluid. When the ground is being used as a heat source (space heating mode, for example), heat is transferred from the ground loop fluid to evaporating refrigerant. This device is intended to accommodate the full refrigerant condensing or evaporating load of the system. To meet these demands, a tube-in-tube helical HX is used, consisting of an inner single-wall fluted tube surrounded by an outer smooth tube. Water (or an antifreeze/water mixture) flows inside the inner wall of the fluted tube while refrigerant passes through the annulus formed between the outside of the outer wall of the fluted tube and the inside of the smooth tube. The arrangement is counter-flow for modes in which the device acts as a refrigerant condenser (space cooling mode, for example) and co-flow when it acts as a refrigerant evaporator (space heating mode, for example).

\subsection{Refrigerant Expansion Devices}

An expansion device is required in the system to turn the stream of hot, high-pressure, liquid refrigerant (produced by whichever HX is acting as the loop condenser) into the stream of cold, low-pressure, vapor/liquid mixture (for introduction into whichever HX is acting as the loop evaporator). The function is accomplished by means of two electronic expansion valves, allowing a range of refrigerant flow control appropriate for the variable capacity capabilities of the system. Only one of these valves is active at any given time. When the fan coil $\mathrm{HX}$ is acting as the evaporator (space cooling mode, for example), the valve associated with it (EVI in Fig. 2.1) is 
active. When the ground coil interface HX is acting as the evaporator (space heating mode, for example), the valve associated with it (EVO in Fig. 2.1) is active.

\subsection{Fan Coil Heat Exchanger}

The fan coil HX is a refrigerant-to-air unit (HXRAI in Fig. 2.1) used as the primary device to condition return air from the space and ventilation air from outside. Therefore, in various modes its serves to heat or cool/dehumidify the air stream after it enters the air handler. To accomplish these functions, a sloped coil with multiple refrigerant circuits, passes, and rows comprised of grooved copper tubing with enhanced aluminum fins is employed. Condensate collection provisions are incorporated into the mounting arrangement.

\subsection{Fan}

The concept requires a high-efficiency, variable-speed motor-fan (FI in Fig. 2.1) combination to draw return air from the space and ventilation air from the outside into the air handler. After interaction with the fan coil HX and the tempering HX in the air handler, the conditioned air is supplied to the space by the fan. To meet these requirements, a centrifugal fan driven directly by an integral electronically commutated motor with pulse-width-modulation speed control and constant airflow control capability is employed.

\subsection{Domestic Hot Water Loop Pump}

The concept requires a pump (PI in Fig. 2.1) to draw water from the bottom section of the hot water storage tank, through the tempering $\mathrm{HX}$ and/or the refrigerant-to-domestic water $\mathrm{HX}$, and to return it to the lower section of the hot water storage tank. To provide these flows within the domestic hot water loop, a single-speed circulator pump suitable for operation with potable water at high temperatures is employed. With elimination of desuperheating operation only one pump speed is deemed necessary [see Murphy et al. (2007b) and discussions in Sections 3 and 4 of this report].

\subsection{Tempering Heat Exchanger}

The tempering HX is a water-to-air unit (HXWA in Fig. 2.1) that acts essentially as an air reheat coil. This unit is a conventional air coil design using aluminum-finned copper tubing with multiple circuits and passes on the water side. It is located within the indoor section enclosure, perpendicular to the air flow and downstream of the fan coil HX. Also contained in the indoor section are electrical resistance air-heating elements to boost space heating capacity during low temperature ambient conditions when heat pumping operation alone cannot meet the load.

\subsection{Hot Water Storage Tank}

A well-insulated potable hot water storage tank (WT in Fig. 2.1) serves as a sump for the domestic hot water loop as well as a receiver for cold water coming from the main and a reservoir for supply of hot water to the household outlets. Upper and lower electrical resistance waterheating elements are included in the tank to preclude running out during high-demand situations when heat pumping operation cannot provide a sufficient supply of hot water. Only one of these elements is active at any given time. 


\subsection{Refrigerant Reversing Valve}

A valve is needed to accommodate mode changes where the relative operational positions of the fan coil HX and the ground coil interface HX in the refrigerant circuit must be reversed. In essence, this device determines which of these two HXs operates on the high-pressure, hot side of the loop and which operates on the low-pressure, cold side of the loop. To accomplish this function, a two-position, four-way, refrigerant reversing valve (RV in Fig. 2.1) is employed.

\subsection{Ground Coil}

The concept requires a coil to carry the ground loop fluid into the ground to allow heat transfer to or from the surrounding earth. To accomplish this function, a vertical-bore ground coil configuration (GC in Fig. 2.1) is used.

\subsection{Ground Coil Loop Pump}

A pump is required to draw water (or water/antifreeze solution in cold climates) from the ground coil and pump it through the ground coil interface HX for recirculation to the ground. To provide this capability within the ground coil loop, a multiple-speed circulator pump (PO in Fig. 2.1) suitable for operation with water or water/antifreeze solution is employed.

\subsection{Bypass Water Valves}

The concept requires means to direct water flow either through or around the two domestic hot water circuit HXs. To provide this capability, a three-way valve in combination with a bypass leg is used for each. The implementation is by means of a binary function for the domestic hot water interface HX (either full through flow or full bypass flow) and a variable function for the tempering HX (continuous range from full through flow to full bypass flow) to permit control of the temperature of the air exiting this device.

\subsection{Development of R-410A GS-IHP Design Using the ORNL HPDM}

For ground-coupled systems, the source and sink conditions seen by the heat pump from the ground loop are related to but minimally influenced by the ambient temperatures. Instead, the entering water (or glycol) temperatures (EWTs) seen by the heat pump depend on the moderated seasonal effects of average ambient temperature levels on the far-field ground temperatures combined with the cumulative energy rejected to and absorbed from the ground by the heat pump during cooling and heating operation. The effect of seasonal ambient temperature variations is realized mainly through the house loads and their effect on the cumulative loading of the ground as the cooling and heating seasons progress.

Other than for strongly heating-dominated climates, the amount of energy rejected to the ground in the summer will be greater than that extracted in the winter. This is because the energy rejected to the ground in the summer is the sum of the delivered cooling load and the system power use, while that extracted in the winter is the delivered heating load minus the system power use. Since the cooling COP is higher than in heating, even for a ground-source heat pump (GSHP), this effect is further enhanced. As a result, the GSHP EWTs throughout the winter are generally somewhat more favorable relative to the ambient conditions than those in the summer. Similarly, the design cooling and heating source/sink conditions seen by the heat pump are not as extreme as the ambient temperature variations, especially for the vertical-coil ground loop coils considered 
here. These moderated EWTs at design and average load conditions were taken into account when determining the sizing and operating strategies appropriate for a GS-IHP.

The ORNL Heat Pump Design Model was used along with the above considerations to develop the sizing and operational design for a GS-IHP using HFC R-410A. System simulations were generated for the appropriate operational speeds and ambient conditions for the following important modes of operation with regard to calculating energy use:

1. Space cooling, with and without full condensing water heating,

2. Space heating, and

3. Dedicated water heating, with outdoor coil as the heat source for heating water in the shoulder months and in the heating season.

Airflows for the indoor blower were set relative to the compressor speed based on optimization simulations done for the AS-IHP design (Murphy et al. 2007b) of equal design cooling capacity. In cooling mode, the indoor airflow was set to maintain an equivalent to slightly lower SHR than that at the design cooling condition as the compressor speed was reduced. In the heating mode, the comfort constraint of supply air temperature was used to limit the indoor airflow reductions possible as compressor speed dropped with heating load.

The same compressor performance characteristics applied recently for the R-410A AS-IHP design (Murphy et al. 2007b) were used in the new R-410A GS-IHP design. A manufacturer's performance map for this small-capacity, state-of-the-art R-410A rotary compressor provided power and refrigerant mass flow rate for expected operating conditions over a wide range of compressor speeds, from 30 to $120 \mathrm{~Hz}$. Because of the more favorable design cooling and heating conditions seen in a ground-source application, the nominal compressor capacity was smaller than that for the recent AS-IHP design. Compressor isentropic and volumetric efficiencies were assumed to remain the same over this range of capacity scaling, and so the compressor maps for power and mass flow were linearly scaled in the model by the nominal capacity ratios. Estimated inverter power losses were added separately for each of the compressor speed maps in the same way as they were for the earlier AS-IHP performance analysis.

A design optimization and control assessment was performed for the ground-source application based on the state-of-the-art compressor characterization and preferred HFC refrigerant, R-410A. For the GS-IHP design, we started with the air-source (AS) IHP design and replaced the outdoor air-to-refrigerant HX and variable-speed fan with a second indoor glycol-to-refrigerant, tube-intube, fluted HX and variable-speed pump. The pump was assumed to have a flow rate capacity of 1 to $4 \mathrm{gpm}$ with a pump power of 20W/gpm. (NOTE: The GS-IHP system design assumes a ground loop pump with multiple (2-4) discrete speeds as noted in section 2.12 above. However, to facilitate an efficient simulation, a pump with continuously variable flow rate between 1 and 4 gpm was used for the design and subsequent performance simulations reported in this section and the following two sections.) The tube-in-tube HX was rated for 18,000 Btu/h design cooling capacity at $4 \mathrm{gpm}$ and $70^{\circ} \mathrm{F}$ EWT and 22,000 heat rejection capacity at 4 gpm and $80^{\circ} \mathrm{F}$ EWT. This sizing was consistent with that for the earlier slightly oversized outdoor coil for the airsource design based on the breadboard test unit.

The same indoor coil design was used as determined for the R-410A AS-IHP. Here the main design change in the air-to-refrigerant $\mathrm{HX}$ was to go from the 5-circuit, 3/8-in.-tube, indoor coil of the breadboard R-22 coil to a 3-circuit, 5/16-in.-tube design. This improved the coil performance with R-410A, especially at low speeds during space cooling and heating. 
Because of the significantly moderated heat source conditions of a ground-source design, a smaller compressor volumetric capacity at maximum heating mode speed is needed to meet design heating conditions. The approach selected to take advantage of this was to increase the design cooling speed from $79 \mathrm{~Hz}$ in the air-source IHP to $100 \mathrm{~Hz}$ for the GS-IHP and to reduce the compressor size slightly more than this ratio to obtain the same design cooling capacity at a lower design condenser entering temperature. This shift up in design cooling speed gives space cooling speed ranges from 36 to $100 \mathrm{~Hz}$, with 30 to $120 \mathrm{~Hz}$ in space heating mode.

The result is only a $20 \%$ over-speed capability in heating mode, relative to the design cooling speed for the GS-IHP design, as compared to the $50 \%$ over-speed used in the AS-IHP. However, as this is all that is required with the elevated heating-mode source temperatures, the heating capacity can be lowered enough to still match the same house loads at milder ambient temperatures with the higher EWTs. This keeps the HXs from being too heavily loaded at higher EWTs to fully realize the attendant efficiency benefits of the more favorable source conditions. One other potential benefit is that in the cooling mode, the minimum operating speed is higher (36 Hz rather than $28 \mathrm{~Hz}$ for the air-source IHP) for the same capacity, and thus the compressor efficiency is higher. So there are benefits realized from the shift to a higher design cooling compressor speed with a ground-source design for both cooling and heating modes.

In dedicated water heating mode, speeds of $45 \mathrm{~Hz}$ to $90 \mathrm{~Hz}$ were selected to provide a 2-to-1 speed ratio while still remaining within the acceptable compressor operating envelope with elevated head pressures. 


\section{OPERATIONAL MODES AND CONTROLS}

\subsection{Primary Functions}

The integrated heat pump is a single system intended to perform a variety of energy-related functions with efficiencies targeted to meet requirements for a $\mathrm{ZEH}$ of the future. The primary functions include space heating, space cooling, dehumidifying, air ventilating, and water heating.

\subsection{System Components and Control Types}

To accomplish these functions, various components must be combined to form the system. To achieve the desired capacities and efficiencies, they must be connected in an appropriate arrangement and controlled effectively. The approach builds, where possible, on methods employed in previous air-source IHP work. In general, priority is given to heat pumping system operation in order to provide the needed home energy services as efficiently as possible. Only when heat pumping operation is unable to fully meet these needs is use made of less efficient secondary systems.

The major and minor energy-consuming components for heat pumping are shown in tables 3.1. and 3.2.

Table 3.1. Major energy-consuming components for heat pumping

\begin{tabular}{|l|l|}
\hline Component & Control type \\
\hline Refrigerant compressor & On/off, variable speed \\
\hline Fan & On/off, variable speed \\
\hline Ground-coil circuit pump & On/off, multiple speed \\
\hline Domestic hot water circuit pump & On/off, single speed \\
\hline
\end{tabular}

Table 3.2. Minor energy-consuming components for heat pumping

\begin{tabular}{|l|l|}
\hline Component & Control type \\
\hline Thermostat & Mode, time, temperature, humidity \\
\hline Microprocessor(s) & Input/output \\
\hline Refrigerant reversing valve actuator & Biposition (cooling or heating) \\
\hline Electronic refrigerant expansion valve actuator(s) & Variable position (opening) \\
\hline Heating water valve actuator & Biposition (open or bypass) \\
\hline Tempering water valve actuator & Variable position (opening) \\
\hline Return air damper actuator & Biposition (open or closed) \\
\hline Ventilation air damper actuator & Biposition (open or closed) \\
\hline
\end{tabular}

Sizing of the system is such that, barring component failure, heat pumping should provide adequate capacity for the space cooling, dehumidifying, and ventilation steady-state loads in the design house. The only loads likely to exceed temporarily the heat pumping system capabilities would be space heating and/or water heating under more extreme conditions (low outdoor temperatures and/or concentrated hot water usage). For these short-duration situations, the secondary, substantially less efficient, energy-consuming components shown in Table 3.3 would be activated. 
Table 3.3. Secondary energy-consuming components

\begin{tabular}{|l|l|}
\hline Component & Control type \\
\hline $\begin{array}{l}\text { Electrical resistance air heating element } \\
\text { (indoor air handler) }\end{array}$ & On/off \\
\hline $\begin{array}{l}\text { Electrical resistance water heating element } \\
\text { (upper hot water storage tank) }\end{array}$ & On/off \\
\hline $\begin{array}{l}\text { Electrical resistance water heating element } \\
\text { (lower hot water storage tank) }\end{array}$ & On/off \\
\hline
\end{tabular}

Crucial to achieving the required performance is the incorporation of efficient variable-speed and/or multiple-speed operation over wide ranges in the major energy consuming components. The compressor and fan are essentially continuously variable over their entire ranges while for the ground-coil circuit pump, multiple speeds should be sufficient. The domestic hot water circuit pump requires only one speed in the current design. Thus, for most of these components, the control system must determine, for given conditions, whether the component should be on or off and, if on, how fast it should be running. For refrigerant expansion and water control valves, the appropriate variable opening needs to be set per calls and conditions to provide the desired control condition, such as prescribed values of condenser subcooling, liquid tube temperature, or supply air temperature.

\subsection{Operational Strategy}

The general intent for the variable- and multiple-speed components is to optimize their speeds for any particular combination of loads so as to provide required capacities at maximum system efficiency. The reduction in HX loadings to just meet the current conditioning loads is the major contribution to higher system efficiency. Also inherent in the strategy is reducing system cycling losses by maximizing run times of the highly efficient components. Generally this implies operation at the lowest speeds that will meet the load requirements. Of course, this must be accomplished within the established performance envelope of each component. For example, in addition to the usual discharge temperature limit for a single-speed compressor, there are generally additional restrictions for a variable-speed compressor such as limits for suction pressure, discharge pressure, and compression ratio that vary for each speed range. In addition, there will likely be limits on ramp (increasing or decreasing) rates when speeds are to be changed.

Other variable components, such as the refrigerant expansion and tempering water valves, will be controlled over their available ranges to accommodate the desired capacities for selected modes. The remaining components require only binary decisions from the control system. In particular, the refrigerant reversing valve is either in the "cooling" position or the "heating" position; the water valve to the refrigerant-to-domestic-water HX is either in the "open" position or the "bypass" position; the return and ventilation air dampers are either open or closed; the air-heating electrical resistance elements are either on or off; and the water-heating electrical resistance elements are either on or off (upper and lower elements are not permitted to operate simultaneously).

The ASHRAE 62.2 (2004) requirement as applied to the candidate ZEH implies an average calculated air flow from the outdoors to the indoors. The intent of the control strategy is to use the system indoor fan to induce this amount of ventilation air flow while the system functions in nearly all the cooling, heating, and dehumidification control modes. When the system does not operate in one of these modes, a ventilation/flow timer will activate the indoor fan to induce 
about three times the calculated flow for 20 minutes of each hour in a ventilation operating mode to meet the requirement, while maintaining adequate air distribution uniformity.

\subsection{Inputs to the Control System}

To decide which components to turn on or off and at what speed or position, the control system requires various inputs (Table 3.4). Some are occupant-selected and some are inputs gathered from various sensors and clocks or timers. The most familiar occupant-selected inputs are fan mode and heating/cooling or season selections at the thermostat. Other common occupant inputs are the air temperature and air humidity set points at the thermostat, as well as time-related options such as day or night setback/setup settings. Common air sensor inputs for space conditioning are humidity and air temperature at the thermostat, in the supply from the air handler, and in the outdoor ambient air. Various refrigerant line temperatures including compressor discharge, accumulator suction, fan coil liquid tube, and ground coil liquid tube are also employed. For water heating purposes, two additional temperature sensor inputs are normally employed: one near the bottom of the water storage tank and one in the upper section of the water storage tank. Additional temperature sensors on the refrigerant HXs may be required for optimum control. Selected clock and timer inputs are also generally incorporated.

Table 3.4. Control inputs and sources

\begin{tabular}{|c|c|}
\hline Input & Source \\
\hline Fan mode & Occupant-selected at thermostat \\
\hline Heating/cooling or season selection & Occupant-selected at thermostat \\
\hline Thermostat air temperature setting & Occupant-selected at thermostat \\
\hline Thermostat air humidity setting & Occupant-selected at thermostat \\
\hline Time-related options (setback, etc.) & Occupant-selected at thermostat \\
\hline Thermostat air humidity & Sensor in thermostat \\
\hline Thermostat air temperature & Sensor in thermostat \\
\hline Supply air temperature & Sensor in air handler section \\
\hline Ambient air temperature & Sensor in outdoor air \\
\hline Compressor refrigerant discharge temperature & Sensor in compressor section \\
\hline Accumulator refrigerant suction temperature & Sensor in compressor section \\
\hline Fan coil refrigerant liquid tube temperature & Sensor in air handler section \\
\hline Ground coil refrigerant liquid tube temperature & Sensor in ground coil interface section \\
\hline Upper tank water temperature & Sensor on upper part of hot water tank \\
\hline Lower tank water temperature & Sensor on lower part of hot water tank \\
\hline $\begin{array}{l}\text { Fan coil heat exchanger mid-point refrigerant } \\
\text { temperature }\end{array}$ & Sensor in air handler section \\
\hline $\begin{array}{l}\text { Ground coil interface heat exchanger mid-point } \\
\text { refrigerant temperature }\end{array}$ & Sensor in ground coil interface section \\
\hline $\begin{array}{l}\text { Domestic hot water interface heat exchanger mid-point } \\
\text { refrigerant temperature }\end{array}$ & Sensor in domestic hot water interface section \\
\hline Fan coil heat exchanger exit refrigerant temperature & Sensors in air handler section \\
\hline $\begin{array}{l}\text { Ground coil interface heat exchanger exit refrigerant } \\
\text { temperature }\end{array}$ & Sensors in ground coil interface section \\
\hline $\begin{array}{l}\text { Domestic hot water interface heat exchanger exit } \\
\text { refrigerant temperature }\end{array}$ & Sensor in domestic hot water interface section \\
\hline \multicolumn{2}{|l|}{ Clock } \\
\hline \multicolumn{2}{|l|}{ Ventilation timer } \\
\hline \multicolumn{2}{|l|}{ Fan delay } \\
\hline Compressor restart timer & \\
\hline
\end{tabular}




\subsection{Operating Modes}

Microprocessors will determine the operating mode of the system based on load demands indicated by the various inputs. The load demands may be for space cooling or heating, water heating, dehumidification, ventilation, or selected combinations of these. The available primary system operating modes corresponding to the loads are:

- $\quad$ space cooling (AC),

- $\quad$ space cooling with enhanced dehumidification (ACEAD),

- $\quad$ space cooling plus water heating (ACWH),

- $\quad$ space cooling with enhanced space dehumidification plus water heating (ACEADWH),

- $\quad$ space heating $(\mathrm{AH})$,

- $\quad$ space heating plus water heating (AHWH),

- $\quad$ water heating (WH),

- dehumidification (AD),

- dehumidification plus water heating (ADWH),

- $\quad$ ventilation (AV), and

- $\quad$ ventilation with ventilation air dehumidification (AVVAD).

The particular mode decision determines which components will operate (Table 3.5) and how they will be controlled. A description of the logic employed by the system for each primary mode follows. Refer to Fig. 2.1 for definitions of abbreviated column headings.

Table 3.5. Mode/component matrix

\begin{tabular}{|c|c|c|c|c|c|c|c|c|c|c|c|}
\hline Mode & & & & & & & Co & nponent & & & \\
\hline & $\mathrm{C}$ & RV & $\mathrm{PO}$ & FI & \begin{tabular}{|c} 
Air \\
return \\
damper \\
\end{tabular} & $\begin{array}{c}\text { Air } \\
\text { ventilation } \\
\text { damper }\end{array}$ & PI & $\begin{array}{l}\text { Water } \\
\text { heating } \\
\text { valve }\end{array}$ & $\begin{array}{c}\text { Water } \\
\text { tempering } \\
\text { valve }\end{array}$ & $\begin{array}{c}\text { Air } \\
\text { resistance } \\
\text { element }\end{array}$ & $\begin{array}{c}\text { water } \\
\text { resistance } \\
\text { elements }\end{array}$ \\
\hline $\mathrm{AC}$ & on & cool & on & on & open & open & & & & & \\
\hline ACEAD & on & cool & on & on & open & open & & & & & \\
\hline ACWH & on & cool & & on & open & open & on & open & bypass & & either \\
\hline $\begin{array}{l}\text { ACEAD } \\
\text { WH }\end{array}$ & on & cool & & on & open & open & on & open & bypass & & either \\
\hline $\mathrm{AH}$ & on & heat & on & on & open & open & & & & either & \\
\hline AHWH & on & heat & on & on & either & either & on & open & bypass & either & either \\
\hline WH & on & heat & on & & closed & closed & on & open & bypass & & either \\
\hline $\mathrm{AD}$ & on & cool & on & on & open & open & on & bypass & Open & & \\
\hline ADWH & on & cool & & on & open & open & on & open & Open & & either \\
\hline AV & & & & on & open & open & & & & & \\
\hline AVVAD & on & cool & on & on & closed & open & on & bypass & Open & & \\
\hline
\end{tabular}




\subsubsection{Space Cooling (AC)}

When the space air temperature exceeds the thermostat cooling temperature set point, a space cooling load is indicated. In the absence of other indicated loads, the refrigerant reversing valve is situated in the cooling position, the return and ventilation air dampers are open, and the heat pump system provides air cooling in proportion to the load by varying the compressor speed (within the permissible envelope) at the rate needed to stay within the thermostat temperature dead band. The coincident fan and ground-coil circuit pump speeds are adjusted in a prescribed manner based on the compressor speed. Heat removed from the indoor air and energy input by the compressor is rejected to the ground (by means of the ground coil).

\subsubsection{Space Cooling With Enhanced Dehumidification (ACEAD)}

When (1) the space air temperature exceeds the thermostat cooling temperature set point and (2) the space relative humidity exceeds the thermostat humidity set point, both air cooling and dehumidification loads are indicated. In the absence of other indicated loads, the reversing valve is situated in the cooling position, the return and ventilation air dampers are open, and, as in the previous case, the heat pump system provides air cooling in proportion to the load by varying the compressor, fan, and ground-coil circuit pump speeds. However, in this case, the air moisture removal rate is increased by reducing the fan speed relative to the compressor speed.

The goal is to increase latent cooling capacity by setting the compressor and fan speeds so as to satisfy the sensible cooling load with a lowered indoor coil temperature to increase dehumidification. Heat removed from the indoor air and energy input by the compressor is rejected to the ground. If the dehumidification load requirement is met before the space cooling load requirement, the control system transitions to the space cooling mode. If the space cooling load requirement is met before the dehumidification mode requirement, the control system transitions to the dehumidification mode.

\subsubsection{Space Cooling Plus “On-Demand” Water Heating (ACWH)}

When (1) the space air temperature exceeds the thermostat cooling temperature set point and (2) the lower water storage tank temperature is below its set point, both space cooling and water heating loads are indicated. In the absence of other indicated loads, the reversing valve is situated in the cooling position, the return and ventilation air dampers are open, the water valve to the domestic hot water interface HX is open, the domestic hot water circuit pump is activated, and the heat pump system provides air cooling in proportion to the air cooling load by varying the compressor and fan speeds.

In this mode, the ground-coil circuit pump is not active, so that the combined heat removed from the indoor air and energy input to the refrigerant from the compressor is transferred to the circulating domestic water (in the domestic hot water interface HX). If the water heating load requirement is met before the space cooling load requirement, the control system transitions to the space cooling mode. If the space cooling load requirement is met before the water heating mode requirement, the control system transitions to the water heating mode.

When (1) the lower water storage tank temperature is below its set point and (2) the upper water storage tank temperature is below its set point, a critical water heating load is indicated. In this situation, the control system activates the upper electrical resistance element to minimize the chance of running out of hot water. 


\subsubsection{Space Cooling With Enhanced Dehumidification Plus “On-Demand” Water Heating (ACEADWH)}

When (1) the space air temperature exceeds the thermostat cooling temperature set point, (2) the space relative humidity exceeds the thermostat humidity set point, and (3) the lower water storage tank temperature is below its set point, three loads are indicated: space cooling, dehumidification, and water heating. In the absence of other indicated loads, the reversing valve is situated in the cooling position, the return and ventilation air dampers are open, the water valve to the domestic hot water interface $\mathrm{HX}$ is open, the domestic hot water circuit pump is activated, and the heat pump system provides air cooling in proportion to the space cooling load by varying the compressor and fan speeds.

In this case, the air moisture removal rate is increased by reducing the fan speed relative to the compressor speed. As before, the goal is to increase latent cooling capacity by setting the compressor and fan speeds so as to satisfy the sensible cooling load with a lowered indoor coil temperature to increase dehumidification. Also in this mode, the ground-coil circuit pump is not active, so that the combined heat removed from the house and energy input to the refrigerant from the compressor is transferred to the circulating water (in the domestic hot water interface HX). If the dehumidification load requirement is met first, the control system transitions to the space cooling plus water heating mode. If the space cooling load requirement is met first, the control system transitions to the dehumidification plus water heating mode. If the water heating load requirement is met first, the control system transitions to the air cooling with enhanced dehumidification mode.

When (1) the lower water storage tank temperature is below its set point and (2) the upper water storage tank temperature is below its set point, a critical water heating load is indicated. In this situation, the control system activates the upper electrical resistance element to minimize the chance of running out of hot water.

\subsubsection{Space Heating (AH)}

When the space air temperature is below the thermostat heating temperature set point, a space heating load is indicated. In the absence of other indicated loads, the reversing valve is situated in the heating position, the return and ventilation air dampers are open, and the heat pump system provides space heating in proportion to the load by appropriately varying the compressor, fan, and ground-coil circuit pump speeds. The control logic varies the compressor and ground-coil circuit pump speeds to meet the space heating load at highest efficiency while the fan speed is varied to maintain comfortable supply air temperatures. Heat removed from the ground and energy input by the compressor is provided to the indoor air. If the space heating load exceeds the heat pump capacity such that the space air temperature falls below the second-stage heating set point, the control system activates the electrical resistance air heaters in the air handler.

\subsubsection{Space Heating Plus “On-Demand” Water Heating (AHWH)}

When (1) the space air temperature is below the thermostat heating temperature set point and (2) the lower water storage tank temperature is below its set point, both space heating and water heating loads are indicated.

For this situation, water heating operation is given priority for heat pump system output unless the space air temperature approaches the second-stage (electrical resistance air heaters) heating set point. That is, the reversing valve is situated in the heating position, the return and ventilation air dampers are closed, the water valve to the domestic hot water interface HX is open, the domestic 
hot water circuit pump is activated, and the heat pump system provides maximum water heating capacity at appropriate compressor and ground-coil circuit pump speeds. In this mode, the fan is not active, so that the combined heat removed from the ground and energy input to the refrigerant from the compressor is transferred to the circulating water (in the domestic hot water interface $\mathrm{HX}$ ). If the capacity of the heat pump is insufficient to meet the water heating load, the control system will activate the lower electrical resistance water heating element in the hot water storage tank. When the water heating load requirement is met, the control system transitions to the space heating mode.

If the space air temperature approaches the second-stage heating set point, space heating operation is given priority for the heat pump system output. That is, the reversing valve is situated in the heating position, the return and ventilation air dampers are open, and the heat pump system provides maximum space heating capacity at appropriate compressor, fan, and ground-coil circuit pump speeds. Heat removed from the ground and energy input by the compressor is provided to the indoor air. If the space heating load exceeds the heat pump capacity such that the space air temperature falls below the second-stage heating set point, the control system activates the electrical resistance air heaters in the air handler. When the space heating load requirement is met, the control system transitions to the water heating mode.

For either water heating or space heating priority operation, when (1) the lower water storage tank temperature is below its set point and (2) the upper water storage tank temperature is below its set point, a critical water heating load is indicated. In this situation, the control system activates the upper electrical resistance element to minimize the chance of running out of hot water.

\subsubsection{Demand Water Heating (WH)}

When the lower water storage tank temperature is below its set point, a water heating load is indicated. In the absence of other indicated loads, the reversing valve is situated in the heating position, the return and ventilation air dampers are closed, the water valve to the domestic hot water interface $\mathrm{HX}$ is open, the domestic hot water circuit pump is activated, and the heat pump system provides water heating in proportion to the water heating load by varying the compressor and ground-coil circuit pump speeds. In this mode, the fan is not active, so that the combined heat removed from the ground and energy input to the refrigerant from the compressor is transferred to the circulating water (in the domestic hot water interface HX). If the capacity of the heat pump is insufficient to meet the water heating load, the control system will activate the lower electrical resistance water heating element in the hot water storage tank.

When (1) the lower water storage tank temperature is below its set point and (2) the upper water storage tank temperature is below its set point, a critical water heating load is indicated. In this situation, the control system activates the upper electrical resistance element to minimize the chance of running out of hot water.

\subsubsection{Dehumidification (AD)}

When the relative humidity exceeds the thermostat humidity set point, a dehumidification load is indicated. In the absence of other indicated loads, the reversing valve is situated in the cooling position, the return and ventilation air dampers are open, and the heat pump system cools the circulated air and removes moisture from it in proportion to the dehumidification load by varying the compressor, fan, and ground-coil circuit pump speeds. In this case, the air moisture removal rate is enhanced by reducing the fan speed relative to the compressor speed. Heat removed from the indoor air and energy input by the compressor is rejected to the ground. The water valve to the water-to-air tempering $\mathrm{HX}$ is open, and the domestic hot water circuit pump is activated to 
allow hot water from the storage tank to be used to provide reheat to maintain the thermostat air temperature set point.

\subsubsection{Space Dehumidification Plus Water Heating (ADWH)}

When (1) the space relative humidity exceeds the thermostat humidity set point and (2) the lower water storage tank temperature is below its set point, both dehumidification and water heating loads are indicated. In the absence of other indicated loads, the reversing valve is situated in the cooling position, the return and ventilation air dampers are open, and the heat pump system cools the circulated air and removes moisture from it in proportion to the dehumidification load by varying the compressor, fan, and ground-coil circuit pump speeds. In this case, the air moisture removal rate is enhanced by reducing the fan speed relative to the compressor speed. The domestic hot water circuit pump is activated and valves are open to both the domestic hot water interface HX and the water-to-air tempering HX. Heat is rejected to the water from the discharge refrigerant and (a smaller amount) rejected by the water through the tempering coil to reheat the dehumidified air as necessary so that the indoor space is maintained at or near the thermostat air temperature set point. If the dehumidification load requirement is met before the water heating load requirement, the control system transitions to the water heating mode. If the water heating load requirement is met before the dehumidification load requirement, the control system transitions to the dehumidification mode.

When (1) the lower water storage tank temperature is below its set point and (2) the upper water storage tank temperature is below its set point, a critical water heating load is indicated. In this situation, the control system activates the upper electrical resistance element to minimize the chance of running out of hot water.

\subsubsection{Ventilation (AV)}

When the ventilation air flow/timer signals that outdoor air is needed to meet minimum requirements, a ventilation load is indicated. In the absence of other indicated loads, the return and ventilation air dampers are open and the fan activated to bring in the prescribed amount of

outdoor air. The timer gives such a signal if the air handler has not operated in another mode for one hour. Equal amounts of ventilation air and return air are employed to temper the outdoor air and promote effective air distribution. If further indoor air tempering is desired, water could be circulated through the water-to-air tempering coil to provide this service.

\subsubsection{Ventilation With Ventilation Air Dehumidification (AVVAD)}

When (1) the ventilation air flow/timer signals that outdoor air is needed to meet minimum requirements and (2) the humidity ratio of the outdoor air (as determined from outdoor sensors) is above a desired set point, both ventilation and ventilation air dehumidification loads are indicated. In the absence of other indicated loads, the return air damper is closed, ventilation air damper is open and the fan activated to bring in the prescribed amount of outdoor air, unmixed with any return air. In this way, only ventilation air is dehumidified to obtain the maximum moisture removal at a given evaporator coil temperature. The reversing valve is situated in the cooling position and the heat pump system cools the ventilation air and removes moisture from it in proportion to the dehumidification load by varying the compressor and ground-coil circuit pump speeds. The compressor speed is increased if the indoor relative humidity level is sensed to increase while in AVVAD mode. Heat removed from the ventilation air and energy input by the compressor is rejected to the ground. The water valve to the water-to-air tempering HX is open, 
and the domestic hot water circuit pump is activated to allow hot water from the storage tank to be used to provide reheat to maintain the thermostat air temperature set point.

This concludes the discussion of the control modes presently envisioned for the GS-IHP. In the following, we describe the GS-IHP internal operational control design optimized for R-410A and a state-of-the-art, R-410A brushless DC-driven rotary compressor for application in a ZEH in a range of climates.

\subsection{GS-IHP System Speed Control Relationships}

With a variable-speed heat pump, as the compressor speed varies to match the load, the indoor and outdoor airflows should be adjusted in somewhat similar measure to obtain highest efficiency (Miller 1988, Rice 1992). However, the goal of highest efficiency must also be tempered by comfort constraints of acceptable indoor air moisture removal and supply temperatures. In addition, the refrigerant flow control should be adjusted with compressor speed to obtain optimal condenser exit subcooling, if possible, while the compressor inlet superheat is maintained at a value sufficient to maintain low superheat levels leaving the evaporator. ${ }^{1}$

As the compressor speed generally has a stronger effect on these optimums than the outdoor source/sink conditions, this variable was used as the independent control variable for the GS-IHP design, as was the case for the air-source IHP design. The ORNL HPDM was used with the R-410A IHP design and component performance specifications to determine an optimal set of control relationships for indoor blower and outdoor pump frequencies (directly proportional to speed) and condenser subcooling vs. compressor speed. This was applied for a target set of space cooling and heating loads and corresponding ambient temperatures so that the appropriate HX loading effects were included.

\subsubsection{Compressor Speed Ratio vs. Ambient in Cooling and Heating Modes}

Figs. 3.1 and 3.2 show the assumed target relationships between the compressor speed ratio (operating speed to nominal, design speed) and the load-related ambient temperatures in cooling and heating modes, respectively, where ratios are shown for generality. (As all of the motors here are synchronous, the frequency ratios and the speed ratios are the same.) The design compressor frequency (at which the design cooling capacity is achieved) in our GS-IHP system is $100 \mathrm{~Hz}$ (speed or $\mathrm{Hz}$ ratio $=1.0$ ). The desired speed range is wider in the heating mode than in the cooling mode to provide more heating capacity at design heating loads where typically the capacity of a single-speed compressor (at a speed ratio of 1) becomes insufficient due to the lowered source temperatures. Here we are using a maximum speed ratio of 1.2 or $20 \%$ overspeed to $120 \mathrm{~Hz}$ for the GS-IHP as compared to 1.5 for the AS-IHP, as discussed earlier in section 2.14.

Rice (1988) has shown that compressors can be operated in constant power overspeed conditions in the heating mode since the torque requirements decrease along with the ambient temperature. Because of this, the motor can be run at reduced volts/hertz ratios (fixed line voltage / increasing frequency) if necessary, at these lower ambient heating conditions. This overspeed operation results in a significant increase in the rated HSPF per the DOE rating procedure (Domanski 1988). The minimum assumed speed for our analysis was $36 \mathrm{~Hz}$ in cooling mode and $30 \mathrm{~Hz}$ in

\footnotetext{
${ }^{1}$ Obtaining this optimal control over a range of ambients will generally require some adjustable level refrigerant charge storage means such as a suction line accumulator or other device which can hold excess charge at some conditions and deliver needed charge back to the system at other conditions and operation modes.
} 
heating. The lower minimum speed in heating mode was selected because of the typically larger offset in source than sink temperature for the ground-source application.



Fig. 3.1. Target compressor speed ratios vs. ambient in the space cooling mode.

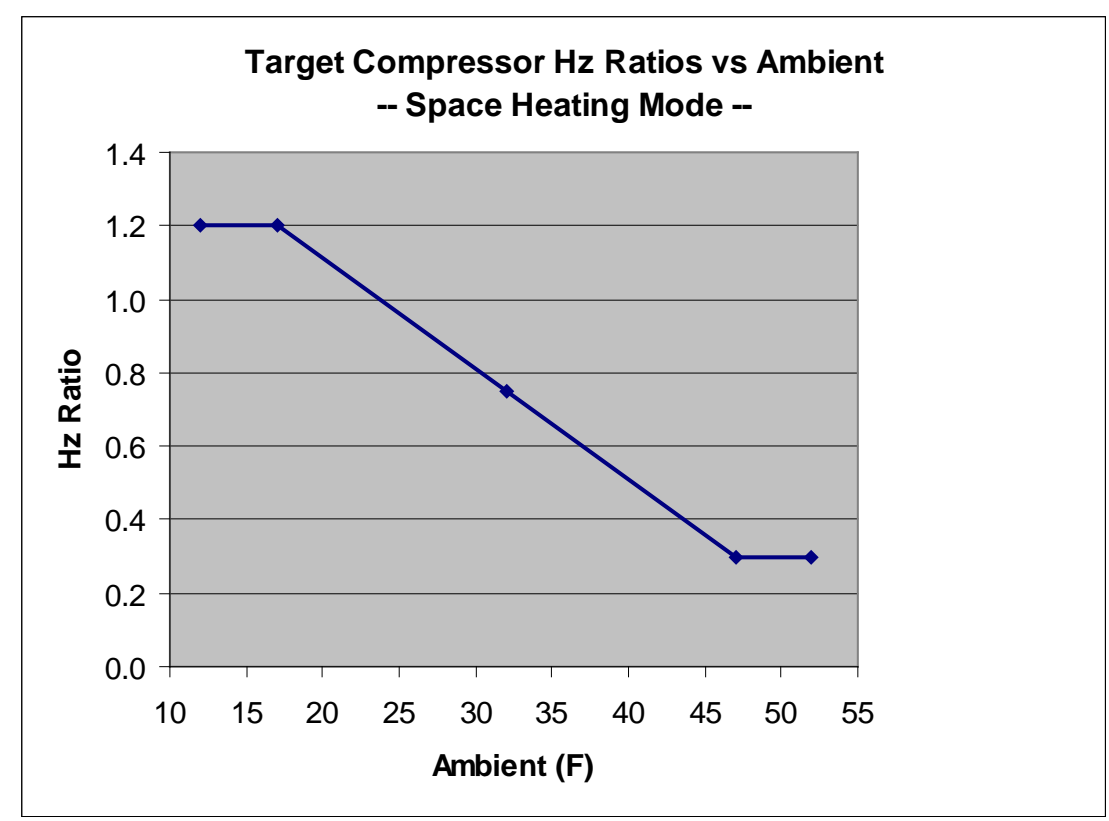

Fig. 3.2. Target compressor speed ratios vs. ambient in the space heating mode.

\subsubsection{Control Parameters vs. Compressor Speed Ratio in the Space Cooling and Heating Modes}

The selected indoor blower and loop pump speed ratios and condenser subcooling control are shown in Figs. 3.3 and 3.4 as functions of the compressor speed ratios for cooling and heating mode, respectively. The nominal HX external flows are $500 \mathrm{cfm}$ indoor and $4 \mathrm{gpm}$ outdoor.

Optimal indoor airflow tends to track the capacity level. In the cooling mode, shown in Fig. 3.3, 
the indoor airflow ratio drops off more slowly than the compressor speed, since the capacity and thus HX loading drops more gradually than compressor speed as well. (A one-to-one speed ratio relationship is shown by the dotted gray line.) This is because as the speed is lowered and the HX unloads, the evaporator pressure rises with increases in the refrigerant suction density entering the compressor. This higher density tends to resist the capacity drop from the compressor speed reduction. The selected indoor airflow trends with compressor speed are also strongly determined by the requirement to maintain approximately the same sensible heat ratios (SHRs) over the ambient temperature range. In the enhanced dehumidification mode, the indoor blower flow ratio values are reduced by $30 \%$, as shown by the dotted lines, to reduce the SHRs. The loop pump flow rates fall off faster with speed ratio, as they are driven more by the benefits of larger pump power reductions as capacity is lowered.

In the heating mode, the indoor airflow again drops off more slowly than the compressor speed for similar HX loading reasons. There is also a need to maintain supply air temperatures around $95^{\circ} \mathrm{F}$ or higher over the range of compressor speeds. At reduced compressor speeds in both modes, the optimal subcooling levels are lower as found by Miller (1988).

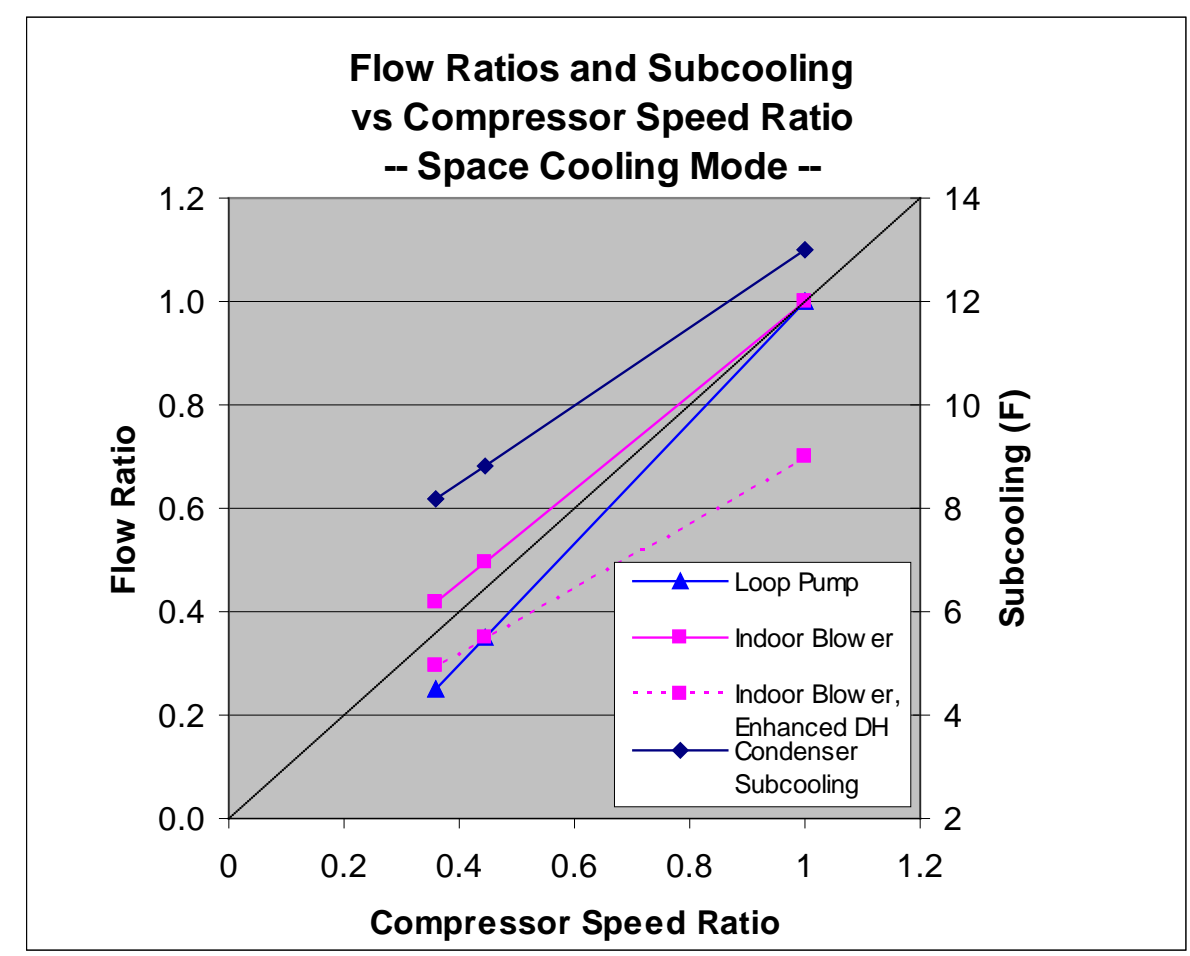

Fig. 3.3. Control parameters versus compressor speed ratio in the space cooling mode. 


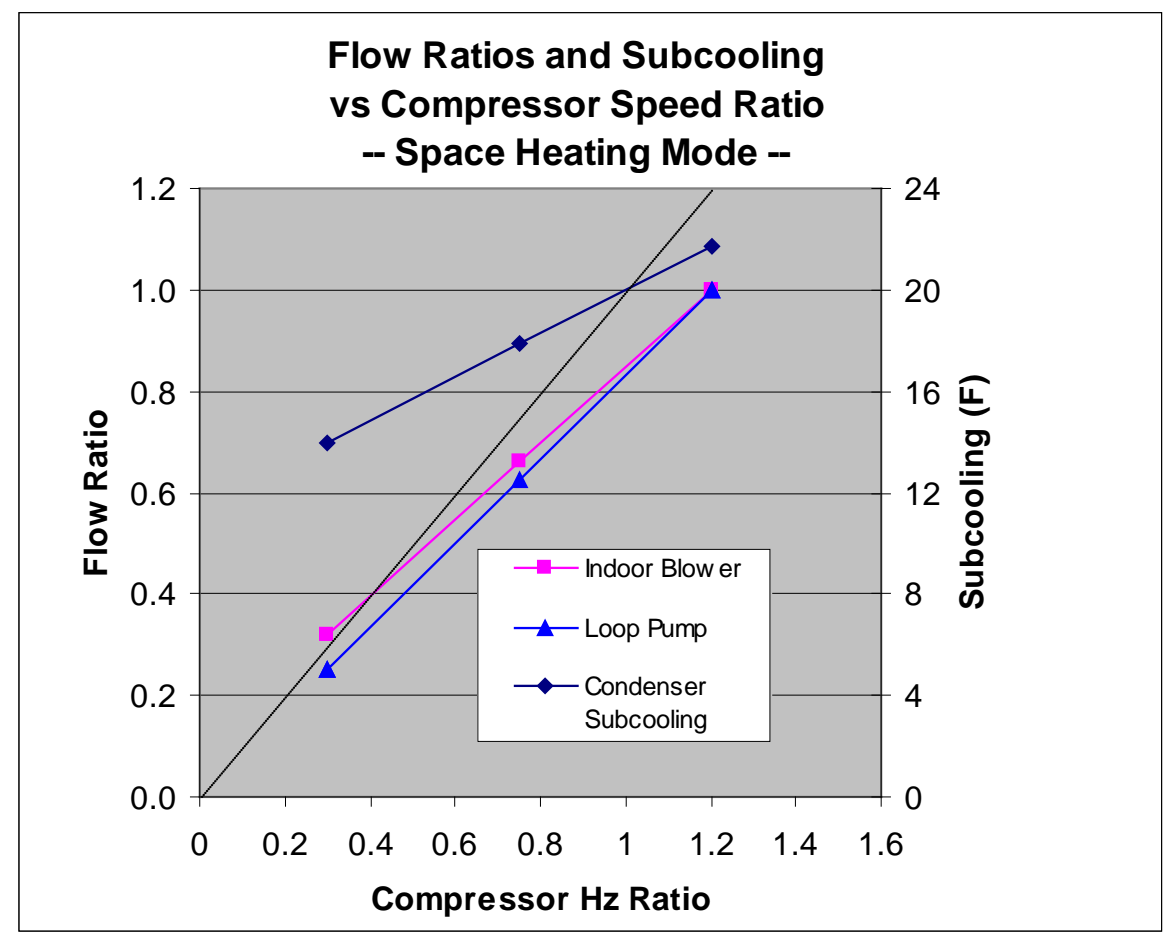

Fig. 3.4. Control parameters versus compressor speed ratio in the space heating mode.

\subsubsection{Control Parameters vs. Compressor Speed Ratio in the Dedicated and Heat Recovery Water Heating Modes}

In the dedicated water heating mode, the approach taken was to allow the compressor speed to vary between 45 and $90 \mathrm{~Hz}$. The compressor cannot be oversped in water heating mode as in space heating because the condensing saturation temperatures can exceed $130^{\circ} \mathrm{F}$ to heat the water to the $120^{\circ} \mathrm{F}$ set point. In this mode, the loop pump flows are set higher than in space heating mode because of the higher loading due to the higher source temperatures. The flow is set to the 4 gpm max at $90 \mathrm{~Hz}$ compressor speed to $2 \mathrm{gpm}$ at $45 \mathrm{~Hz}$ speed to reduce the water-to-refrigerant temperature differences further for more optimum water heating COP as compared to the relative flow settings in the space heating mode. The condenser subcooling is also held to a moderately low value of $8^{\circ} \mathrm{F}$ as compared to the space heating mode to keep the condensing saturation temperatures to more acceptable levels when heating water to the $120^{\circ} \mathrm{F}$ set point. The DWH pump flow is held at a constant value because of the fairly constant HX loading resulting expected from running at the lower compressor speeds at higher outdoor source temperatures. The compressor inlet superheat is held constant at the values used for the space heating mode. These control ratios for the dedicated water heating mode are shown in Fig. 3.5. 


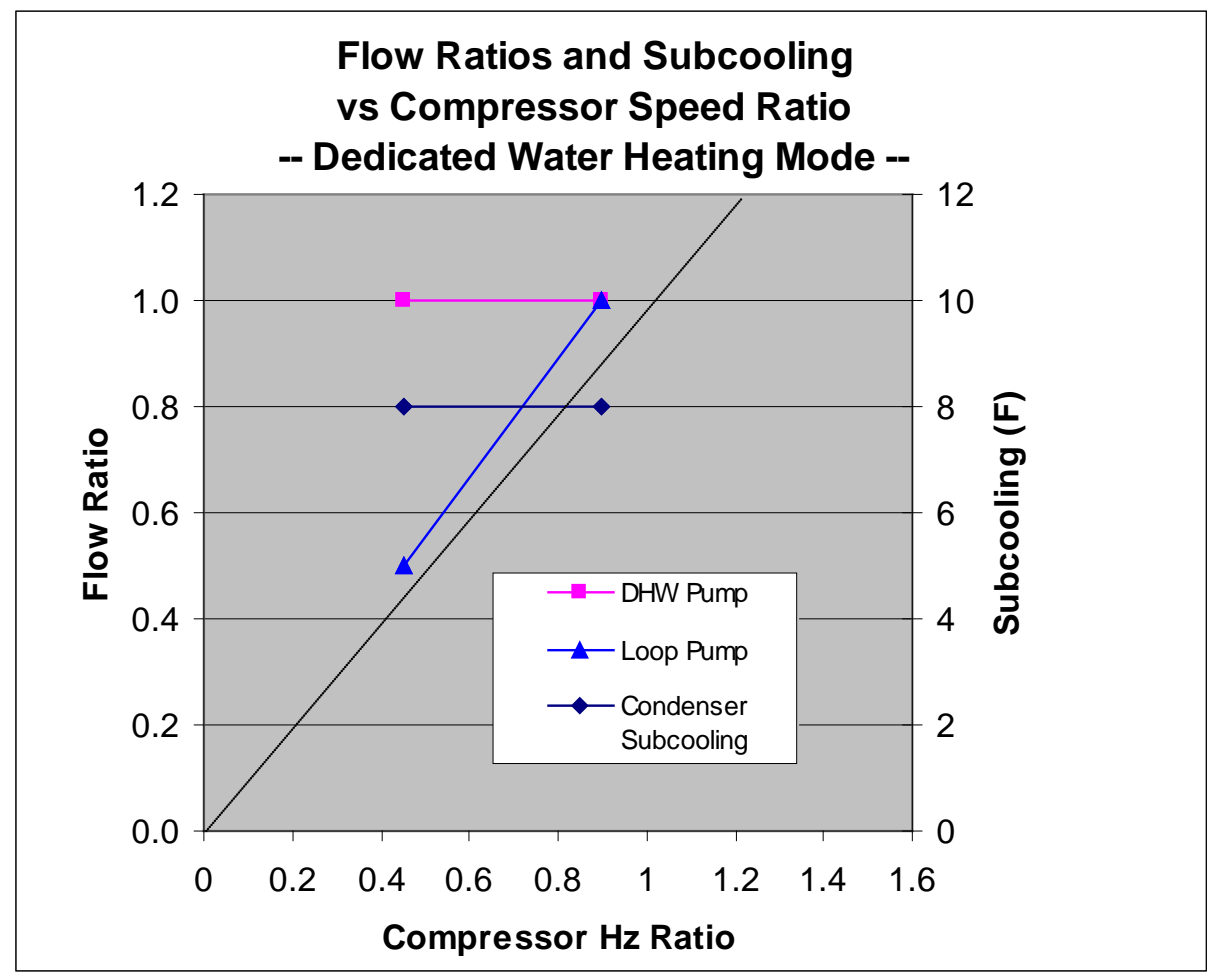

Fig. 3.5. Control parameters versus compressor speed ratio in the dedicated water heating mode.

In the heat recovery modes where the unit is providing space cooling, enhanced space cooling, or dedicated dehumidification with full condensing water heating, the condensing temperature is elevated from the usual space cooling levels due to the higher DWH tank sink conditions. As a result, the compressor flow rate is lowered and the evaporator is somewhat unloaded. To offset this effect and maintain acceptable SHR levels, the indoor blower speed is set to the reduced flows of the enhanced dehumidification mode. The condenser subcooling levels are also reduced from those for the space cooling mode to lower the condensing temperatures to more acceptable levels. The DHW pump flow is kept at the fixed speed level also to keep the condensing temperatures lower, especially for the reduced compressor speed operation where the maximum condensing temperature levels for the compressor are lower. Control operation in this mode is shown in Fig. 3.6 


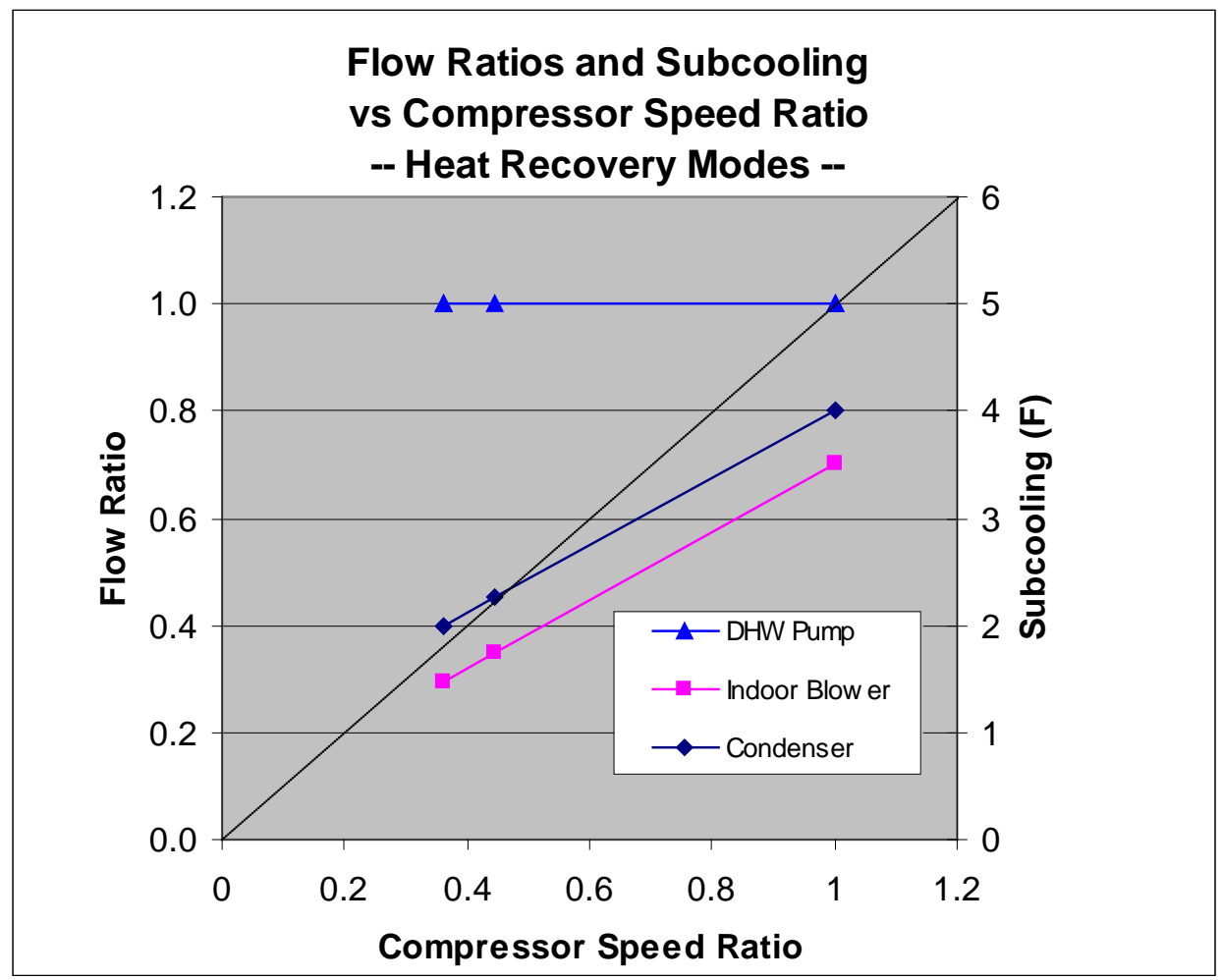

Fig. 3.6. Control parameters versus compressor speed ratio in space cooling / heat recovery modes.

\subsubsection{Target Speed Ratios and Refrigerant Flow Control vs. Ambient in Space Cooling and Heating Modes}

In Fig. 3.7, the target speed ranges in cooling mode for all three modulating components are shown as a function of ambient temperature along with the specified condenser subcooling and compressor inlet superheat levels. This plot shows the speed ranges for an expected average cooling load matching with ambient. As the cooling load varies from this expected relationship, the compressor speed will adjust to match the load seen by the thermostat, and the airflows and subcooling levels would be adjusted based on the revised compressor speed. Fig. 3.8 shows a similar set of control values expected for an expected average heating load matching over the range of ambient temperatures. Again, depending on the actual heating load characteristics of a given building, the compressor speed would adjust to meet the actual load at a given ambient, and the other control parameters would be adjusted accordingly by the equipment control logic. 




Fig. 3.7. Target speed ratios and refrigerant flow control vs. ambient in space cooling mode.

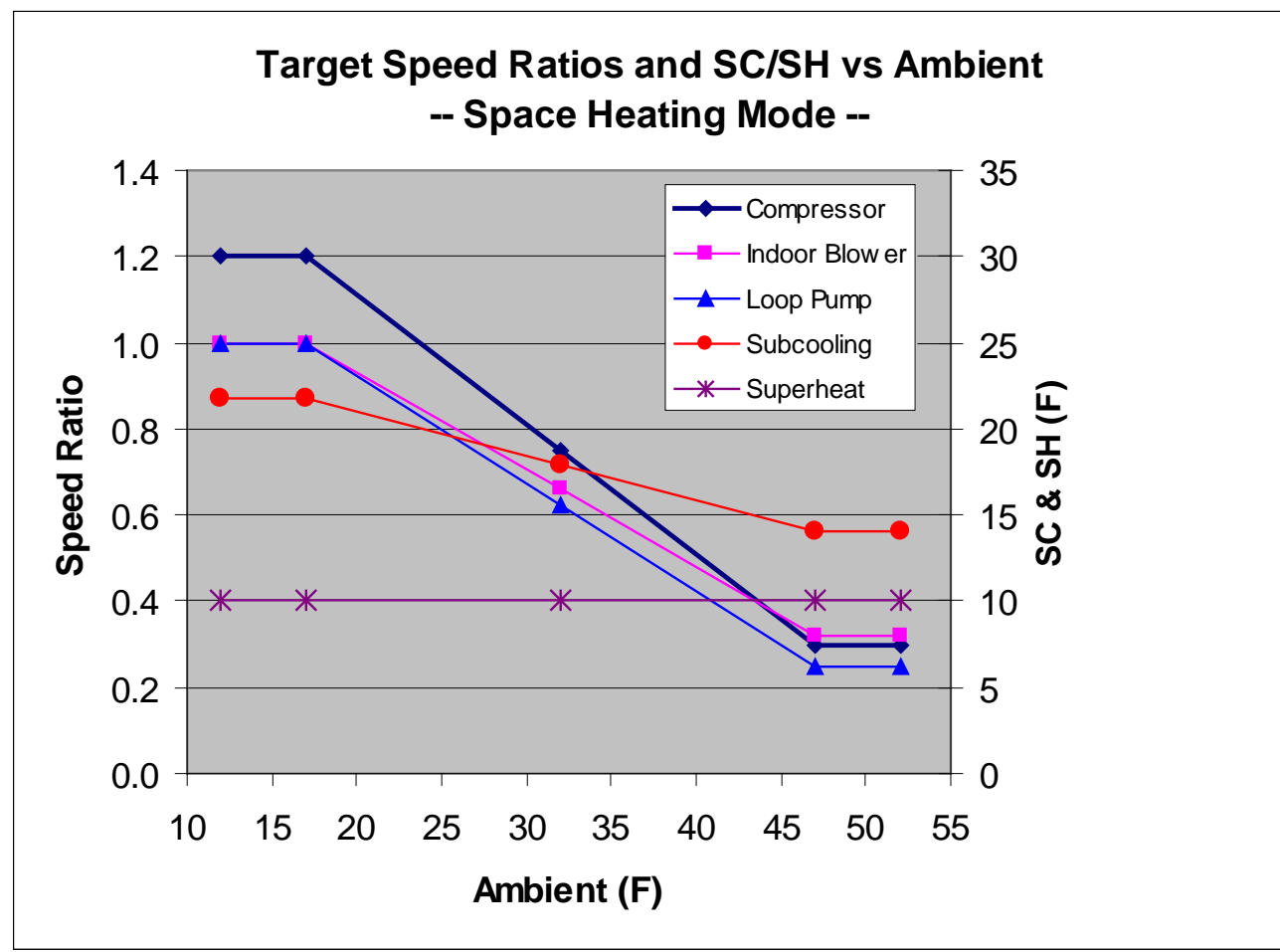

Fig. 3.8. Target speed ratios and refrigerant flow control vs. ambient in space heating mode. 


\subsubsection{Target Compressor Speed Ratios For Space Heating, Space Cooling, Water Heating, and Ventilation Cooling Modes vs. Ambient}

In Fig. 3.9, the target compressor operating speed ratios vs. ambient temperature are summarized for space heating, space cooling, water heating, and ventilation cooling.

Dedicated water heating is shown to operate at target maximum speed at $45^{\circ} \mathrm{F}$ ambient and below, slowing to minimum speed at $65^{\circ} \mathrm{F}$ ambient (from 45 to $90 \mathrm{~Hz}$ in this case) for shoulder month operation. Expected dedicated water heating operation is shown up to $80^{\circ} \mathrm{F}$ ambient as beyond this temperature, space conditioning is expected to take priority with water heating provided by the other heat recovery combination modes as described earlier.

Target speed ranges for ventilation cooling are also shown in Fig. 3.9. Two curves are shown for different humidity removal requirements, from $100 \%$ relative humidity outdoor air to spaceneutral and from an average outdoor humidity ratio to space-neutral. In this mode, the airflow across the indoor coil is fixed at the ventilation flow rate (e.g., $144 \mathrm{cfm}$ for the timed 20-min duration) and the compressor speed is increased to provide more dehumidification as needed based on the indoor relative humidity sensor (from 37 to $45 \mathrm{~Hz}$ for the average humidity case and 39 to $76 \mathrm{~Hz}$ for the high humidity case). The loop pump flow and the condenser subcooling in the ventilation cooling mode are controlled as in space cooling.

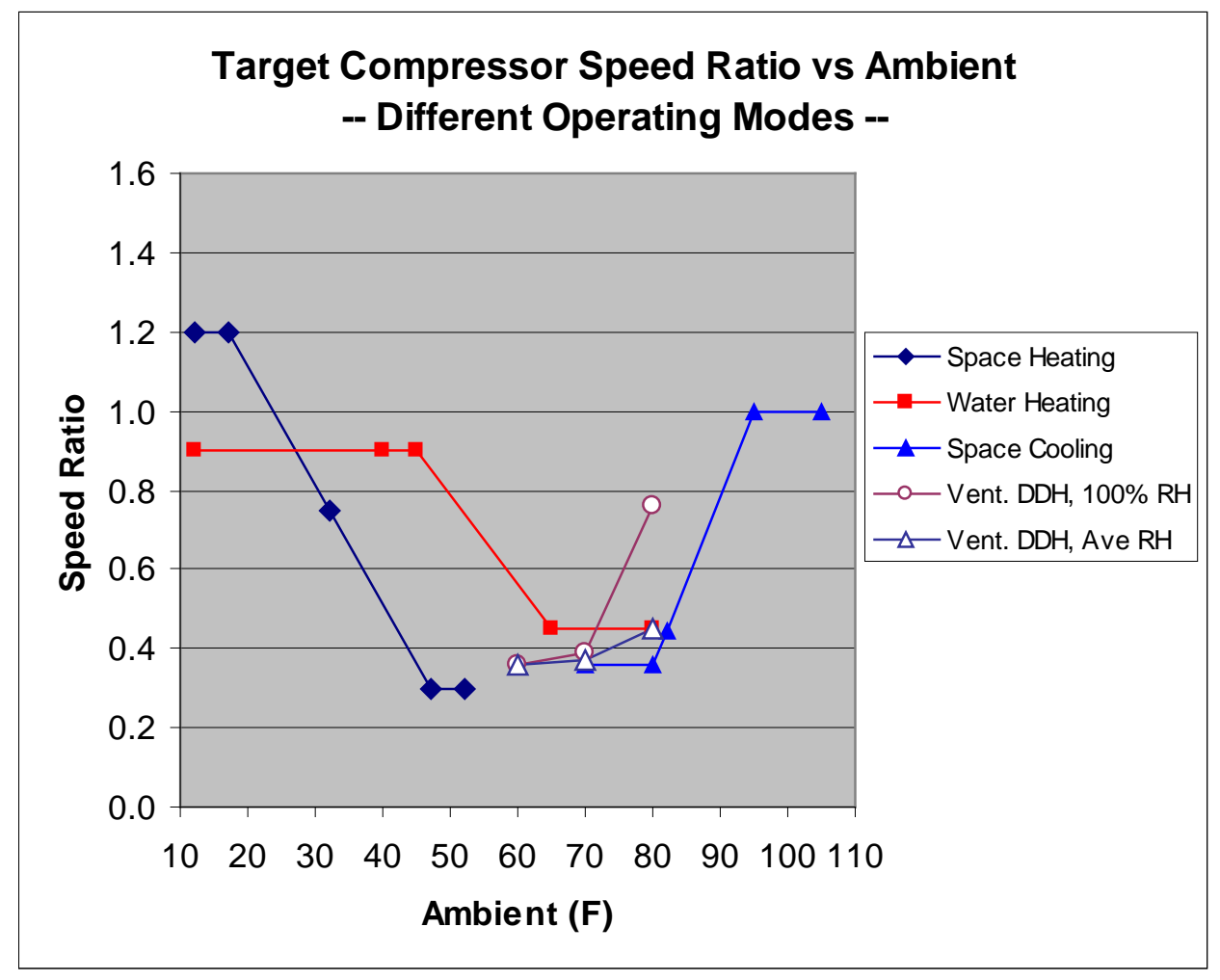

Fig. 3.9. Target compressor speed ratios for various operating modes versus ambient (DDH = dedicated dehumidification; $\mathrm{RH}$ = relative humidity).

These target speeds are to be used by the microprocessor as starting points for the various operating modes, to be adjusted by the thermostat controllers to meet the required indoor dry bulb 
temperature, humidity, or domestic hot water set points, with load following where possible for maximum efficiency. In the case of water heating, higher capacity output from the heat pump at the lower temperatures is selected rather than higher COP to avoid the need for resistance heat elements, which may be needed if the unit cannot keep up with hot water demand when space heating takes priority. 


\section{PREDICTED PERFORMANCE AND ENERGY SAVINGS FOR ZEHS}

The proposed operational control relationships from section 3.6 were next applied to target space conditioning loads and expected source and sink conditions to obtain target GS-IHP performance levels over a selected range of operating modes. These provide a general indication of the energy efficiency ratio (EER) or COP and capacity levels to be expected from the present GS-IHP design to meet expected ZEH space conditioning, ventilation, and water heating loads as a function of relevant source and sink conditions.

The approaches developed to simulate the time-series-based performance of an IHP are then described as are the baseline equipment performance levels against which the GS-IHP is to be compared. The section concludes with comparison of the annual energy savings predicted for the GS-IHP in ZEHs in five climates.

\subsection{GS-IHP System Target Performance}

To calculate target performance levels for the GS-IHP over a range of expected space conditioning loads and water heating conditions, some specific means was needed to relate ambient temperatures to water temperatures returning from the ground loops. For this purpose, we used estimated temperature offsets in cooling and heating modes to shift the temperatures used in the performance calculations from the ambient conditions to equivalent EWTs to the glycol-to-refrigerant HX. In the plots which follow, the ambient temperatures shown are pseudoor "equivalent" temperatures resulting from assumed offsets of $-12^{\circ} \mathrm{F}$ in space cooling mode and $+18^{\circ} \mathrm{F}$ in space heating mode. In the dedicated water heating mode, the same $+18^{\circ} \mathrm{F}$ offset is assumed for ambient temperatures lower than $40^{\circ} \mathrm{F}$ with a somewhat smaller offset of $+5^{\circ} \mathrm{F}$ assumed for milder temperatures between 45 and $80^{\circ} \mathrm{F}$.

\subsubsection{Target GS-IHP Space Heating and Cooling Performance With Proposed Control Relationships for Load Tracking}

In Fig. 4.1, the target performance of the GS-IHP is shown for space heating and cooling for assumed load tracking behavior of target space conditioning loads as a function of ambient temperature. This is where the compressor and indoor and outdoor fan speed ratios as well as the subcooling and superheat are assumed to follow the relationships given in Figs. 3.7 and 3.8 for space cooling and heating, respectively.

However, to determine the performance of the GS-IHP for a particular set of assumed load lines, assumptions must be made about the relationship between the ambient temperatures and corresponding EWTs that are the actual source or sink conditions for the ground-source heat pump. As noted earlier in section 3.6, to calculate representative GS-IHP performances matching house loads which are a function of ambient, relationships between outdoor air temperatures and EWTs in the space heating and cooling modes must be known or assumed. For present representation purposes we have assumed a constant offset of $+18^{\circ} \mathrm{F}$ in space heating and $-12^{\circ} \mathrm{F}$ in space cooling. (In actuality, the offset is expected to be a more involved function of ambient and to vary by time into the cooling or heating season.) Under these assumptions, the GS-IHP performance was calculated at EWTs given by the ambient temperature plus the offset for the respective season. Accordingly, in Fig. 4.1, the x-axis is defined as equivalent ambients. For the purpose of defining the house load lines, the $\mathrm{x}$-axis is actual ambient, but with regard to the performance of the GS-IHP it represents equivalent ambient. 
The respective EERs versus equivalent ambient temperatures are shown by the solid lines, and the delivered capacities are given by the dotted lines. The points where the trend lines change slope are where the minimum and maximum compressor speeds are reached and the system reverts to trends similar to those of a single-speed unit. It can be seen from this plot that the design cooling capacity at $95^{\circ} \mathrm{F}$ equivalent ambient is just over $15 \mathrm{MBtu} / \mathrm{h}$ or 1.25 tons. Similarly at the maximum overspeed operation in heating mode, a heating capacity of $14.3 \mathrm{MBtu} / \mathrm{h}$ is reached at about $17^{\circ} \mathrm{F}$ ambient. Typically a single-speed air-source heat pump has about the same heating capacity at $47^{\circ} \mathrm{F}$ as the design cooling capacity and then drops with ambient to a much lower capacity at $17^{\circ} \mathrm{F}$, having a capacity similar to the variable-speed system shown here only at the design speed of $100 \mathrm{~Hz}$ (speed ratio of 1.0) at $24^{\circ} \mathrm{F}$ ambient. A constant outdoor relative humidity of $73 \%$ was assumed, as used in the ARI rating conditions.



Fig. 4.1. Target GS-IHP space heating and cooling performance versus ambient with proposed control relationships for load tracking. 
Fig. 4.2 shows the GS-IHP performance of the proposed design directly as a function of EWT. This would likely be the representation more familiar to ground-source heat pump designers. Note that there is overlap in EWTs between the heating and the cooling modes between $57^{\circ} \mathrm{F}$ and $75^{\circ} \mathrm{F}$.

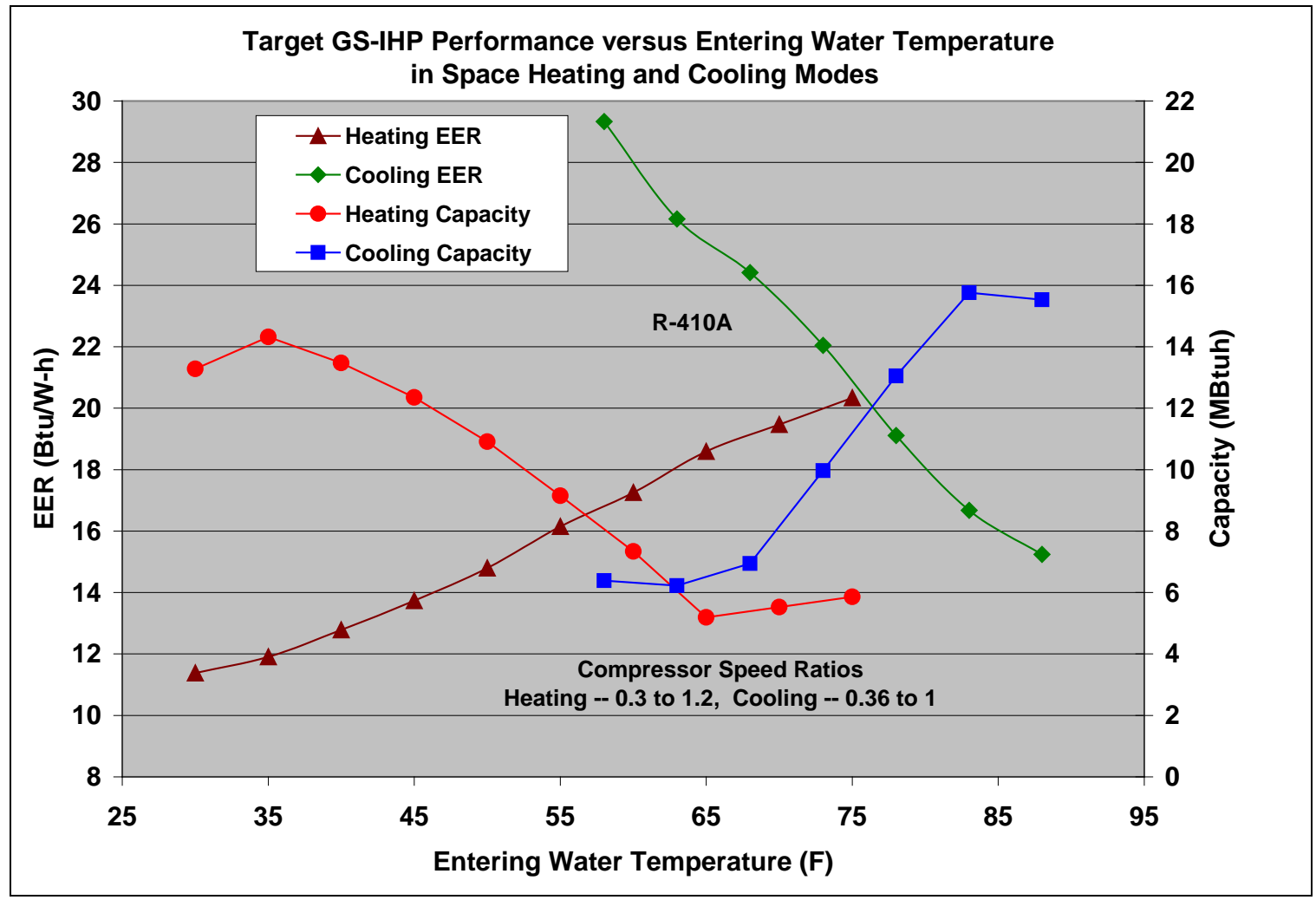

Fig. 4.2. Target GS-IHP space heating and cooling performance versus EWT with proposed control relationships for load tracking.

\subsubsection{GS-IHP vs. AS-IHP Space Heating and Cooling Performance for Equivalent Ambients}

Next we compare the performance of the ground-source and air-source IHPs in meeting the same assumed house loads with ambient temperature. Fig. 4.3 shows how the EERs of the GS-IHP are increased due to the more favorable outdoor source and sink conditions used in the analysis. For the assumed load lines and temperature offsets, the EERs for the GS-IHP are from 14 to $28 \%$ higher in the cooling mode, with the percentage gains increasing with ambient. In the heating mode, the EERs (or HSPF) gains range from 14 to 31\% with the larger percentage gains at the lower ambients. Note that the gains in actual applications in different climates should be expected to vary somewhat from those determined here for a target set of loads and offsets. (This is because of the differing space conditioning loads and temperature offsets between EWTs and ambients in the varying climates and ground-water temperatures. The example given here shows that under certain target conditions, both the ground- and air-source IHP designs can meet the same space conditioning loads over a similar range of minimum to maximum compressor speeds.) 


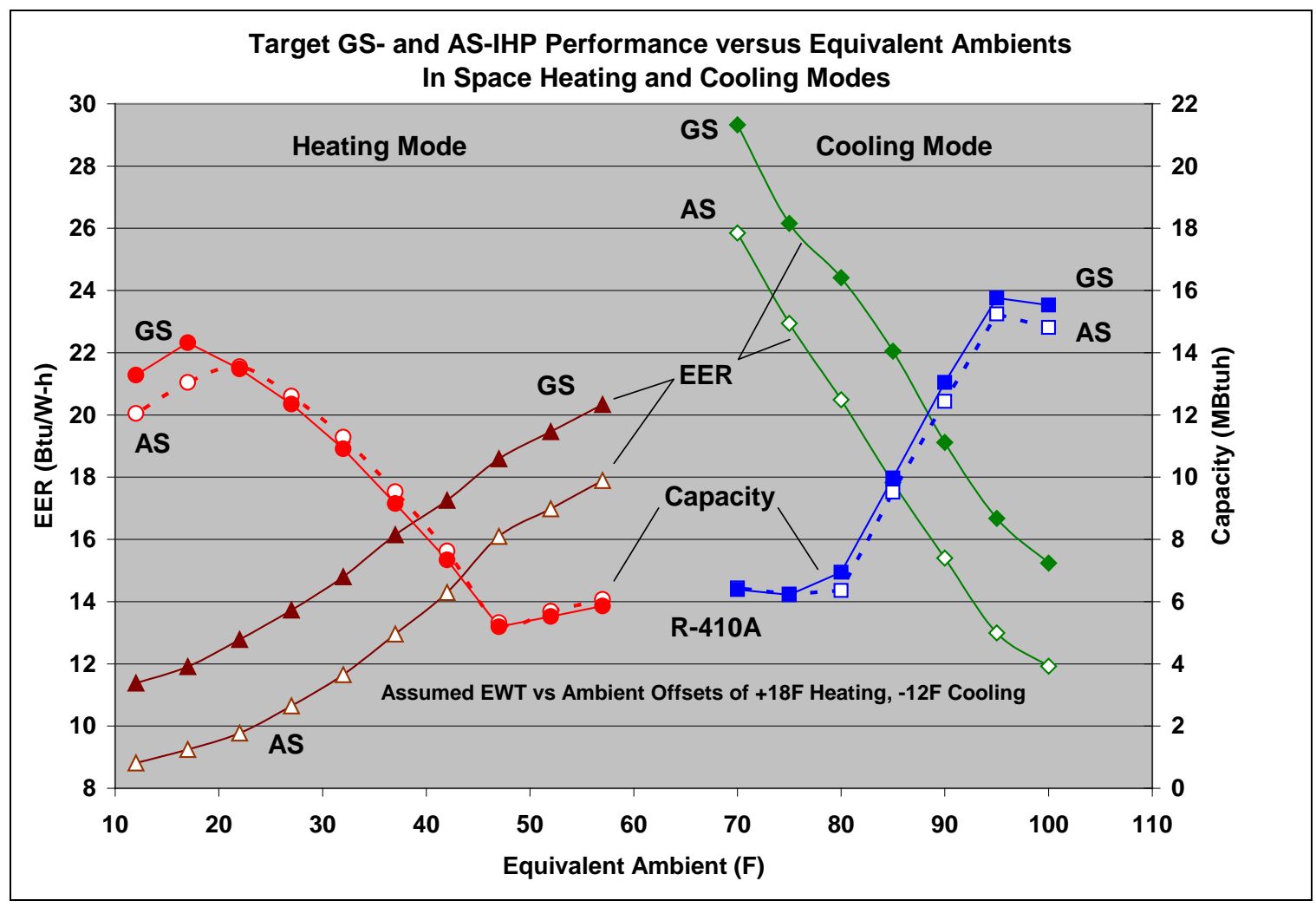

Fig. 4.3. Comparison of target GS- and AS-IHP space heating and cooling performances as a function of equivalent ambient.

\subsubsection{Target GS-IHP Water Heating Performance With Proposed Control Relationships}

The target water heating performance in outdoor source mode is shown in Figs. 4.4 and 4.5 for expected equivalent ambients for shoulder month and main heating season operation, respectively. The temperature offsets between the outdoor air temperature and the EWT seen by the GS-IHP are assumed to be $+5^{\circ} \mathrm{F}$ for the shoulder months and $+18^{\circ} \mathrm{F}$ for the heating season, the latter as assumed for the space heating analysis.

The assumed inlet water temperature to the water heating condenser for this analysis was $108^{\circ} \mathrm{F}$, which is consistent with the rating point used in the HydroTech 2000 performance ratings. (This is expected to be a representative temperature of the water leaving the bottom of the domestic water tank during a call for water heating that is to be supplied by the heat pump to reheat after a moderate draw or sufficient tank heat loss. At bottom tank temperatures below $100^{\circ} \mathrm{F}$, the control logic would likely be calling for resistance heat.)

In Fig. 4.4, the compressor speed ratio is assumed to vary from $0.9(90 \mathrm{~Hz})$ at $45^{\circ} \mathrm{F}$ to $0.45(45$ $\mathrm{Hz}$ ) at $65^{\circ} \mathrm{F}$ ambient. The water heating capacity ranges from about $12,000 \mathrm{Btu} / \mathrm{h}$ (equal to a 3.5$\mathrm{kW}$ heating element) at the assumed $45^{\circ} \mathrm{F}$ equivalent ambient to $9,000 \mathrm{Btu} / \mathrm{h}$ at $65^{\circ} \mathrm{F}$ ambient. In the latter case, the lower heating output was selected to provide higher water heating COP, as 
there is no compelling need to heat the water faster at this ambient where there will be little if any call for coincident space cooling or heating. Accordingly, the delivered COPs for dedicated water heating range from about 3.0 at $45^{\circ} \mathrm{F}$ to 5.3 at $80^{\circ} \mathrm{F}$, the highest ambient expected for outdoor source water heating. Note that in the cooling season, most water heating is expected to be done in heat recovery mode where both space cooling and hot water are delivered outputs and the effective COP including water heating is much higher.

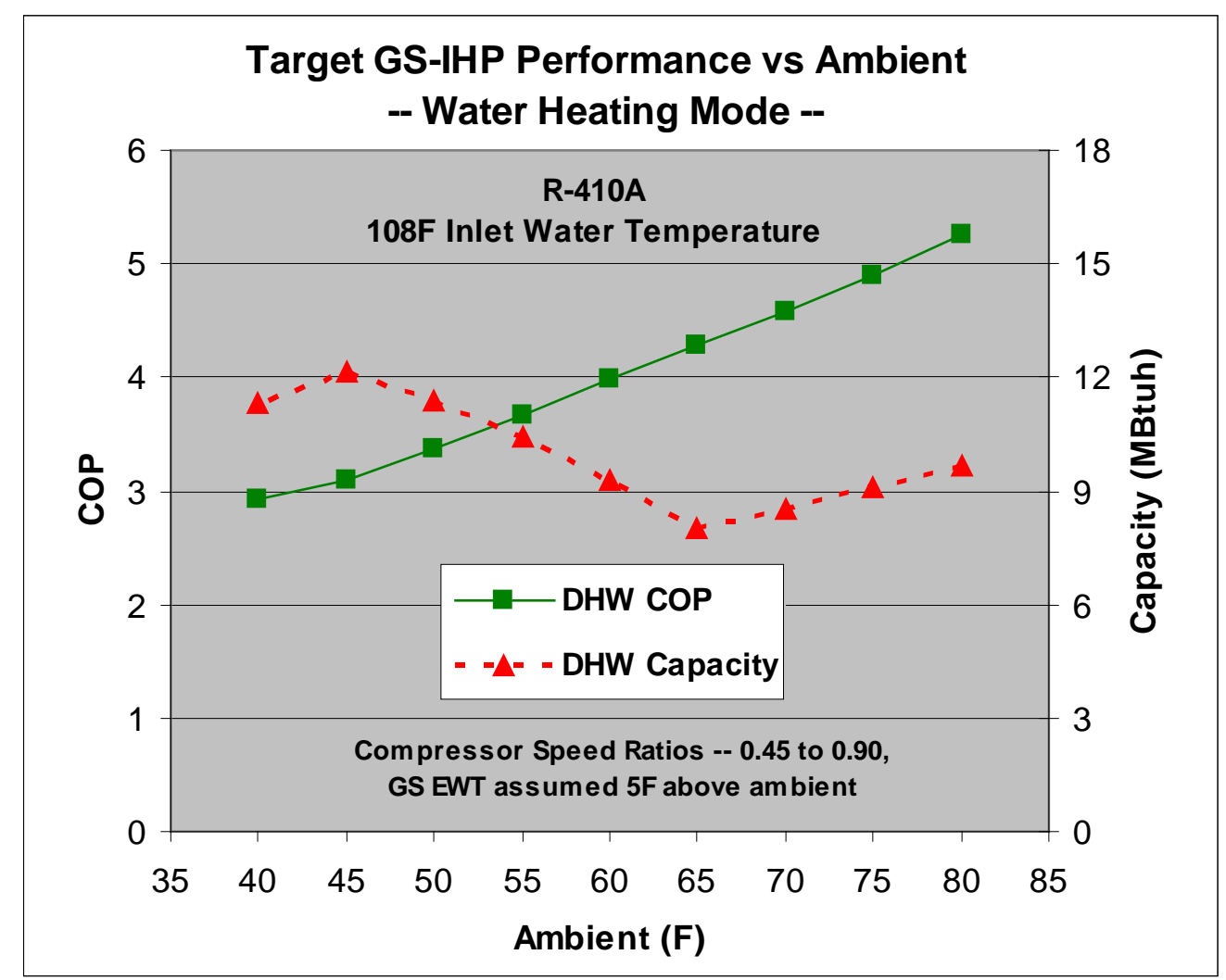

Fig. 4.4. Target GS-IHP water heating performance vs. ambient for shoulder season operation with the proposed control relationships.

In Fig. 4.5, the expected performance during priority water heating operation with space heating calls is shown. In this case, there is an assumed $+18^{\circ} \mathrm{F}$ offset between the ambient temperature and outdoor ground-source EWT as used for the space heating example. By the present control logic, in this mode the compressor runs at maximum water heating speed of $90 \mathrm{~Hz}$. Under these conditions, the COP ranges from 2.5 to 3.5 while the capacity increases from 9,000 to 14,000 $\mathrm{Btu} / \mathrm{h}$. Thus a water heating COP over 3 and capacity of about 12,000 Btu/h is expected with a $32^{\circ} \mathrm{F}$ equivalent ambient, i.e., a $50^{\circ} \mathrm{F}$ ground loop EWT. 


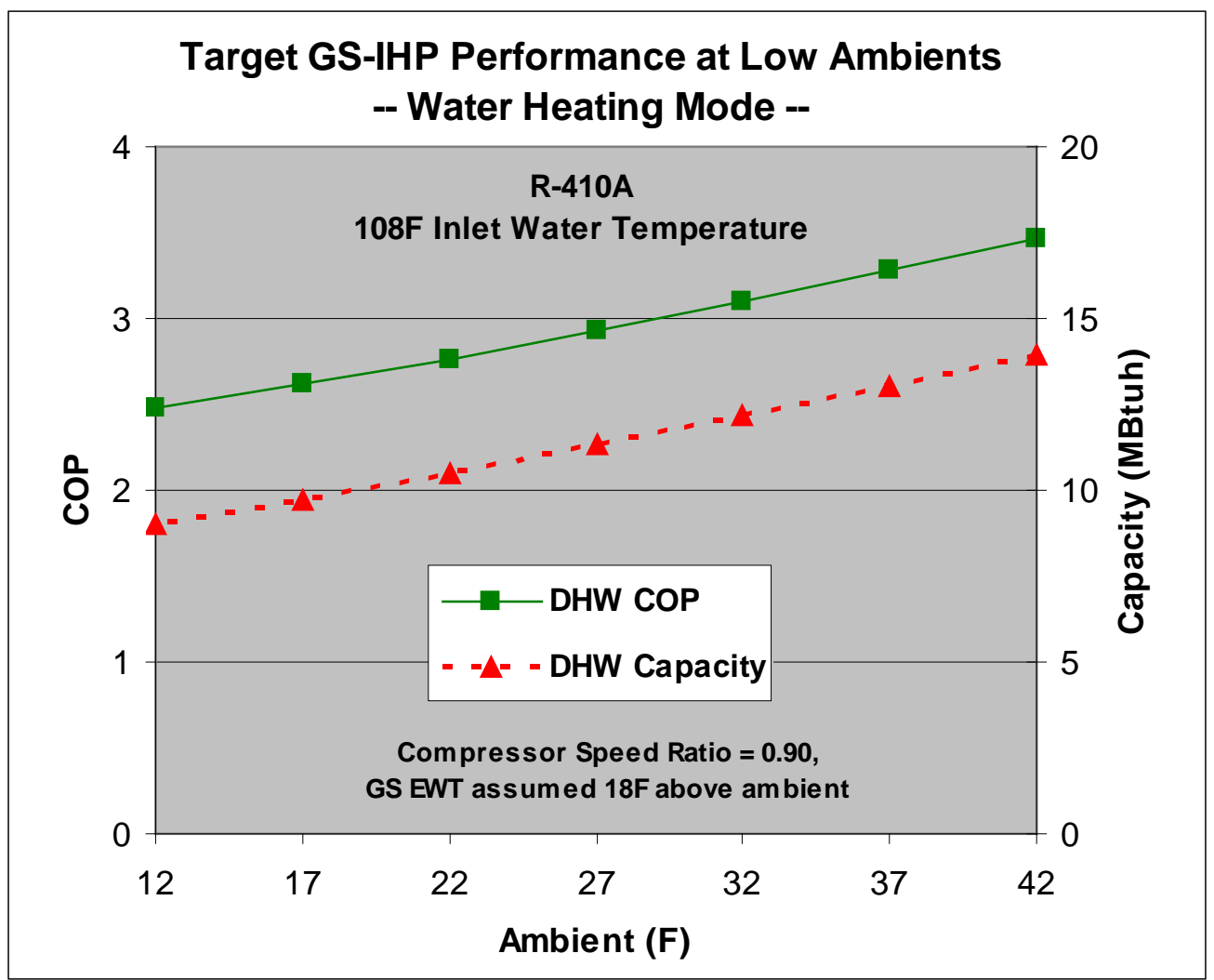

Fig. 4.5. Target GS-IHP water heating performance vs. for heating season operation with the proposed control relationships.

In actuality the water heating capacity is expected to reach an asymptotic value at lower ambient temperatures as the EWTs decrease more gradually than linearly with the outdoor air temperature. An example of the relationship between ambient and ground loop EWTs is shown in Fig. 4.6 for the GS-IHP operating in Atlanta. Here it can be seen that the EWT does not drop below $46^{\circ} \mathrm{F}$ for ambients below $22^{\circ} \mathrm{F}$. 


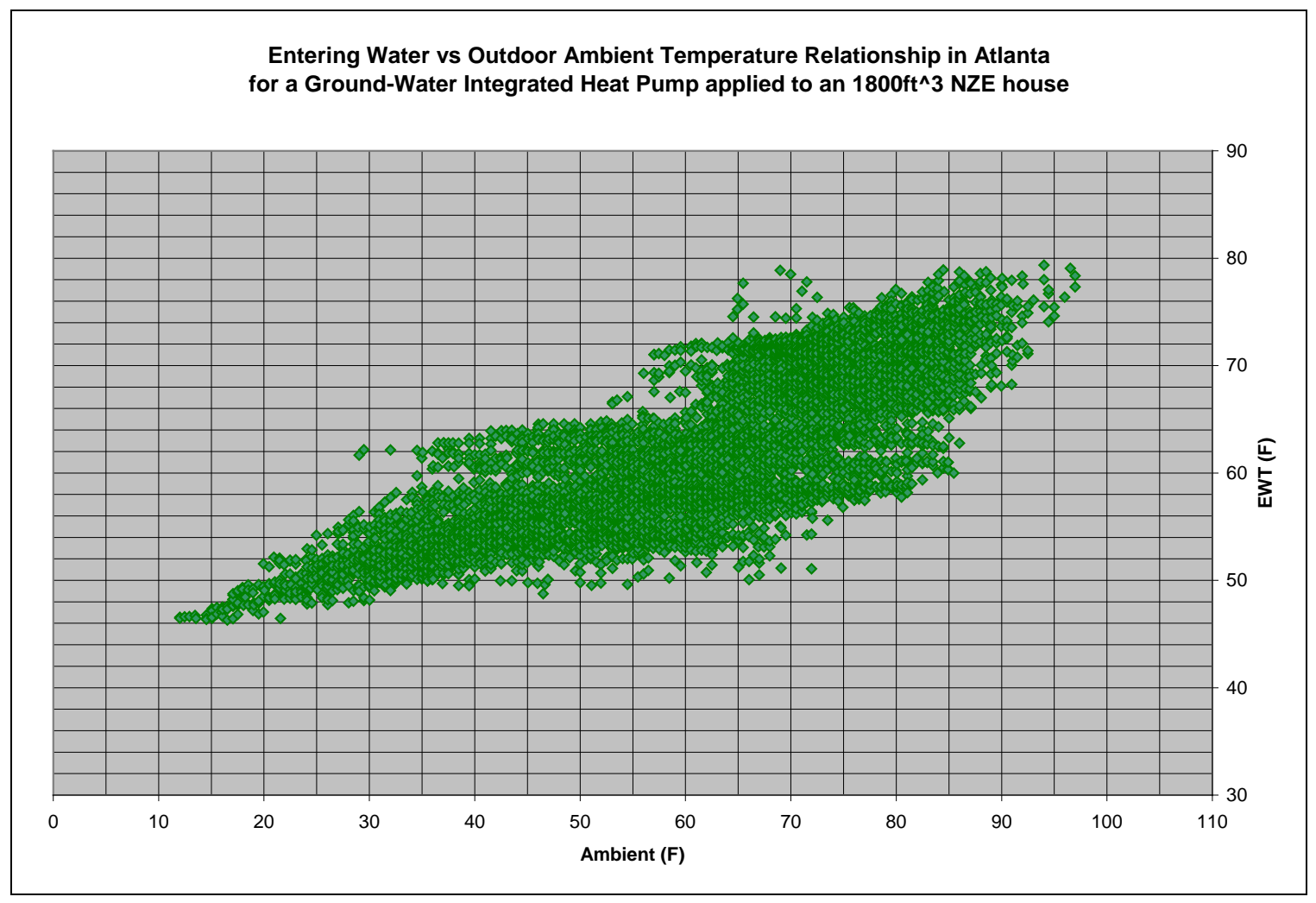

Fig. 4.6. Relationship of ground-loop entering water temperatures to ambient for the GSIHP applied to a ZEH in Atlanta.

\subsubsection{Target ground-source IHP ventilation cooling performance vs. ambient with proposed control relationships.}

Target performance in the ventilation cooling mode (as described in section 3.5.11) is shown in Fig. 4.7 for ambients ranging from 70 to $80^{\circ} \mathrm{F}$. An average outdoor humidity ratio of $0.0155 \mathrm{lbm}$ water/lbm dry air is assumed for the constant ventilation flow rate of $144 \mathrm{cfm}$. This ventilation rate is that required over a 20 -minute operation period to provide the required $48 \mathrm{cfm} / \mathrm{hr}$ ventilation rate. By using a 20-minute rather than continuous ventilation period, more reasonable minimum airflow rates and compressor speeds can be utilized. It is also assumed for ventilation air cooling, as opposed to ventilation air-only operation (section 3.5.10), that the indoor return air damper is closed and that only outdoor air is being circulated in the house. Thus the indoor conditions seen by the cooling coil are those of the outdoor ambient at the specified humidity ratio. The ground-loop EWT was assumed to be $65^{\circ} \mathrm{F}$ for this analysis.

The compressor speed is controlled in this case to provide a constant dehumidification rate and thereby supply air with space-neutral humidity with the ground-loop flow rate and subcooling adjusted according to compressor speed as in regular space cooling mode. 


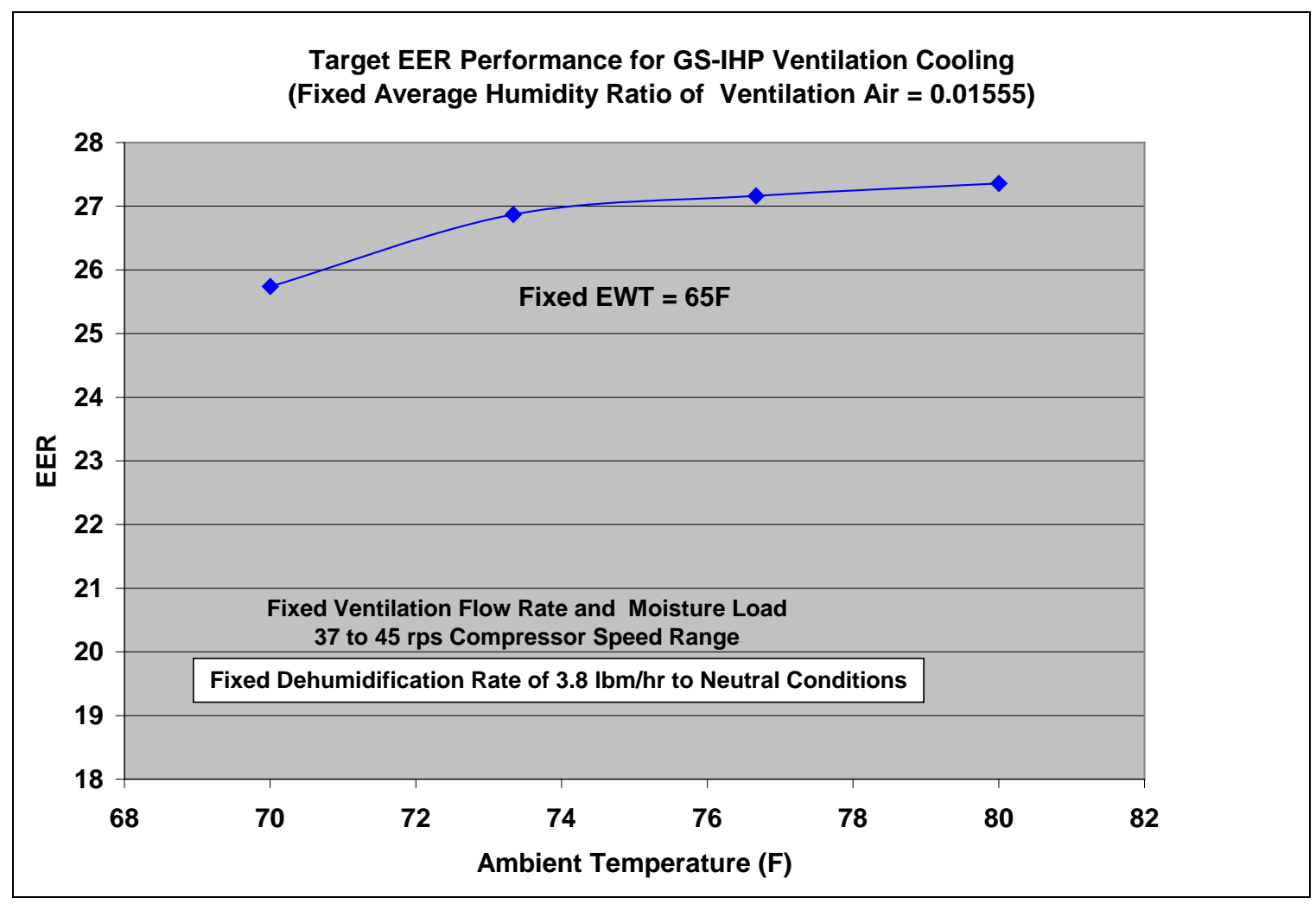

Fig. 4.7. Target GS-IHP ventilation cooling performance vs. ambient with proposed control relationships.

In Fig. 4.8, the delivered sensible heat ratio is seen to range from 0.37 to 0.48 by directly working on the humidity ratio of the outdoor ventilation air without any dilution with indoor return air. This provides a high operating EER for this dehumidification function and even more importantly minimizes the tempering heat that is needed to offset the part of the accompanying sensible cooling that exceeds the required cooling load for the 20-minute operation period. 


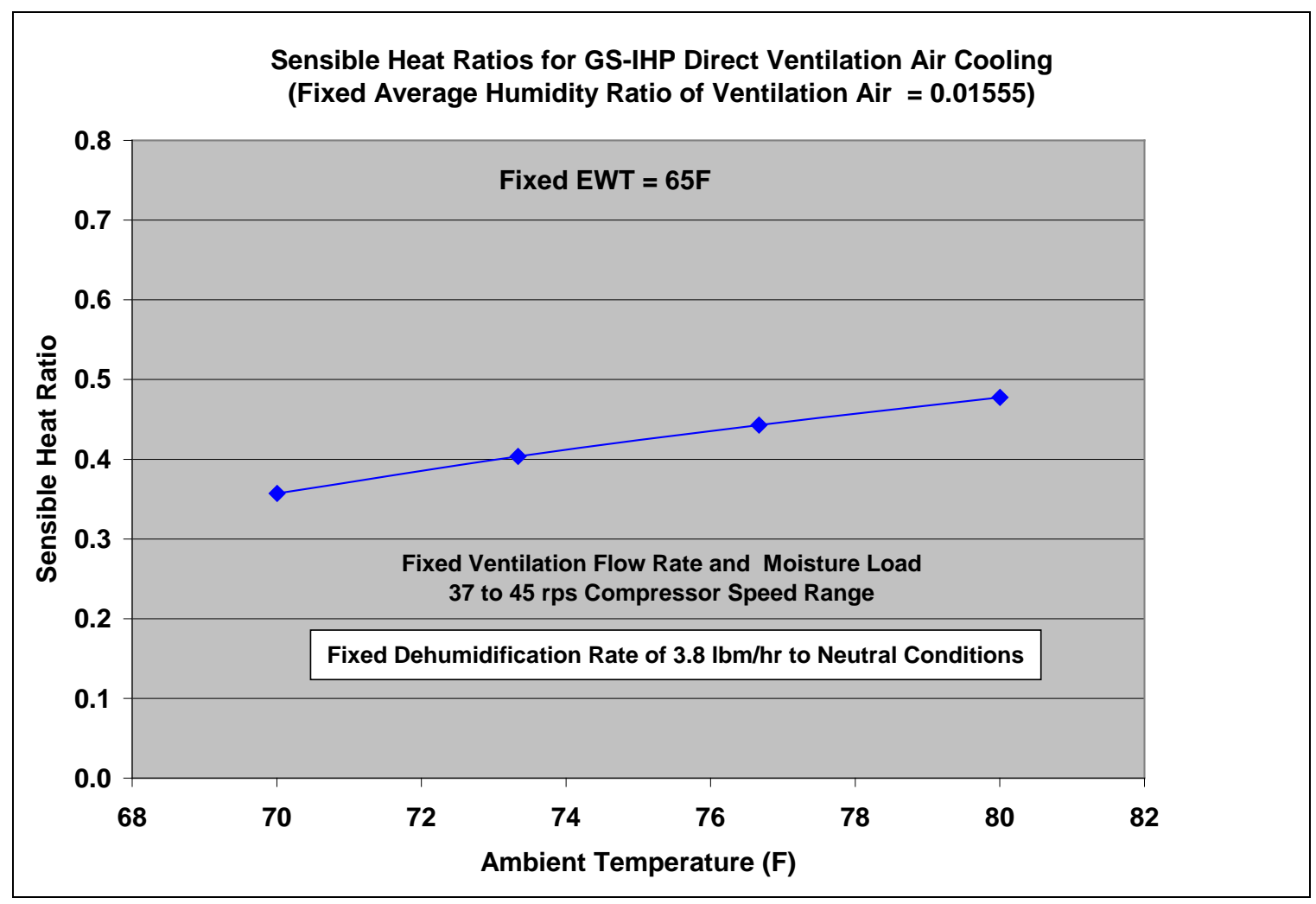

Fig. 4.8. Target GS-IHP ventilation cooling sensible heat ratio (SHR) vs. ambient with proposed control relationships.

\subsection{Development of Time-Series-Based Energy Use Calculations for IHPs}

Once the operational performance of the integrated equipment can be calculated in all the various control modes, the next challenge is to make estimates of the energy use of such equipment operating over a season or year in a specified house and climate. This step is somewhat more involved for integrated equipment than for a suite of individual units in that it requires a coupling with the usage history and thermal state of the domestic water heater. In addition, there may be competing calls for different modes of operation, for which the control logic must determine the appropriate sequencing. An appropriate way to properly account for these interactions is to perform a time-series-based calculation based on a suitable starting point for a year of operation. For conventional HVAC systems without strong coupling to the DHW system, this is done on an hourly basis with energy use simulation codes such as DOE 2. However, in the case of an integrated heat pump such as is under development here, the use of one HVAC system to provide multiple outputs requires a sub-hourly analysis to most accurately account for the various interactions, the competing operating modes, and representative inlet conditions that will be seen simultaneously by the water-to-refrigerant DHW and source HXs while heating water.

\subsubsection{Direct HPDM Call Implementation}

In FY06, detailed calculations of the yearly energy use for an integrated heat pump were developed by linking the HPDM with TRNSYS (Solar Energy Laboratory, et al. 2006), a timeseries-dependent simulation model capable of determining the energy use of building cooling and 
heating equipment as applied to a defined house on a sub-hourly basis. This required an extensive effort to couple the HPDM to TRNSYS in a fully consistent manner so that the outputs of the TRNSYS from modeling the time-dependent indoor space water heater conditions would become inputs to the HPDM. The HPDM output conditions of the indoor air and water leaving the equipment HXs were then also coupled back to the TRNSYS house and DHW modules to update their operating states. For the ground-coupled situation, an additional TRNSYS vertical ground loop module was linked into the TRNSYS project containing house, HVAC equipment and controller, DHW tank, ventilation, and indoor ducting. Further details of the house and controls modeling are described by Baxter (2007).

From the summer of FY06 into the fall of FY07, indoor humidity control was also added to our TRNSYS-based analysis capability, first for stand-alone dehumidifiers and then for the AS-IHP, by including the control logic for enhanced, dedicated, and ventilation air dehumidification. The direct-mode HPDM coupling along with the indoor humidity control was first used for an initial business cases analysis for the AS-IHP as reported by Baxter (2007).

The HPDM modules within TRNSYS were set up to call one of three heat pump description data files depending on which of three basic modes of operation were active as determined by the temperature and relative humidity thermostat calls: space conditioning, space cooling and water heating, and dedicated water heating. The desired settings of air and water flows, subcooling, and superheat as a function of compressor speed and mode (as discussed in Chapter 3) were defined in an IHP system control routine. The sub-modes of space cooling operation for enhanced, dedicated, or ventilation air dehumidification were activated by TRNSYS as needed by the temperature, relative humidity and/or outdoor humidity thermostat calls.

This direct HPDM/TRNSYS coupling provided for the first time the ability to simulate in a subhourly analysis the annual performance of a multi-function, multi-mode developmental IHP without having to provide a detailed set of curve-fitted equations representing the system performance over a range of conditions and airflows in multiple operating modes. It also provided the ability to modify the components and/or the compressor speed versus HX flow controls of the system and evaluate the annual energy use implications without having to provide new sets of performance equations.

The observed drawbacks of the initial direct HPDM/TRNSYS coupling after use for the initial business case analyses were the following:

1) Increase in computation time. Although an HPDM call typically executes in a fraction of a second, with the TRNSYS model running on a 3-minute time step, it usually required more than 160,000 calls to the HPDM for a yearly simulation. This resulted in an increase in the total run time by a factor of 4 to 5 .

2) Decrease in model robustness. With more than 100,000 calls to an iterative solution model such as the HPDM, the odds of having the solution crash once in the yearly simulation were difficult to reduce to zero. While this was not a major issue for air-source analysis where one-year runs would need to be restarted occasionally, for our companion GS-IHP analyses where 10- or 20-year runs were occasionally needed (to confirm proper ground HX sizing by looking at the long term effect on ground temperature), these occasional solution glitches became more problematical.

3) IHP system design control logic hard-coded into a TRNSYS module. The need to incorporate the speed control equations shown in Chapter 3 into TRNSYS code required code recompiling for each design change and so made it somewhat inconvenient to change the system internal design controls. 


\subsubsection{Map-Based IHP Modeling Implementation}

The HPDM was directly linked to TRNSYS for the needed assessment capabilities for two primary reasons. First, it was seen as the most immediately achievable way to obtain this capability to model multi-function, multi-mode performance. Second, direct call provided the ability to experiment with design changes without having to regenerate a new set of performance curves, a task that would be particularly onerous, time-consuming, and error prone. However, mainly because of the model run-time and robustness issues noted above, an alternative way to provide this capability while minimizing or eliminating the drawbacks was being considered. What emerged from this rethinking process was a map-based approach combined with multidimensional interpolation.

By tabulating all the operating modes and range of operating conditions needed to represent the envelopes of IHP performance, we determined that it was not unreasonable to generate performance arrays that would encompass the full range of expected operation. While the number of required calls to obtain close interpolations of IHP performance in all modes was not small, at a few thousand, this was much smaller than the more than 160,000 calls needed for the direct HPDM approach. As importantly, once these runs were completed successfully once, the data array could be saved and reused by recall at the outset of successive runs for different climates, or houses, or even most control logic strategies.

In mid-FY07, new TRNSYS modules were prepared to generate a full set of AS-IHP performance maps for the first TRNSYS runs with a new R-410A AS-IHP design. These performance maps were set up to save all output values (presently numbering 30 ) that might be needed for linkage to the rest of the TRNSYS equipment and house models.

Once the performance map array was generated by running the HPDM model in map generation mode and written to disk for later reuse, the HPDM module would perform similarly to a direct HPDM call case. However, in this case, it is by performing multi-parameter interpolations (of three to four independent parameters) of heat pump performance for the active operation mode for the current 3-minute time step. Such interpolations are much faster than an HPDM call and so the computational slowdown is eliminated save for an initial IHP performance map generation step. This initial set of calls typically takes 5 to 6 minutes and needs to be done only once for each IHP design.

Compressor speed values and step sizes are made consistent with the presently allowed five or six speed steps available for the space conditioning thermostat controls and four speed steps used in the TRNSYS controller for the water heating thermostat speed control logic. This eliminates the compressor speed interpolation error, which is potentially the largest source of error with a limited number of speed steps.

To specify the heat pump configurations needed for the IHP performance maps, we use five heat pump input data files: for space cooling, space heating, space cooling with heat recovery water heating, outdoor source water heating, and ventilation air cooling.

To define the range of parametrics and the heat pump control design, we use eight parametric input control files, one for each possible mode of heat pump operation. The parametrics needed for the performance mapping, in addition to compressor speed, are indoor temperature and relative humidity and outdoor temperature for space cooling modes, and outdoor temperature and relative humidity and indoor temperature for space heating. For the water heating modes, the range of possible inlet water temperatures is used in place of outdoor temperature for the 
combined space cooling mode. For the outdoor source water heating, the inlet water temperature parametric replaces that of the indoor air temperature. In the ventilation air cooling mode, only outdoor temperature and relative humidity are needed.

The parametrics data files were set up consistent with the existing two-variable parametric capability of the HPDM (Rice 1991). The main change was to extend the number of possible parametrics from two to five and to enable the parametric control input to operate properly with up to five possible independent variables changing. The capability to handle five-variable parametrics was included to accommodate possible future needs to handle split condensers rejecting heat from two sources. In such cases, parametrics for two sink temperature ranges could be needed.

Because the parametrics files are input to the HPDM/TRNSYS analysis tool, all the mapping and heat pump system design control information is now modifiable outside of the source code. This structure resolved the remaining "lesson learned" as noted earlier in this section from the direct call/control experiences. By having all of the heat pump equipment design specifics external to the TRNSYS code, it is much easier to modify and track the current design approach being used.

Further, because the performance map generation process is easily done as a one-time computation once the input heat pump data and parametric control files are prepared, a change of heat pump designs is much less time consuming than it would if equipment performance curve fits were required to be generated and input to the program. This meets a longstanding need for a way to conveniently yet accurately incorporate advanced heat pump designs with two or more operating modes into the more detailed hourly and sub-hourly whole-house energy use simulations.

To test the accuracy of the performance mapping approach, we compared the energy use results for each operating mode with the direct HPDM call approach. This was possible because both options were preserved in the current TRNSYS implementation. The comparison proved useful as well in debugging the mapping and interpolation implementation. In the end, we found close agreement between the two approaches with the mapping approach having only a minimal increase in run time (using a saved performance map) compared with a baseline air-source heat pump case using curve-fitted performance equations.

The TRNSYS/HPDM annual performance analysis for the new AS-IHP design was followed by setup and application to a similar new R-410A system design for the GS-IHP prototype as discussed in Chapters 2 and 3. In general the mapping requirements are slightly simpler for the ground-source application as the outdoor relative humidity variable is eliminated. This reduces the mapping needs for the space heating and dedicated water heating modes. However, the required mapping runs are increased for the ground-source ventilation cooling case where the outdoor source and the outdoor ambient temperature are no longer the same.

As in the AS-IHP case, we compared the direct HPDM call approach with that for the map-based approach to validate the modified implementation for a ground-source application. This validation exercise uncovered a few problems that were resolved before making production analysis runs.

The design approach described in Chapter 2 and the control relationships shown in Chapter 3 were used to define new heat pump input data sets and parametric data files for generation of a new GS-IHP performance map. This map was applied with the multi-mode, multi-variable interpolation approach in the new TRNSYS/HPDM modules and related system controller to 
predict annual performance and energy use for the new R-410A GS-IHP design. The results of this analysis for an $1800-\mathrm{ft}^{2} \mathrm{ZEH}$ in five climates are described in the following sections.

\subsubsection{Aids for IHP Operation and Controls Assessment from TRNSYS Results}

Improvements were also made to the reporting and tabulation of results from TRNSYS yearly simulations. This was needed to provide sufficient information for review by design engineers to determine if the systems controls were operating as intended and to study the delivered performance and relative run time of the IHP in each operation mode.

New summary TRNSYS output was added to provide:

o energy use and delivered loads in each TRNSYS operating mode,

o total hours in each operation mode and further hours breakdown at each speed level, and

o three-minute tracking of HP and DHW tank operating conditions and compressor saturation temperatures.

With this improved level of mode operation detail available, we are able to better evaluate the operational conditions seen by the equipment and the modal performance, and to investigate needed refinements. For example, by having the number of hours operating at each speed, we can see if the speed distribution seems reasonable and make modifications as indicated. This information was used to adjust the starting points for the compressor speed versus ambient temperature in ventilation cooling when they were seen to not be starting when intended.

With the amount of information available from 3-minute time steps and hourly summaries, it is a continuing challenge to manage and digest the information in ways that are most helpful for operation and controls assessment. Supporting spreadsheet summaries were also developed tabulating:

o minimum, maximum, and average source/sink temperatures in major operating modes,

o hours that temperature / RH levels exceed targeted levels,

o annual average and top tank temperatures,

o energy use and delivered output by major operating modes and overall,

o house delivered space conditioning energy characteristics versus outdoor air temperature, and

o ground loop EWT vs. outdoor air temperature comparisons.

From a study of the tank temperatures for the GS-IHP compared to the baseline with resistance water heating, modifications were made to the water heater thermostat settings to obtain more comparable average tank temperatures and charged conditions.

\subsection{Applied Annual Sub-Hourly Performance Analyses Using R-410A}

TRNSYS capabilities were used to simulate not only the annual performance of the current GSIHP design but also for a suitable suite of baseline equipment for use in determining the potential energy savings of the GS-IHP in a ZEH providing the same energy services.

\subsubsection{Baseline HVAC/WH/DH/H System}

A standard split-system (separate indoor and outdoor sections), air-to-air heat pump provides space heating and cooling under control of a central thermostat that senses indoor space temperature. It also provides dehumidification when operating in space cooling mode but does not separately control space humidity. Rated system efficiencies were set at the DOE minimum 
required levels in effect for 2006 (SEER 13 and HSPF 7.7). Water heating is provided using a standard 50-gallon electric storage water heater $(\mathrm{WH})$ with energy factor $(\mathrm{EF})$ set at the current DOE-minimum requirement $(\mathrm{EF}=0.90)$ for this size heater. Ventilation meeting the requirements of ASHRAE Standard 62.2-2004 (ASHRAE 2004a) is provided using a central exhaust fan. A separate dehumidifier is included as well to meet house dehumidification needs when the central heat pump is not running to provide space cooling.

Dehumidifier location, sizing, and efficiency level. Rudd et al. (2005) indicates that perhaps the most cost-effective approach for adding separate dehumidification capability to a house is to locate a stand-alone dehumidifier in the conditioned space, preferably in close proximity to the main HVAC system return air grill. That is the approach adopted in the present analysis. A manufacturer of typical stand-alone dehumidifiers, Heat Controller, includes a table on their web site that suggests a 30-50 pint/day (7-12 L/d) capacity would be sufficient for a $2000-\mathrm{ft}^{2}$ house (http://www.heatcontroller.com/products/pdf/dehumidbroch.pdf). A 40 pt/d size was chosen and this proved to be adequate for the ZEH in all locations. In this case adequate was taken to mean that indoor RH levels would exceed $60 \%$ for no more than about $2 \%$ of the year. The $60 \%$ criterion matches that used by Rudd et al. (2005) in their study. Other studies use 65\% including a recent one by Witte and Henninger (2006) for ASHRAE that evaluated humidity control capability of various unitary system designs. For the cooling set point of $76^{\circ} \mathrm{F}$ used in our analyses, ASHRAE's thermal comfort standard indicates a maximum acceptable RH of about $65 \%$ for spaces with activity levels typical of offices (ASHRAE 2004b).

There is currently no DOE-mandated minimum efficiency value for residential dehumidifiers. However, amendments to the Energy Policy and Conservation Act of 1975 included in the Energy Policy Act of 2005, P.L. 109-58, expanded DOE’s energy conservation program to include certain commercial equipment and residential products, including dehumidifiers. In compliance with this directive, DOE/BT has recently specified a default minimum dehumidifier energy factor $\left(\mathrm{EF}_{\mathrm{d}}\right)$ for $40 \mathrm{pt} / \mathrm{d}$ dehumidifiers of $1.3 \mathrm{~L} / \mathrm{kWh}$, effective in 2007, and a default minimum of $1.4 \mathrm{~L} / \mathrm{kWh}$ to be effective in 2012 (DOE/BT 2006). According to comments submitted by Whirlpool to EPA regarding their recent revision of the Energy Star requirements for dehumidifiers, the 35-54 pt/d capacity range represents nearly $60 \%$ of all dehumidifier shipments (Hoyt 2005). DOE will focus its rulemaking analysis for dehumidifiers on the 35-45 pt/d size range only. The Energy Star website (http://www.energystar.gov/index.cfm?c=dehumid.pr_dehumidifiers) indicates that the current efficiency of Energy Star-qualified dehumidifiers of the above capacity ranges from 1.3 to $1.5 \mathrm{~L} / \mathrm{kWh}$ (rated at $80^{\circ} \mathrm{F}$ and $60 \% \mathrm{RH}$ indoor conditions). Based on that information, it was decided to use $\mathrm{EF}_{\mathrm{d}}=1.4$ for the baseline system dehumidifier efficiency in the present analysis.

A whole-house humidifier similar to a model offered by Research Products Corporation (http://aprilaire.com/index.php?znfAction=ProductDetails\&category=5\&item=550) was included to provide the winter humidification (H) function. Product data for the model (sized for $<3000 \mathrm{ft}^{2}$, tightly constructed homes) specifies a fixed water input flow of $0.5 \mathrm{gal} / \mathrm{hr}$ when operating. Hot water from the DHW tank was used for the humidifier supply based on manufacturer specifications for application with heat pump systems, and this was the value used for the baseline system (http://aprilaire.com/themes/aa/en/manuals/400.pdf). Fig. 4.9 provides an illustration representative of how such a humidifier might be installed. Some of the indoor air stream is diverted or bypassed through the humidifier where water is evaporated from a 
distribution pad. Energy consumption of the system will be increased compared to operation without a humidifier in two ways: 1) extra water heater consumption to cover the humidifier water usage and 2) extra heat pump energy use to overcome the cooling effect of the water evaporation on the air stream. The type of humidifier adopted for the analyses reported herein consumes no power other than a negligible amount needed to operate the water flow control solenoid valve.

System control set points were as follows: $71^{\circ} \mathrm{F} \pm 2.5^{\circ} \mathrm{F}$ and $76^{\circ} \mathrm{F} \pm 2.5^{\circ} \mathrm{F}$ for first-stage space heating and cooling, respectively; $66 \mathrm{~F} \pm 2^{\circ} \mathrm{F}$ for second-stage space heating (electric back-up heater); $120^{\circ} \mathrm{F} \pm 5^{\circ} \mathrm{F}$ for water heating; $55 \% \mathrm{RH} \pm 4 \%$ for dehumidification; and $34 \% \mathrm{RH} \pm 4 \%$ for heating.

The hot water draw schedule assumed for the TRNSYS analyses is shown in Table 4.1. The total daily hot water consumption assumed was $\sim 65$ gallons.

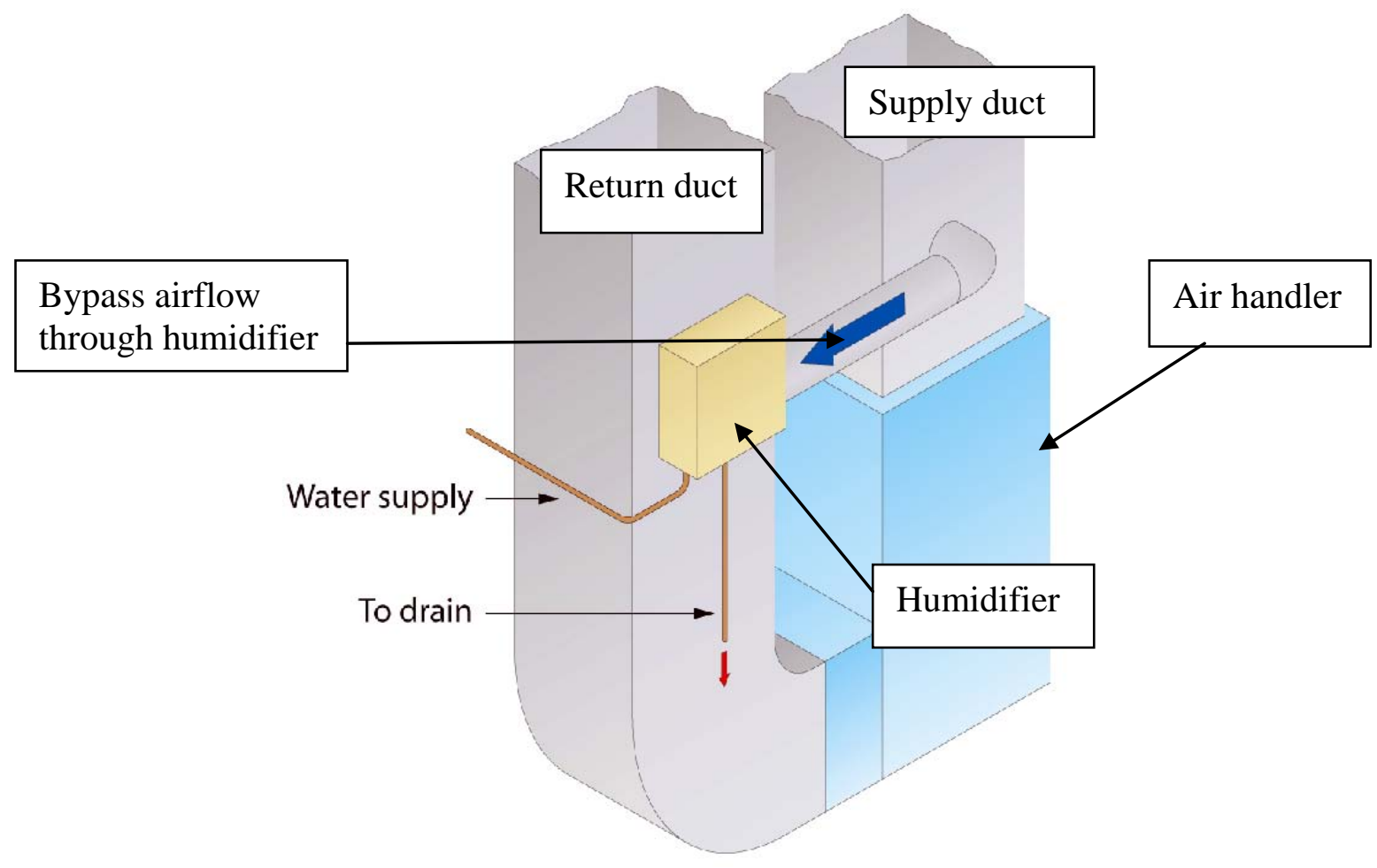

Fig. 4.9. Representative humidifier installation. 
Table 4.1. Daily hot water draw schedule assumed for analyses

\begin{tabular}{|l|r|c|c|}
\hline \hline Event & $\begin{array}{c}\text { Start time } \\
\text { (h) }\end{array}$ & $\begin{array}{c}\text { Duration } \\
\text { (min) }\end{array}$ & $\begin{array}{c}\text { Fraction of } \\
\text { daily } \\
\text { consumption }\end{array}$ \\
\hline Shower & a.m. 6:00 & 12 & 0.172 \\
Shower & $6: 15$ & 12 & 0.172 \\
Shower & $6: 30$ & 12 & 0.172 \\
Lavatory & $6: 00$ & 1 & 0.014 \\
Lavatory & $6: 15$ & 1 & 0.014 \\
Kitchen sink & $6: 45$ & 2 & 0.029 \\
Kitchen sink & $7: 30$ & 2 & 0.029 \\
Clothes wash cycle & $9: 00$ & 3 & 0.204 \\
Lavatory & p.m. $12: 15$ & 1 & 0.014 \\
Kitchen sink & $12: 30$ & 1 & 0.014 \\
Lavatory & $4: 45$ & 1 & 0.014 \\
Lavatory & $5: 15$ & 1 & 0.014 \\
Dishwasher (1 ${ }^{\text {st }}$ wash) & $7: 30$ & 1.5 & 0.048 \\
Dishwasher (2 ${ }^{\text {nd }}$ wash) & $8: 00$ & 1.5 & 0.048 \\
Lavatory & $9: 45$ & 1 & 0.014 \\
Lavatory & $10: 15$ & 1 & 0.014 \\
Lavatory & $10: 30$ & 1 & 0.014 \\
\hline \hline
\end{tabular}

\subsubsection{Ground-Source Integrated Heat Pump (GS-IHP)}

This system concept, as shown conceptually in Fig. 1.1 and schematically in Fig. 2.1, uses one variable-speed modulating compressor, a variable-speed indoor blower, a multiple-speed pump for ground heat exchange fluid circulation, a single-speed pump for hot water circulation, and a total of four HXs (one air-to-refrigerant, two water-to-refrigerant, and one air-to-water) to meet all the HVAC and WH loads. A 50-gallon WH tank (same size as for baseline) is included. The same type humidifier as used for the baseline system was assumed to be included with the GSIHP. Initially the same humidifier water flow as for the baseline case was used as well. But simulations using this flow rate showed water use more than double that of the baseline system with the excess water simply going down the drain. To limit excessive water consumption we cut the humidifier water supply rate in half for IHP application.

The set points for first- and second-stage space heating, space cooling, dehumidification, and heating as used for the baseline were also used for the GS-IHP. For WH, the first-stage (IHP water heating) set point was $115^{\circ} \mathrm{F} \pm 5^{\circ} \mathrm{F}$ with a second-stage set point of $107.5^{\circ} \mathrm{F} \pm 2.5^{\circ} \mathrm{F}$ to control an electric resistance back-up heating element in the upper portion of the DHW tank. The second-stage WH set point was intentionally set lower than the first-stage set point to maximize the amount of water heating supplied by the IHP.

Based on findings from the most recent AS-IHP technology development status report (Murphy et al. 2007b) and further evaluations, it was decided to assign priority to WH over space heating in winter. The basic control priority is summarized below. 
When there is a call for water heating while in space heating mode, then the unit switches to water heating mode at maximum compressor speed and runs there until either the water heating need is satisfied or there is a call for backup resistance space heating. If the latter occurs, the unit switches back to space heating and runs at max speed until the backup resistance heat call is satisfied. Then the unit switches back to water heating mode. Once the water heating demand is met, the unit switches back to space heating operation at the compressor speed specified by the controller and continues until the space heating need is met or there is another call for water heating.

Results from the assessment of this WH priority approach for the AS-IHP showed that overall IHP efficiency with this modified WH control was clearly improved (Murphy et al. 2007b). While energy use in space heating mode increases somewhat when compared with performance using a space heating priority control approach, the reduction in water heater backup electric element usage more than compensates. The option of combined space heating and water heating, as discussed in section 3.5.6, was not included in this analysis. This was because the simulation model cannot yet model these dual HX modes. As such, there are dual HX opportunities to reduce the water heating use in winter that have not yet been simulated There are also other possible approaches to apportion priority for space heating and water heating, one of which was investigated here.

A unique aspect of the IHP is that the ventilation air is conditioned by the heat pump in both space cooling and space heating modes, and on demand if neither heating nor cooling is required. The ventilation dehumidification mode logic used in the TRNSYS simulation was to initiate when (1) there is no space conditioning call for 1 hour, (2) the outdoor humidity ratio exceeds both a standard indoor humidity ratio of 0.0095 and the indoor humidity ratio, and (3) the outdoor temperature exceeds $68.5^{\circ} \mathrm{F}$.

The unit also cycles on demand to dehumidify the space whether or not heating or cooling is required. The air-to-water HX uses recovered hot water generated in the space cooling and dedicated dehumidification heat recovery modes to temper the ventilation air, as needed, for space neutral conditions. A HX effectiveness of $60 \%$ was assumed for the tempering coil in the TRNSYS simulation. Compressor and indoor fan speed modulation is used to control both indoor humidity and temperature, when needed. For the TRNSYS simulations, when in the demand dehumidification mode described in section 3.5.8, the water flow to the tempering coil was also modulated by a bypass valve to maintain a neutral supply air temperature.

Another potentially attractive aspect of the IHP concept is that, being a single equipment package, it is better suited than the baseline suite of equipment for being able to curb demand when the grid is stressed in response to a utility's or independent system operator's radio signal.

\subsubsection{Analysis Approach and Results}

The annual energy use simulations for the baseline and IHP HVAC systems were performed using the TRNSYS 16 platform. This required conversion of the $1800-\mathrm{ft}^{2}$ prototype ZEH description to TRNSYS Type 56 representations. Annual, sub-hourly simulations were performed for the baseline system and AS-IHP for five locations: Atlanta, mixed-humid type climate; Houston, hot-humid; Phoenix, hot-dry; San Francisco, marine; and Chicago, cold. Annual simulations for the IHP systems required that HPDM (Rice and Jackson 2002) be integrated into the TRNSYS simulation system as described earlier in this section. 
As described previously, the IHP is a continuously variable-speed device and would likely use a proportional/integral/differential (PID) type scheme to set the speeds of the compressor and fans in response to inputs from the various control thermostats. In these simulations this PID control approach was approximated by assuming several discrete speed/capacity levels for the various operating modes: six levels for space heating, five levels for space cooling and demand dehumidification, and four levels for demand water heating.

Also noted earlier, the ground HX circulation pump is assumed to be a multiple-speed type (having $2-4$ discrete speeds). For simulation convenience the ground HX flow is modeled in these analyses as continuously variable between limits of 1 and 4 gpm with the pump power input modeled as a constant ratio of watts input to gpm, in this case $20 \mathrm{~W} / \mathrm{gpm}$.

Table 4.2 provides summary results of TRNSYS/HPDM sub-hourly simulations for the baseline HVAC system for an $1800-\mathrm{ft}^{2}$ prototype net ZEH for each of the five locations examined in this study. Table 4.3 provides results for the GS-IHP including hourly peak kW demand. Maximum peaks occurred in the winter and generally between 6 and 8 a.m. (roughly coincident with winter utility peak periods). The water use schedule assumed for the analysis included a significant draw during that time of day, making electric backup element activity likely (adding to backup electric space heating in the colder locales). Maximum summer peaks are somewhat lower and generally occurred between 6 and 8 a.m. as well for the same reason. Summer hourly peaks during noon to 7 p.m. (roughly coincident with summer utility peak time period) were about $1.6-2.4 \mathrm{~kW}$ for the baseline system vs. about $0.6-1.2 \mathrm{~kW}$ for the GS-IHP.

Detailed results from the simulations for the ZEH are given in Table 4.4. The total energy consumption and consumption by individual modes for the baseline system are from the hourly TRNSYS simulations. For the IHPs the total energy consumption, that of the ventilation fan, and for the electric backup water heating and space heating are from the detailed TRNSYS simulations. Breakdowns for the other modes for the IHPs were taken from the hourly simulations as well, but with adjustments to fairly charge the water pump power in combined modes to the water heating function. Indoor temperature control for the IHPs (average indoor temperature and magnitude and duration of extreme high and low periods) was equal or better than for the baseline in all cities. Indoor space RH control by the IHP met the criteria of no more than about $2 \%$ of hours with $\mathrm{RH}>60 \%$ in all locations. Average annual domestic hot water temperature with the IHP was generally a few degrees $\left(2-4^{\circ} \mathrm{F}\right)$ warmer than for the baseline system. However, the water temperature at the top of the DHW tank in the case of the IHP was $4-5^{\circ} \mathrm{F}$ cooler than for the baseline, indicating somewhat less stratification in the tank water temperatures with the IHP. At no time in any of the cities did the average hourly hot water delivery temperature fall below $105^{\circ} \mathrm{F}$ for either the IHP or the baseline system.

The results summarized in Tables 4.3 and 4.4 show that the GS-IHP, with the revised WH and dehumidification operational control strategies now being employed, achieved greater than $50 \%$ savings over the baseline system in this study in all locations including Chicago.

Winter peak $\mathrm{kW}$ ranged from about 30 - 70\% lower for the IHPs than for the baseline. Maximum summer peaks were about $70-75 \%$ lower, while summer mid-afternoon IHP peaks were about $45-70 \%$ lower than those of the base system, depending upon location.

The analysis results summarized in Table 4.4 are for WH priority control in winter and also with desuperheating operation eliminated. In our prior analyses, it had been assumed that we would take advantage of available refrigerant desuperheat energy in the IHP compressor discharge gas for water heating whenever the IHP was operating for space cooling, space heating, or 
dehumidification. Results of elimination of the desuperheating operation for each city are given in Table 4.5. Overall the GS-IHP gained about $1-2.4 \%$ in energy savings vs. the baseline system depending on location when desuperheating was eliminated. Other advantages from eliminating desuperheating operation, as discussed earlier in the report, include switching from a two-speed to a single-speed water pump, elimination of a water temperature control valve, and overall simplification of the IHP control scheme. In addition, there was a major reduction in the run time for the pump with expected attendant benefits of increased pump life. Given these advantages we decided to drop desuperheating operation from IHP designs going forward.

Table 4.2. Annual site HVAC/WH system energy use and peak for $1800-\mathrm{ft}^{2} \mathrm{ZEH}$ house with baseline HVAC/WH system

\begin{tabular}{|c|c|c|c|}
\hline Location & $\begin{array}{c}\text { Heat pump } \\
\text { cooling capacity } \\
\text { (tons) }\end{array}$ & $\begin{array}{c}\text { HVAC site } \\
\text { energy use } \\
\text { (kWh) }\end{array}$ & $\begin{array}{c}\text { HVAC hourly peak } \\
\text { kW demand } \\
\text { (W/S/SA)* }\end{array}$ \\
\hline Atlanta & 1.25 & 7230 & $8.6 / 4.6 / 2.1$ \\
\hline Houston & 1.25 & 7380 & $6.1 / 4.4 / 2.2$ \\
\hline Phoenix & 1.50 & 6518 & $6.1 / 3.9 / 2.1$ \\
\hline San Francisco & 1.00 & 4968 & $5.7 / 5.6 / 1.6$ \\
\hline Chicago & 1.25 & 10773 & $9.7 / 6.1 / 2.4$ \\
\hline
\end{tabular}

* W - winter morning; S - summer maximum; SA - summer mid-afternoon

Table 4.3. Estimated annual site HVAC/WH system energy use and peak for $1800-\mathrm{ft}^{2} \mathrm{ZEH}$ house with GS-IHP system (winter humidification active)

\begin{tabular}{|c|c|c|c|c|}
\hline Location & $\begin{array}{c}\text { Heat pump } \\
\text { cooling capacity } \\
\text { (tons) }\end{array}$ & $\begin{array}{c}\text { HVAC/WH } \\
\text { site energy use } \\
(\mathrm{kWh})\end{array}$ & $\begin{array}{c}\text { HVAC/WH hourly } \\
\text { peak kW demand } \\
\text { (W/S/SA)* }\end{array}$ & $\begin{array}{c}\text { Energy savings vs. } \\
\text { ZEH/Baseline } \\
(\%)\end{array}$ \\
\hline Atlanta & 1.25 & 3007 & $2.0 / 1.1 / 1.0$ & 58.4 \\
\hline Houston & 1.25 & 3290 & $1.8 / 1.1 / 1.0$ & 55.4 \\
\hline Phoenix & 1.50 & 2909 & $1.7 / 1.2 / 1.2$ & 55.4 \\
\hline San Francisco & 1.00 & 1699 & $1.8 / 1.6 / 0.6$ & 65.8 \\
\hline Chicago & 1.25 & 5126 & $6.9 / 1.7 / 0.8$ & 52.4 \\
\hline
\end{tabular}

* W - winter morning; S - summer maximum; SA - summer mid-afternoon 
Table 4.4. IHP performance vs. baseline system in ZEH (with humidifier)

\begin{tabular}{|c|c|c|c|c|}
\hline \multirow{2}{*}{\multicolumn{2}{|c|}{$\begin{array}{l}\text { Loads (1800 } \mathrm{ft}^{2} \text { ZEH from TRNSYS } \\
\text { simulation with Baseline system) }\end{array}$}} & \multicolumn{3}{|c|}{ Equipment } \\
\hline & & \multirow{2}{*}{$\begin{array}{c}\text { Baseline } \\
\text { Energy use, } \\
\text { kWh }\left(I^{2} r\right)\end{array}$} & \multicolumn{2}{|c|}{ GS-IHP } \\
\hline Source & kWh & & $\begin{array}{c}\text { Energy use, } \\
\text { kWh }\left(\mathrm{I}^{2} \mathrm{r}\right)\end{array}$ & \begin{tabular}{|c|}
$\begin{array}{c}\text { Energy reduction } \\
\text { compared to } \\
\text { baseline }\end{array}$ \\
\end{tabular} \\
\hline \multicolumn{5}{|c|}{ Atlanta } \\
\hline Space Heating & 4775 & $1789(51)$ & 1066 & $40.4 \%$ \\
\hline Space Cooling & 5735 & 1643 & 996 & $39.4 \%$ \\
\hline Water Heating & 3032 & 3402 & $855(144)$ & $74.9 \%$ \\
\hline Dedicated DH & 158 & 208 & 73 & $64.9 \%$ \\
\hline Ventilation fan & - & 189 & 17 & $90.9 \%$ \\
\hline Totals & 13701 & 7230 & 3007 & $58.4 \%$ \\
\hline Humidifier water use & $499 \mathrm{~kg}$ & & $647 \mathrm{~kg}$ & \\
\hline \multicolumn{5}{|c|}{ Houston } \\
\hline Space Heating & 1766 & 648 & 381 & $41.1 \%$ \\
\hline Space Cooling & 9927 & 2853 & 1936 & $32.1 \%$ \\
\hline Water Heating & 2505 & 2816 & $477(76)$ & $83.1 \%$ \\
\hline Dedicated DH & 704 & 875 & 484 & $44.7 \%$ \\
\hline Ventilation fan & - & 189 & 11 & $94.3 \%$ \\
\hline Totals & 14902 & 7380 & 3290 & $55.4 \%$ \\
\hline Humidifier water use & $75 \mathrm{~kg}$ & & $89 \mathrm{~kg}$ & \\
\hline \multicolumn{5}{|c|}{ Phoenix } \\
\hline Space Heating & 1580 & 535 & 279 & $47.9 \%$ \\
\hline Space Cooling & 9759 & 3317 & 2038 & $38.6 \%$ \\
\hline Water Heating & 2189 & 2477 & $560(1)$ & $77.4 \%$ \\
\hline Dedicated DH & - & - & - & - \\
\hline Ventilation fan & - & 189 & 32 & $83.1 \%$ \\
\hline Totals & 13527 & 6518 & 2909 & $55.4 \%$ \\
\hline Humidifier water use & $170 \mathrm{~kg}$ & & $240 \mathrm{~kg}$ & \\
\hline \multicolumn{5}{|c|}{ San Francisco } \\
\hline Space Heating & 2881 & 932 & 616 & $33.9 \%$ \\
\hline Space Cooling & 88 & 26 & 19 & $25.3 \%$ \\
\hline Water Heating & 3387 & 3767 & 1025 (203) & $72.8 \%$ \\
\hline Dedicated DH & 42 & 54 & 10 & $80.6 \%$ \\
\hline Ventilation fan & - & 189 & 28 & $85.2 \%$ \\
\hline Totals & 6398 & 4968 & 1699 & $65.8 \%$ \\
\hline Humidifier water use & $34 \mathrm{~kg}$ & & $29 \mathrm{~kg}$ & \\
\hline \multicolumn{5}{|c|}{ Chicago } \\
\hline Space Heating & 11425 & $5448(1415)$ & 3133 (293) & $42.5 \%$ \\
\hline Space Cooling & 2550 & 729 & 335 & $54.0 \%$ \\
\hline Water Heating & 3807 & 4286 & $1568(371)$ & $63.4 \%$ \\
\hline Dedicated DH & 94 & 121 & 75 & $38.0 \%$ \\
\hline Ventilation fan & - & 189 & 15 & $92.2 \%$ \\
\hline Totals & 17877 & 10773 & 5126 & $52.4 \%$ \\
\hline Humidifier water use & $1369 \mathrm{~kg}$ & & $1721 \mathrm{~kg}$ & \\
\hline
\end{tabular}


Table 4.5. Comparison of GS-IHP performance vs. baseline HVAC/WH system with and without use of desuperheating for water heating

\begin{tabular}{|c|c|c|c|c|c|}
\hline \multirow{2}{*}{ Location } & \multicolumn{3}{|c|}{ HVAC site energy use, kWh } & \multicolumn{2}{c|}{$\begin{array}{c}\text { Energy savings vs. baseline } \\
\text { HVAC (\%) }\end{array}$} \\
\hline & Baseline & $\begin{array}{c}\text { IHP with } \\
\text { DS }\end{array}$ & $\begin{array}{c}\text { IHP without } \\
\text { DS }\end{array}$ & IHP with DS & IHP without DS \\
\hline Atlanta & 7230 & 3123 & 3007 & 56.8 & 58.4 \\
\hline Houston & 7380 & 3429 & 3290 & 53.5 & 55.4 \\
\hline Phoenix & 6518 & 2985 & 2909 & 54.2 & 55.4 \\
\hline San Francisco & 4968 & 1816 & 1699 & 63.4 & 65.8 \\
\hline Chicago & 10773 & 5238 & 5126 & 51.4 & 52.4 \\
\hline
\end{tabular}




\section{UPDATED GS-IHP BUSINESS CASE ASSESSMENT}

Since publication of the initial IHP business case assessment earlier this year (Baxter 2007) the system controls and design developments as discussed in this report have significantly improved the IHP energy efficiency. Installed costs, operating costs, and payback estimates have accordingly been revised. The revised estimates are presented in this section.

\subsection{Baseline System Estimated Costs}

Central heat pump; minimum estimate: From the 2002 technical support document (Technical Support Document (TSD)/heat pump] for DOE's central heat pump efficiency standards (DOE/BT 2002), the estimated cost to manufacture a 13-SEER, 3-ton, split-system heat pump in 1998 dollars was \$743.36. Data from the U.S. Department of Labor (DOL 2006a) indicates that the Producer Price Index for finished goods less food and energy has inflated by $10.8 \%$ from 1998 to 2006. Applying this factor to the 1998 cost estimate yields an estimated cost to manufacture of \$823.64 in 2006 dollars. The TSD/heat pump also estimated markup factors for manufacturer, distributor, and dealer of 1.23, 1.26, and 1.27, respectively. Applying these factors to the manufacturing cost estimate yields an estimated selling price for a 3-ton heat pump of \$1621.13 (2006 dollars). Pricing data obtained in 2006 from the Smarterway.com Web site (www.smarterwayinc.com/), a source used by NREL in obtaining cost data for BEopt analyses, indicates that 1.5-ton systems are on average about $80 \%$ of the cost of 3-ton models. So, an estimate for the selling price of a 1.5-ton heat pump is $\$ 1305.01$ in 2006 dollars.

Central heat pump; maximum estimate: Average pricing data for 12 different manufacturers' brands from the Smarterwayinc.com site is plotted in Fig. 5.1 for 13-SEER heat pumps from 1.5 to 4.0 tons nominal cooling capacity. Price increases approximately linearly with capacity above the 2-ton level. Below this level the price is much less sensitive to capacity, beginning to show asymptotic behavior. Prices for 1.0- and 1.25-ton sizes are estimated based on this assumption. It is assumed that these prices include manufacturer, distributor and dealer markups.



Fig. 5.1. Average 2006 selling prices for 13-SEER, split-system heat pumps. (Source: www.smarterwayinc.com, 11/13/2006.)

Central heat pump; site installation cost estimate: The TSD/heat pump estimated average 1998 installation costs for a central heat pump to be \$2280 with no differentiation for size. The U.S. Department of Labor's Consumer Price Index (CPI) for all items less food and energy was used 
to inflate this cost to 2006 dollars (DOL 2006b). Between 1998 and 2006 the CPI has increased about $18.3 \%$. Based on that factor the adjusted site installation cost estimate for a baseline central heat pump in 2006 dollars is about $\$ 2690$.

Water heater (WH): From the 2000 technical support document (TSD/WH) for DOE's water heater efficiency standards (DOE/BT 2000), the estimated cost to manufacture a 50-gallon electric storage water heater in 1998 dollars was \$166.60. This cost includes the following efficiency enhancement features needed to reach the prescribed efficiency level: a heat trap, 2.5 in. of foam insulation, and foam insulation on the tank bottom. Applying the 1998-2006 Producer Price Index of 1.108 (above), the estimated manufacturing cost is \$184.60 in 2006 dollars. The TSD/WH estimated an overall markup factor of 1.7 for manufacturer to consumer, which yields an estimated selling price of \$313.82 in 2006 dollars. 1998 installation costs estimated in the TSD/WH are \$160, and after inflating using the 1998-2006 CPI (above), this yields an installation cost of \$188.8 in 2006 dollars. The overall estimated cost to the consumer for a 50-gallon storage electric water heater in 2006 dollars is therefore $\$ 502.62$.

Dehumidifier (DH): Costs for a $50 \mathrm{pt} / \mathrm{d}$ stand-alone dehumidifier are estimated at $\$ 400$ (2001 dollars) based on data presented by Rudd et al. (2005). This includes cost of the dehumidifier, an overflow drain pan, and running a condensate line to nearest drain. The CPI inflated by an estimated 10\% for the period from 2001 to 2006 (U.S. Dept. of Labor), so this cost would be \$440 in 2006 dollars. The Web site of “AC for sale" (http://acforsale.com), another source of cost data for BEopt, includes recent prices for dehumidifiers to enable estimation of the relative cost of a $40 \mathrm{pt} / \mathrm{d}$ model compared to the $50 \mathrm{pt} / \mathrm{d}$ size. Based on this data, stand-alone $40 \mathrm{pt} / \mathrm{d}$ dehumidifier cost in 2006 dollars is estimated to be about $\$ 415$.

Ventilation fan: The minimum continuous ventilation rate for an $1800-\mathrm{ft}^{2}\left(167-\mathrm{m}^{2}\right)$ house with three bedrooms is $48 \mathrm{cfm}$ per ASHRAE Standard 62.2-2004 (ASHRAE 2004a). A typical 50-cfm exhaust fan ducted to the nearest exterior wall is assumed to be used to provide this function, with makeup air provided by infiltration through the building envelope. RSMeans Mechanical Cost Data (Means 2005) indicates that the installed cost of this item (assuming $4 \mathrm{ft}$ of 6-in.-diameter duct and exterior weather cap) in 2005 dollars is about \$300. Since the CPI increase from January 2005 to January 2006 was about 1.9\%, the cost in 2006 dollars would be about $\$ 305$.

Humidifier: The system performance estimates presented in this report all include a central system humidifier to maintain a minimum indoor $\mathrm{RH}$ level of $30 \%$ during the heating season. Inquiries to the manufacturer of the humidifier model we based our analyses on indicated that the product cost alone is about $\$ 175$, in 2006 dollars, with a typical installation running about $\$ 350$ 400 (RPC 2007). It is reasonable that a heat pump original equipment manufacturer (OEM) buying in some quantity might be able to offer this option at about half this amount or $\sim \$ 200$ installed. However, since we have assumed the same, relatively simple humidifier for both baseline and IHP systems, there would be no differential impact on system installation costs.

Total baseline HVAC/WH/DH system cost estimate: Table 5.1 provides the baseline system costs for the ZEH at each of the five locations used in this study. 
Table 5.1. Estimated installed costs for ZEH baseline HVAC/WH system (2006 dollars)

\begin{tabular}{|c|c|c|c|c|c|c|c|c|}
\hline City & $\begin{array}{c}\text { Heat pump } \\
\text { nominal cooling } \\
\text { capacity (tons) }\end{array}$ & $\begin{array}{c}\text { DH } \\
\text { size } \\
\text { (pts/d) }\end{array}$ & $\begin{array}{c}\text { Heat pump } \\
\text { cost }- \\
\text { installed }\end{array}$ & $\begin{array}{c}\text { DH } \\
\text { cost }\end{array}$ & $\begin{array}{c}\text { WH } \\
\text { cost }\end{array}$ & $\begin{array}{c}\text { Vent } \\
\text { fan } \\
\text { cost }\end{array}$ & $\begin{array}{c}\text { H } \\
\text { cost }\end{array}$ & Total cost \\
\hline Atlanta & 1.25 & 40 & $\$ 3985-4590$ & $\$ 415$ & $\$ 503$ & $\$ 305$ & $\$ 200$ & $\$ 5408-6013$ \\
\hline Houston & 1.25 & 40 & $\$ 3985-4590$ & $\$ 415$ & $\$ 503$ & $\$ 305$ & $\$ 200$ & $\$ 5408-6013$ \\
\hline Phoenix & 1.50 & 40 & $\$ 3995-4628$ & $\$ 415$ & $\$ 503$ & $\$ 305$ & $\$ 200$ & $\$ 5418-6051$ \\
\hline $\begin{array}{c}\text { San } \\
\text { Francisco }\end{array}$ & 1.00 & 40 & $\$ 3974-4578$ & $\$ 415$ & $\$ 503$ & $\$ 305$ & $\$ 200$ & $\$ 5397-6001$ \\
\hline Chicago & 1.25 & 40 & $\$ 3985-4590$ & $\$ 415$ & $\$ 503$ & $\$ 305$ & $\$ 200$ & $\$ 5408-6013$ \\
\hline
\end{tabular}

\subsection{GS-IHP Cost Estimate}

An artist's concept for the GS-IHP system as modified to reflect changes in the tempering coil and water heating HX operation as discussed earlier in this report is shown in Fig. 5.2. In the original business case analyses (Baxter 2007) costs for the GS-IHP were based on those of the similar air-source integrated heat pump system. The basic heat pump system for the GS-IHP is similar to the baseline AS-IHP but with the outdoor coil, outdoor fan, and refrigerant connecting line set replaced with a refrigerant/water HX (R-W HX1 in Fig. 5.2) and a multi-speed circulating pump. To complete the IHP system, the following are added to the basic heat pump: a water heater (with backup electric elements and controls), a refrigerant/water HX (for water heating), a hot water circulation pump (single speed), connecting piping between the water heater and heat pump, a water/air HX coil (for tempering heat during dehumidification operation), two water flow control valves (for tempering water flow and water heating operation), a return air damper, a humidifier, a short duct with motorized damper for ventilation air, and a relief damper for the ventilation air.

Cost estimates for each of these elements are presented below. Where these have changed since completion of the earlier business case report, they are so noted in the text.

1. For the AS-IHP, the basic heat pump cost was assumed to be twice that of the baseline 13-SEER air-source heat pump, or \$2610 to \$3876 for a 1.5-ton system. Cost for the basic heat pump portion of the GS-IHP (with a refrigerant/water HX and multi-speed pump replacing the outdoor air coil and variable-speed fan, but with outdoor fan/coil enclosure, refrigerant line set, and defrost cycle with its associated controls all eliminated) was assumed to be $10 \%$ less than that for the AS-IHP for similar production volumes, or $\$ 2359$ to $\$ 3484$.

2. The electric water heater tank installed cost is assumed the same as for the baseline system, or $\$ 503$.

3. Prices for the refrigerant/water, water-heating HX (R-W HX2 in Fig. 5.2) were obtained from a major water-source heat pump manufacturer (Ellis 2006). Quantity costs for highefficiency HXs to a WSHP OEM were estimated at \$180 each by the manufacturer. To obtain an estimate of the cost to the consumer as assembled into the IHP package the markup factors for manufacturer (1.23), distributor (1.26), and dealer (1.27) from the TSD/heat pump (DOE/BT 2002) were assumed to apply. Total estimated cost for this item is $\$ 355$ as assembled into the IHP package. 


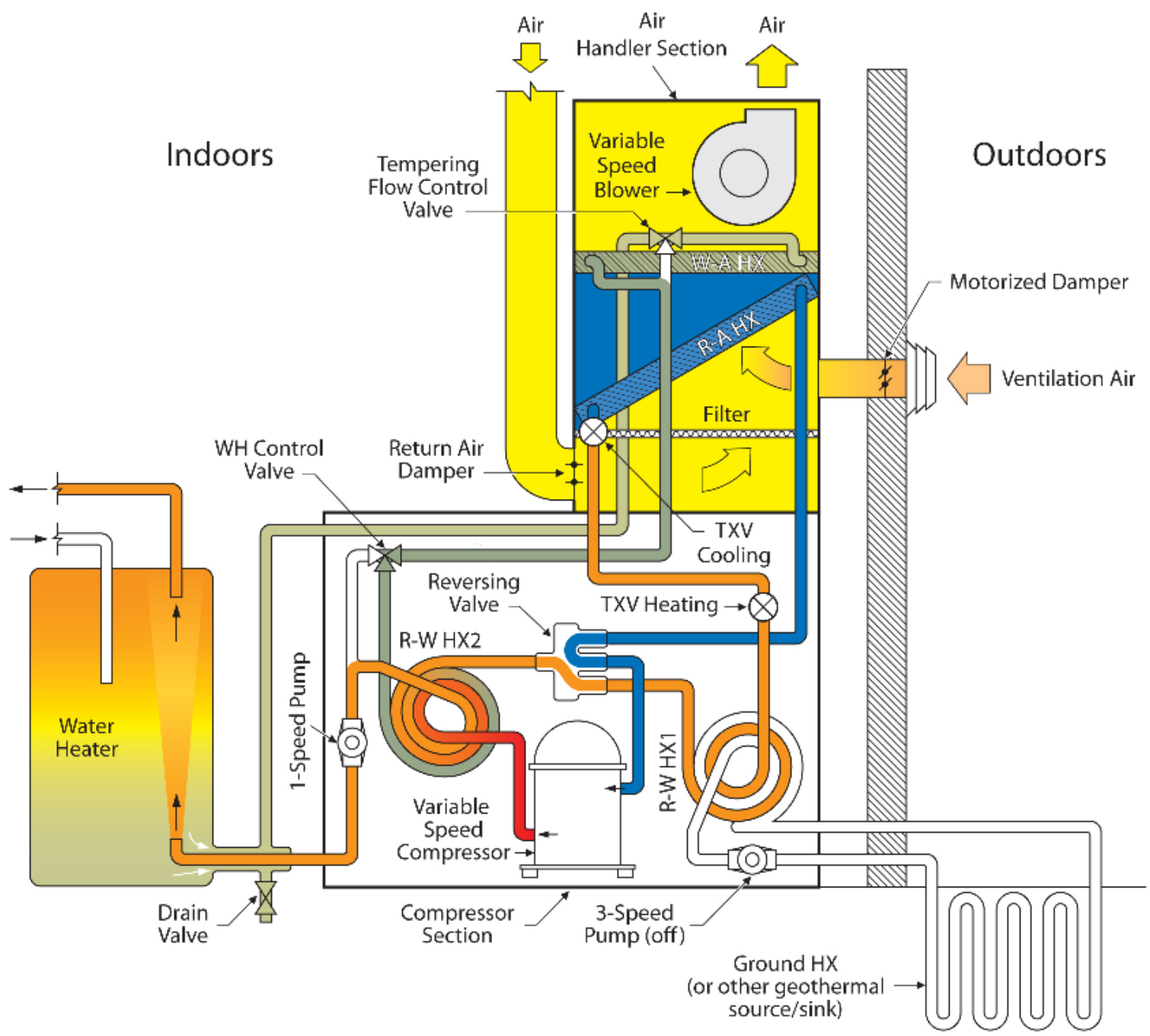

Fig. 5.2. GS-IHP schematic. Dedicated dehumidification and water heating mode is shown (with modifications resulting from elimination of desuperheating and changes in water-toair HX operation).

4. The hot water circulating pump item has changed since the original business case. With the decision to eliminate desuperheating to heat water during normal space cooling and space heating operation, a multi-speed hot water pump was no longer required. Therefore the cost to the consumer for this pump has been re-estimated based on a single-speed version. The cost of the pump in quantity was estimated to be about $\$ 40$ based on input from Ellis (2006). The markup factors from the TSD/heat pump were assumed to apply, giving an estimated cost to consumer of $\$ 79$ as assembled into the IHP package. (Note that the original estimate for a multi-speed pump was \$118.)

5. With the elimination of desuperheating, changes in water heating $\mathrm{HX}$ and tempering coil (W-A HX) operation, and location of most interconnecting piping within the heat pump package, connection of the IHP to the WH tank became much simpler. Based on the assumption that the WH tank and heat pump would be installed in very close proximity (10 feet or less), connection could be accomplished with two 15-ft, 3/4-in. hoses (suitable for water temperatures over $155^{\circ} \mathrm{F}$ ) and a coaxial fitting that could be installed in the water tank drain fitting. A suggested arrangement of the coaxial fitting is given in 
Fig. 5.3. Hose bibb connections would be provided on the coaxial fitting and the IHP package to provide for quick installation. Based on data in Means (2005) cost of the water hoses and the coaxial fitting are estimated at about \$160. Assuming an IHP OEM could purchase these items at a 50\% quantity discount, the estimated cost to the consumer would be $\$ 80$. Installation of the coaxial fitting in the water tank and hose connection is assumed to be covered under IHP site installation in item 11 below. For the interconnecting piping within the IHP unit, $15 \mathrm{ft}$ of $1 / 2$-in. copper tubing together with two tees and six 90-degree elbows are assumed. Based on material costs in Means and applying the TSD markup factors, the estimated cost to the consumer for this piping as assembled into the IHP unit is \$40. Thus the total estimated cost for these items to the consumer is $\$ 120$. (Note that the original estimate for WH-to-IHP connecting piping and installation was \$525.)

6. Tempering coil HX (W-A HX in Fig. 5.2) costs were estimated based on input obtained from HeatCraft, Inc., makers of this item for the lab prototype IHP system. Their estimated pricing for 300 units was \$32.67 each in 2006 dollars, reflecting current copper and aluminum commodity prices (Hutchins 2006). The markup factors from the TSD/heat pump were applied to this manufacturer cost, yielding a total estimated cost of about $\$ 64$ as assembled into the IHP package.

7. For the WH control valve item, a three-way, motor-actuated valve to allow bypassing of the WH HX when necessary was assumed. Means (2005) price data for this type valve, inflated to 2006 dollars, is about \$226. We assume that an OEM buying in large quantities could get this item for $\$ 113$. With the TSD/heat pump markup factors applied, cost to the consumer as assembled into the IHP package would be about $\$ 222$. (Note that the original estimate for this item was $\$ 157$ based on using a simple two-way solenoid valve.)

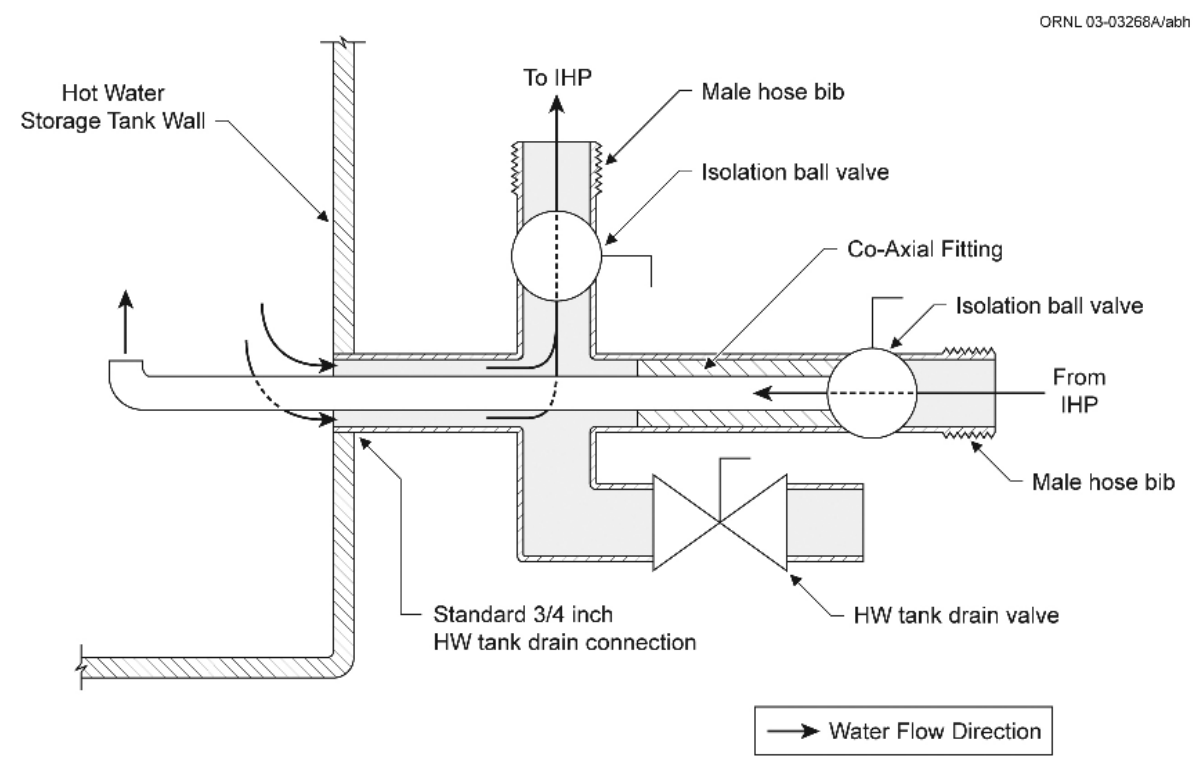

\section{Fig. 5.3. Suggested arrangement for coaxial fitting for domestic hot water tank in IHP system.}

8. The same type valve as in item 7 was assumed for the tempering coil water flow control. Its functions are to 1) control hot water flow to the water-to-air HX coil during dedicated 
dehumidifier operation to assure that air leaves the indoor blower section at the summer temperature set point of $76^{\circ} \mathrm{F}$ and no higher, and 2) bypass the coil when not needed. Cost to the consumer as assembled into the IHP package would be about $\$ 222$. (Note that the original estimate for this item was \$207 based on using a two-way variable-position control valve.)

9. For the vent line with motorized damper and exterior weather cap, cost data from Means assuming a 2-ft-long, 6-in.-diameter line resulted in a cost estimate for the basic materials of about $\$ 102$. We assume that an OEM buying in large quantities could get these items for $\$ 51$. With the TSD/heat pump markup factors applied, cost to the consumer would be about $\$ 100$.

10. For the return air damper, a motorized damper of 16 by $12 \mathrm{in}$. is assumed. This size was chosen to keep the main return and supply air duct velocities below the maximum limits for $600 \mathrm{cfm}$ (1.5-ton design capacity) design flow as specified by ACCA Manual D (ACCA 1995). The cost of this size damper from Means (2005) is about \$122 in 2006 dollars. We assume that an OEM buying in large quantities could get this item for $\$ 61$. With the TSD/heat pump markup factors applied, cost to the consumer as assembled into the IHP package would be about $\$ 120$.

11. Site installation cost of the AS-IHP in the original business case report was assumed to be $\$ 3000$ (about 12\% over that of the baseline system SEER-13 heat pump to cover miscellaneous contingencies for the IHP case). Installation of the GS-IHP (exclusive of the ground HX) should be somewhat less involved than for the AS-IHP since there would be no outdoor fan/coil enclosure (eliminating the need for labor/materials for the mounting pad, setting the enclosure on the pad, and installation of the associated electrical power/control wiring and refrigerant line set). Based on the foregoing and assuming similar numbers of jobs, site installation costs for the GS-IHP package were therefore estimated to be $15 \%$ less than for the AS-IHP, or \$2550.

For the vertical-bore ground HX option, the installed cost in 2006 dollars of the ground HX (including hookup to the GS-IHP package) was estimated at $\$ 5 / \mathrm{ft}$ of bore $(\$ 1000 /$ ton for 200 bore feet per ton) based on input from a large, experienced installation contractor (Schoen 2006, 2007). Table 5.2 gives the estimated bore lengths for a vertical ground $H X$ in each of the five cities as derived from long-term sizing runs using the TRNSYS/HPDM model. Sizing was based on limiting the long-term EWT to the IHP from the ground HX to a maximum of $95^{\circ} \mathrm{F}$ during cooling operation in all cities. For heating operation, the long-term minimum EWT criteria was $42^{\circ} \mathrm{F}$ (using water as the HX fluid) for all cities except Chicago, where the minimum EWT criteria was $30^{\circ} \mathrm{F}$ (using a $20 \%$ propylene glycol brine solution).

Table 5.2. Estimated total bore lengths and installed costs for vertical ground heat exchangers in the five study locations

\begin{tabular}{|l|c|c|}
\hline City & Total bore length, $\mathrm{ft}$ & Installed cost, 2006\$ \\
\hline Atlanta & 360 & $\$ 1800$ \\
\hline Houston & 360 & $\$ 1800$ \\
\hline Phoenix & 505 & $\$ 2525$ \\
\hline San Francisco & 360 & $\$ 1800$ \\
\hline Chicago & 328 & $\$ 1640$ \\
\hline
\end{tabular}

Total system cost estimates for each city are given in Table 5.3. Estimated energy cost savings and simple paybacks are included. The energy cost savings for each city throughout this report 
were calculated based on 2006 electricity prices as implemented into BEopt (Spencer 2006) $\$ 0.0872 / \mathrm{kWh}$ for Atlanta, $\$ 0.108 / \mathrm{kWh}$ for Houston, $\$ 0.0896 / \mathrm{kWh}$ for Phoenix, $\$ 0.1196 / \mathrm{kWh}$ for San Francisco, and $\$ 0.0844 / \mathrm{kWh}$ for Chicago. For differential humidifier water costs (baseline vs. IHP), internet searches were done to obtain current (2006) water costs for residential customers in each city. These costs are \$0.0133/gal for Atlanta, \$0.00133/gal for Chicago, \$0.00268/gal in Houston, \$0.00184/gal in Phoenix (winter rate), and \$0.00263/gal in San Francisco. The impact of the added water use cost for the IHP is included in these numbers, but its impact is negligible. GS-IHP marginal water costs ranged from less than $\$ 0.01$ in Houston and San Francisco (minimal usage) to about \$0.50 in Atlanta (moderately high usage and highest water rates).

Table 5.3. Estimated installed costs for ZEH GS-IHP system with humidifier (2006 dollars), assuming vertical-bore ground $\mathrm{HX}$

\begin{tabular}{|c|c|c|c|c|c|c|c|c|}
\hline City & $\begin{array}{c}\text { Heat pump } \\
\text { capacity } \\
\text { (tons) }\end{array}$ & \multicolumn{2}{|c|}{ Total cost } & \multicolumn{2}{c|}{$\begin{array}{c}\text { Premium over } \\
\text { baseline system }\end{array}$} & $\begin{array}{c}\text { Energy cost } \\
\text { savings }\end{array}$ & $\begin{array}{c}\text { Simple payback } \\
\text { over baseline } \\
\text { system, years }\end{array}$ \\
\cline { 3 - 9 } & & low & High & Low & high & & Low & high \\
\hline Atlanta & 1.25 & $\$ 8,671$ & $\$ 9,748$ & $\$ 3,263$ & $\$ 3,735$ & $\$ 368$ & 8.9 & 10.1 \\
\hline Houston & 1.25 & $\$ 8,671$ & $\$ 9,748$ & $\$ 3,263$ & $\$ 3,735$ & $\$ 442$ & 7.4 & 8.5 \\
\hline Phoenix & 1.50 & $\$ 9,410$ & $\$ 10,549$ & $\$ 3,992$ & $\$ 4,498$ & $\$ 323$ & 12.3 & 13.9 \\
\hline San Francisco & 1.00 & $\$ 8,657$ & $\$ 9,724$ & $\$ 3,260$ & $\$ 3,723$ & $\$ 391$ & 8.3 & 9.5 \\
\hline Chicago & 1.25 & $\$ 8,511$ & $\$ 9,588$ & $\$ 3,103$ & $\$ 3,575$ & $\$ 477$ & 6.5 & 7.5 \\
\hline
\end{tabular}

As noted previously, the system control changes described for water heating and dehumidifier operation also apply to the AS-IHP system. The impact on system costs as described for items 4, 5, 7, and 8 above would apply to the AS-IHP as well. Estimated installed costs for the AS-IHP system in each city including theses changes are given in Table 5.4. In comparison, Thorne (1998) noted an installed cost range for AS-IHPs available at the time (space conditioning and water heating functions only) of $\$ 4,325$ to $\$ 5,875$ in 1998 dollars (costs include $\$ 475$ for the electric water heater tank). This equates to about $\$ 5,100$ to $\$ 6,950$ in 2006 dollars using the 19982006 CPI increase of 1.183. The energy cost savings and estimated simple payback periods vs. the baseline system in the ZEH in Table 5.4 similarly reflect improved performance for the ASIHP system due to use of the control strategy setting water heating priority above space heating and eliminating the desuperheater operational modes.

Table 5.4. Estimated installed costs for ZEH AS-IHP system (2006 dollars)

\begin{tabular}{|c|c|c|c|c|c|c|c|c|}
\hline City & \multirow{2}{*}{$\begin{array}{c}\text { Heat } \\
\text { pump } \\
\end{array}$} & \multicolumn{2}{|c|}{ Total cost } & \multicolumn{2}{|c|}{$\begin{array}{c}\text { Premium over } \\
\text { baseline system }\end{array}$} & \multirow{2}{*}{$\begin{array}{c}\text { Energy } \\
\text { cost } \\
\text { cavings } \\
\text { (tons) }\end{array}$} & \multicolumn{2}{|c|}{$\begin{array}{c}\text { Simple payback } \\
\text { over baseline } \\
\text { system, years }\end{array}$} \\
\cline { 3 - 9 } & low & High & low & High & & Low & high \\
\hline Atlanta & 1.25 & $\$ 7,582$ & $\$ 8,786$ & $\$ 2,174$ & $\$ 2,773$ & $\$ 338$ & 6.4 & 8.2 \\
\hline Houston & 1.25 & $\$ 7,582$ & $\$ 8,786$ & $\$ 2,174$ & $\$ 2,773$ & $\$ 428$ & 5.1 & 6.5 \\
\hline Phoenix & 1.50 & $\$ 7,596$ & $\$ 8,862$ & $\$ 2,178$ & $\$ 2,811$ & $\$ 283$ & 7.7 & 9.9 \\
\hline San Francisco & 1.00 & $\$ 7,568$ & $\$ 8,762$ & $\$ 2,171$ & $\$ 2,761$ & $\$ 399$ & 5.4 & 6.9 \\
\hline Chicago & 1.25 & $\$ 7,582$ & $\$ 8,786$ & $\$ 2,174$ & $\$ 2,773$ & $\$ 414$ & 5.2 & 6.7 \\
\hline
\end{tabular}

Note that the cost and payback estimates in tables 5.3 through 5.6 are particularly sensitive to the assumptions made about the IHP site installation costs. In this study we have assumed only a modest increase in these costs compared to those of the baseline heat pump. A more conservative 
assumption about site installation cost (read "higher") would of course result in commensurately higher estimated paybacks.

\subsection{GS-IHP/SWS Cost Estimate}

The solid-water-sorbent- (SWS) enhanced environmental coupling concept is being investigated for its potential to reduce the size (and cost) of the ground HX required for the GS-IHP. Results of field experiments conducted at a ZEH research house (ZEH5) in the Lenoir City, Tennessee, Habitat for Humanity site indicated that a horizontal ground HX of about $700 \mathrm{ft}$ of $3 / 4-i n$. HDPE pipe surrounded by $80 \mathrm{lb}$ of SWS material and $3200 \mathrm{lb}$ of water enclosed in a vapor barrier surrounding the pipe would be sufficient to handle the peak heat rejection load from a 1-ton heat pump system (Ally 2006). The $1200-\mathrm{ft}^{2} \mathrm{ZEH} 5$ house (30-ft by $40-\mathrm{ft}$ footprint) at the site has a conventional ground-source heat pump with a horizontal-loop ground HX of $1500 \mathrm{ft}$ of 3/4-inch HDPE that was installed completely within the excavation needed for the house foundation. The HX pipe length for ZEH5 was determined per design by Bob Brown of WaterFurnace (Brown 2006). Thus the FY06 test results indicated that use of the SWS could potentially reduce the required HX length for that house by at least a factor of two. A horizontal HX enhanced with the SWS material should fit comfortably within the available foundation and utility service trench length for the ZEH's used in this study (30-ft by 30-ft footprint).

In FY07 analyses of the ZEH5 ground-source heat pump were conducted using the TRNSYS model to evaluate potential size and costs of an SWS-enhanced horizontal ground heat exchanger (GHX) as applied to that site. The results indicated that a total trench length about equal to that required for the water supply line or sewer discharge line would be adequate for a SWS GHX sized for ZEH5 (design cooling load of 2 tons). Cost for the SWS-enhanced GHX was estimated at $\$ 400 /$ ton assuming quantity production of the SWS HX modules (Ally 2007). The SWS GHX sizing in this case was based on accommodating the heat rejection load as measured for the conventional ground-source heat pump in ZEH5 for August 2007, the hottest month on record for this area.

Total system cost estimates for each city are given in Table 5.5. Estimated energy cost savings and simple paybacks for this GS-IHP system option assume that overall energy efficiency would be equal to that of the GS-IHP with a vertical-bore GHX.

Table 5.5. Estimated installed costs for ZEH SWS-enhanced GS-IHP system (2006 dollars)

\begin{tabular}{|c|c|c|c|c|c|c|c|c|}
\hline City & \multirow{2}{*}{$\begin{array}{c}\text { Heat pump } \\
\text { capacity } \\
\text { (tons) }\end{array}$} & \multicolumn{2}{|c|}{ Total cost } & \multicolumn{2}{|c|}{$\begin{array}{c}\text { Premium over } \\
\text { baseline system }\end{array}$} & $\begin{array}{c}\text { Energy cost } \\
\text { savings }\end{array}$ & $\begin{array}{c}\text { Simple payback } \\
\text { over baseline } \\
\text { system (years) }\end{array}$ \\
\cline { 3 - 9 } & & Low & High & Low & high & & Low & High \\
\hline Atlanta & 1.25 & $\$ 7371$ & $\$ 8448$ & $\$ 1963$ & $\$ 2,435$ & $\$ 368$ & 5.3 & 6.6 \\
\hline Houston & 1.25 & $\$ 7371$ & $\$ 8448$ & $\$ 1963$ & $\$ 2,435$ & $\$ 442$ & 4.4 & 5.5 \\
\hline Phoenix & 1.50 & $\$ 7485$ & $\$ 8624$ & $\$ 2067$ & $\$ 2,573$ & $\$ 323$ & 6.4 & 8.0 \\
\hline San Francisco & 1.00 & $\$ 7257$ & $\$ 8324$ & $\$ 1860$ & $\$ 2,323$ & $\$ 391$ & 4.8 & 5.9 \\
\hline Chicago & 1.25 & $\$ 7371$ & $\$ 8448$ & $\$ 1963$ & $\$ 2,435$ & $\$ 477$ & 4.1 & 5.1 \\
\hline
\end{tabular}

\subsection{Cost Sensitivities}

The simple paybacks in Tables 5.3, 5.4, and 5.5 assume no favorable tax incentives or utility rate structures designed to promote use of IHPs or other highly efficient HVAC/WH system options. 
An estimate of the sensitivity of IHP payback vs. the base system to these factors was developed for two levels of tax incentive and a postulated time-of-use (TOU) + demand charge utility rate structure.

Early in 2006, the Internal Revenue Service issued guidelines for a new, two-year program of tax incentives for energy conservation (http://www.irs.gov/newsroom/article/0, id=154657,00.html). These incentives include a \$300 tax credit to home owners for purchase of "energy efficient property" including air-source heat pumps which have a minimum SEER of 15, HSPF of 9, and rated EER at $95^{\circ} \mathrm{F}\left(\mathrm{EER}_{95}\right)$ of 13 . Based on the prototype AS-IHP lab system tests (Tomlinson 2005), its estimated SEER and HSPF are 17.9 and 11.3, respectively, both well in excess of the rebate requirements. IHP peak reduction potential during peak cooling season was estimated at $60-75 \%$ from the analyses summarized in Section 6 of this report. In comparison, the average EER $_{95}$ of 57 single-speed heat pump models with 13 SEER is 11.3 according to Southern California Edison (2005) in their Database for Energy Efficiency Resources study for the California Energy Commission. So the 13 EER $_{95}$ requirement represents about a 6\% peak efficiency improvement or average peak power reduction (12 vs. 11.3). With a \$300 credit, simple paybacks for the IHP systems are reduced by $0.6-1.0$ years depending on location. If the credit could be increased to $\$ 1000$, paybacks would fall by $2-3$ years. These results are summarized in Table 5.6.

Table 5.6. Sensitivity of AS-IHP and GS-IHP system payback vs. baseline system to assumed tax credits and TOU/demand electricity pricing

\begin{tabular}{|c|c|c|c|c|c|c|c|c|}
\hline \multirow[t]{2}{*}{ City } & \multirow{2}{*}{$\begin{array}{c}\text { Heat } \\
\text { pump } \\
\text { capacity } \\
\text { (tons) }\end{array}$} & \multicolumn{2}{|c|}{ Total cost } & \multicolumn{2}{|c|}{$\begin{array}{c}\text { Premium over } \\
\text { baseline system }\end{array}$} & \multirow[t]{2}{*}{$\begin{array}{l}\text { Energy } \\
\text { cost } \\
\text { savings } \\
\end{array}$} & \multicolumn{2}{|c|}{$\begin{array}{l}\text { Simple payback } \\
\text { over baseline } \\
\text { system, years }\end{array}$} \\
\hline & & Low & High & low & high & & low & High \\
\hline \multicolumn{9}{|c|}{$\$ 300$ system tax credit } \\
\hline \multicolumn{9}{|l|}{ AS-IHP } \\
\hline Atlanta & 1.25 & $\$ 7,282$ & $\$ 8,486$ & $\$ 1,874$ & $\$ 2,473$ & $\$ 338$ & 5.5 & 7.3 \\
\hline Houston & 1.25 & $\$ 7,282$ & $\$ 8,486$ & $\$ 1,874$ & $\$ 2,473$ & $\$ 428$ & 4.4 & 5.8 \\
\hline Phoenix & 1.50 & $\$ 7,296$ & $\$ 8,562$ & $\$ 1,878$ & $\$ 2,511$ & $\$ 283$ & 6.6 & 8.9 \\
\hline San Francisco & 1.00 & $\$ 7,268$ & $\$ 8,462$ & $\$ 1,871$ & $\$ 2,461$ & $\$ 399$ & 4.7 & 6.2 \\
\hline Chicago & 1.25 & $\$ 7,282$ & $\$ 8,486$ & $\$ 1,874$ & $\$ 2,473$ & $\$ 414$ & 4.5 & 6.0 \\
\hline \multicolumn{9}{|c|}{ GS-IHP, vertical ground HX } \\
\hline Atlanta & 1.25 & $\$ 8,371$ & $\$ 9,448$ & $\$ 2,963$ & $\$ 3,435$ & $\$ 368$ & 8.0 & 9.3 \\
\hline Houston & 1.25 & $\$ 8,371$ & $\$ 9,448$ & $\$ 2,963$ & $\$ 3,435$ & $\$ 442$ & 6.7 & 7.8 \\
\hline Phoenix & 1.50 & $\$ 9,110$ & $\$ 10,249$ & $\$ 3,692$ & $\$ 4,198$ & $\$ 323$ & 11.4 & 13.0 \\
\hline San Francisco & 1.00 & $\$ 8,357$ & $\$ 9,424$ & $\$ 2,960$ & $\$ 3,423$ & $\$ 391$ & 7.6 & 8.8 \\
\hline Chicago & 1.25 & $\$ 8,211$ & $\$ 9,288$ & $\$ 2,803$ & $\$ 3,275$ & $\$ 477$ & 5.9 & 6.9 \\
\hline \multicolumn{9}{|c|}{ GS-IHP, SWS-enhanced } \\
\hline Atlanta & 1.25 & $\$ 7,071$ & $\$ 8,148$ & $\$ 1,663$ & $\$ 2,135$ & $\$ 368$ & 4.5 & 5.8 \\
\hline Houston & 1.25 & $\$ 7,071$ & $\$ 8,148$ & $\$ 1,663$ & $\$ 2,135$ & $\$ 442$ & 3.8 & 4.8 \\
\hline Phoenix & 1.50 & $\$ 7,185$ & $\$ 8,324$ & $\$ 1,767$ & $\$ 2,273$ & $\$ 323$ & 5.5 & 7.0 \\
\hline San Francisco & 1.00 & $\$ 6,957$ & $\$ 8,024$ & $\$ 1,560$ & $\$ 2,023$ & $\$ 391$ & 4.0 & 5.2 \\
\hline Chicago & 1.25 & $\$ 7,071$ & $\$ 8,148$ & $\$ 1,663$ & $\$ 2,135$ & $\$ 477$ & 3.5 & 4.5 \\
\hline
\end{tabular}




\begin{tabular}{|c|c|c|c|c|c|c|c|c|}
\hline \multicolumn{9}{|c|}{$\$ 1000$ system tax credit } \\
\hline \multicolumn{9}{|l|}{ AS-IHP } \\
\hline Atlanta & 1.25 & $\$ 6,582$ & $\$ 7,786$ & $\$ 1,174$ & $\$ 1,773$ & $\$ 338$ & 3.5 & 5.2 \\
\hline Houston & 1.25 & $\$ 6,582$ & $\$ 7,786$ & $\$ 1,174$ & $\$ 1,773$ & $\$ 428$ & 2.7 & 4.1 \\
\hline Phoenix & 1.50 & $\$ 6,596$ & $\$ 7,862$ & $\$ 1,178$ & $\$ 1,811$ & $\$ 283$ & 4.2 & 6.4 \\
\hline San Francisco & 1.00 & $\$ 6,568$ & $\$ 7,762$ & $\$ 1,171$ & $\$ 1,761$ & $\$ 399$ & 2.9 & 4.4 \\
\hline Chicago & 1.25 & $\$ 6,582$ & $\$ 7,786$ & $\$ 1,174$ & $\$ 1,773$ & $\$ 414$ & 2.8 & 4.3 \\
\hline \multicolumn{9}{|c|}{ GS-IHP, vertical ground HX } \\
\hline \begin{tabular}{|l|} 
Atlanta \\
\end{tabular} & 1.25 & $\$ 7,671$ & $\$ 8,748$ & $\$ 2,263$ & $\$ 2,735$ & $\$ 368$ & 6.1 & 7.4 \\
\hline Houston & 1.25 & $\$ 7,671$ & $\$ 8,748$ & $\$ 2,263$ & $\$ 2,735$ & $\$ 442$ & 5.1 & 6.2 \\
\hline Phoenix & 1.50 & $\$ 8,410$ & $\$ 9,549$ & $\$ 2,992$ & $\$ 3,498$ & $\$ 323$ & 9.3 & 10.8 \\
\hline San Francisco & 1.00 & $\$ 7,657$ & $\$ 8,724$ & $\$ 2,260$ & $\$ 2,723$ & $\$ 391$ & 5.8 & 7.0 \\
\hline Chicago & 1.25 & $\$ 7,511$ & $\$ 8,588$ & $\$ 2,103$ & $\$ 2,575$ & $\$ 477$ & 4.4 & 5.4 \\
\hline \multicolumn{9}{|c|}{ GS-IHP, SWS-enhanced } \\
\hline Atlanta & 1.25 & $\$ 6,371$ & $\$ 7,448$ & $\$ 963$ & $\$ 1,435$ & $\$ 368$ & 2.6 & 3.9 \\
\hline Houston & 1.25 & $\$ 6,371$ & $\$ 7,448$ & $\$ 963$ & $\$ 1,435$ & $\$ 442$ & 2.2 & 3.2 \\
\hline Phoenix & 1.50 & $\$ 6,485$ & $\$ 7,624$ & $\$ 1,067$ & $\$ 1,573$ & $\$ 323$ & 3.3 & 4.9 \\
\hline \begin{tabular}{|l|} 
San Francisco \\
\end{tabular} & 1.00 & $\$ 6,257$ & $\$ 7,324$ & $\$ 860$ & $\$ 1,323$ & $\$ 391$ & 2.2 & 3.4 \\
\hline Chicago & 1.25 & $\$ 6,371$ & $\$ 7,448$ & $\$ 963$ & $\$ 1,435$ & $\$ 477$ & 2.0 & 3.0 \\
\hline \multicolumn{9}{|c|}{$\$ 1000$ system tax credit + TOU/demand rates } \\
\hline \multicolumn{9}{|l|}{ AS-IHP } \\
\hline Atlanta & 1.25 & $\$ 6,582$ & $\$ 7,786$ & $\$ 1,174$ & $\$ 1,773$ & $\$ 758$ & 1.5 & 2.3 \\
\hline Houston & 1.25 & $\$ 6,582$ & $\$ 7,786$ & $\$ 1,174$ & $\$ 1,773$ & $\$ 830$ & 1.4 & 2.1 \\
\hline Phoenix & 1.50 & $\$ 6,596$ & $\$ 7,862$ & $\$ 1,178$ & $\$ 1,811$ & $\$ 627$ & 1.9 & 2.9 \\
\hline San Francisco & 1.00 & $\$ 6,568$ & $\$ 7,762$ & $\$ 1,171$ & $\$ 1,761$ & $\$ 740$ & 1.6 & 2.4 \\
\hline Chicago & 1.25 & $\$ 6,582$ & $\$ 7,786$ & $\$ 1,174$ & $\$ 1,773$ & $\$ 784$ & 1.5 & 2.3 \\
\hline \multicolumn{9}{|c|}{ GS-IHP, vertical ground HX } \\
\hline Atlanta & 1.25 & $\$ 7,671$ & $\$ 8,748$ & $\$ 2,263$ & $\$ 2,735$ & $\$ 795$ & 2.8 & 3.4 \\
\hline Houston & 1.25 & $\$ 7,671$ & $\$ 8,748$ & $\$ 2,263$ & $\$ 2,735$ & $\$ 860$ & 2.6 & 3.2 \\
\hline Phoenix & 1.50 & $\$ 8,410$ & $\$ 9,549$ & $\$ 2,992$ & $\$ 3,498$ & $\$ 719$ & 4.2 & 4.9 \\
\hline San Francisco & 1.00 & $\$ 7,657$ & $\$ 8,724$ & $\$ 2,260$ & $\$ 2,723$ & $\$ 729$ & 3.1 & 3.7 \\
\hline Chicago & 1.25 & $\$ 7,511$ & $\$ 8,588$ & $\$ 2,103$ & $\$ 2,575$ & $\$ 868$ & 2.4 & 3.0 \\
\hline \multicolumn{9}{|c|}{\begin{tabular}{|l|} 
GS-IHP, SWS-enhanced \\
\end{tabular}} \\
\hline Atlanta & 1.25 & $\$ 6,371$ & $\$ 7,448$ & $\$ 963$ & $\$ 1,435$ & $\$ 795$ & 1.2 & 1.8 \\
\hline Houston & 1.25 & $\$ 6,371$ & $\$ 7,448$ & $\$ 963$ & $\$ 1,435$ & $\$ 860$ & 1.1 & 1.7 \\
\hline Phoenix & 1.50 & $\$ 6,485$ & $\$ 7,624$ & $\$ 1,067$ & $\$ 1,573$ & $\$ 719$ & 1.5 & 2.2 \\
\hline San Francisco & 1.00 & $\$ 6,257$ & $\$ 7,324$ & $\$ 860$ & $\$ 1,323$ & $\$ 729$ & 1.2 & 1.8 \\
\hline Chicago & 1.25 & $\$ 6,371$ & $\$ 7,448$ & $\$ 963$ & $\$ 1,435$ & $\$ 868$ & 1.1 & 1.7 \\
\hline
\end{tabular}

To estimate the potential impact of utility rates based on TOU rate + demand, a rate structure was postulated as shown in Table 5.7. The TOU rate itself is patterned after a residential rate structure that was in use on a trial basis in Laredo, Texas, in the early 1990s (Goldman et al. 1995). A demand charge of $\$ 10 /$ peak $\mathrm{kW} /$ month was added to the TOU hourly use rates for purposes of the sensitivity analysis described herein. Applying this postulated rate structure to the baseline and IHP ZEH systems in the five study locations yielded increased annual energy cost savings. Table 5.6 includes simple payback impacts from combining the TOU + demand rates with a \$1000 tax credit. In this scenario, simple paybacks for the GS-IHP with vertical GHX ranged from about 2 
to 4 years depending on location; with a SWS-enhanced horizontal GHX (using trenching normally required for utilities) the estimated paybacks ranged from about 1 to 2 years.

Table 5.7. Postulated TOU + demand rate structure used for IHP simple payback sensitivity assessment

\begin{tabular}{|c|c|c|c|}
\hline Season & Time of day & Rate as fraction of average rate & Demand charge, \$/peak kW/m \\
\hline \multirow{3}{*}{ Summer } & 1 p.m. -4 p.m. & 1.375 & \multirow{2}{*}{10} \\
\cline { 2 - 3 } & 4 p.m. -5 p.m. & 4.375 & \\
\cline { 2 - 3 } & 5 p.m. -7 p.m. & 1.375 & \\
\cline { 2 - 3 } & 7 p.m. -1 p.m. & .7125 & \\
\hline \multirow{2}{*}{ Winter } & 1 p.m. -7 p.m. & .9125 & \multirow{2}{*}{10} \\
\cline { 2 - 3 } & 7 p.m. -1 p.m. & .7125 & \\
\hline
\end{tabular}




\section{CONCLUSIONS AND RECOMMENDATIONS}

The following specific conclusions are highlighted.

1. The GS-IHP system (using R410A) is estimated to achieve greater than $50 \%$ energy savings vs. the baseline system used in the study in all locations including Chicago.

These predicted savings are obtained with active humidity control applied throughout the year.

2. In the base scenario (no system cost reduction or utility cost incentives), simple payback of the IHP systems vs. the baseline system in the ZEH was, perhaps predictably, relatively high, ranging from about 5 to 10 years for the AS-IHP and 6.5 to 14 years for the GS-IHP (with vertical-bore ground HX). For a scenario including a \$1000 system tax credit combined with a favorable time-of-use + demand utility rate structure, these paybacks fall to about 1.5 to 3 years and 2.5 to 5 years, respectively.

3. Using an SWS-enhanced horizontal ground HX requiring no additional trenching beyond that required for water supply or sewer piping, the estimated first cost of the GS-IHP is reduced to about the same as that for the AS-IHP, and base scenario simple paybacks are about 4 to 8 years.

4. Desuperheating operation with the GS-IHP was found not to be beneficial compared to the currently employed alternative water heating approaches. Eliminating this operation mode reduces the cost, simplifies the controls, and greatly reduces the run-time of the domestic hot water loop pump.

5. A new approach was developed for the domestic hot water loop of the IHP that reduces the maximum condensing temperatures when simultaneously tempering indoor air and water heating, uses lower temperature water to accomplish indoor air tempering, and simplifies the water tank connections.

\section{Recommendations}

1. Implementation and analysis of split condenser operation in the winter heating mode is needed to assess the benefits of simultaneous space heating and water heating operation. This same analysis capability can be used as needed to look further at possible dual condenser operation in cooling mode to reduce condensing temperatures under low-speed cooling operation where compressor head pressure capabilities are more limited.

2. Consideration should be given to obtaining further water heating by cooling the compressor with water leaving the indoor water-to-refrigerant HX. This would boost the water temperatures returning to the water heater tank with compressor shell heat loss without raising condensing temperatures and could provide a beneficial means to cool the compressor motor under the elevated head pressures seen with full condensing water heating. 


\section{REFERENCES}

ACCA (1995). Residential Duct Systems - Manual D. Air Conditioning Contractors of America, Washington, DC.

Ally, M. R., (2006). Data and Analyses of SWS Performance in Field Experiments for Interim DOE Go/No-Go Decision, ORNL/TM-2006/621, December.

Ally, M. R., and W. G. Craddick (2007). Exploratory Development of SWS Enhanced Ground Coupled Heat Pump Technology, ORNL/TM-2007/176. September 30.

ASHRAE (2004a). ANSI/ASHRAE Standard 62.2-2004: Ventilation and Acceptable Indoor Air Quality in Low-Rise Residential Buildings.

ASHRAE (2004b). ANSI/ASHRAE Standard 55-2004: Thermal Environmental Conditions for Human Occupancy.

Baxter, V., (2007). Integrated Heat Pump HVAC Systems for Near-Zero-Energy Homes Business Case Assessment, ORNL/TM-2007/064, May.

Brown, R., (2006). Personal communication to Van Baxter, July 12.

Carrier Corporation (1989a). Carrier Heating and Cooling Residential Heat Pump System Startup and Service Manual (HydroTech 2000 Models), July.

Carrier Corporation (1989b). Carrier Start-up and Troubleshooting Service Manual (HYDROTECH 2000 Residential Heat Pump).

DOE/BT (U.S. Department of Energy, Building Technologies Program) (2000). Technical Support Document: Energy Efficiency Standards for Consumer Products: Residential Water Heaters, December.

DOE/BT (2002). Technical Support Document: Energy Efficiency Standards for Consumer Products: Residential Central Air Conditioners and Heat Pumps, May.

DOE/BT (2006). Rulemaking Framework for Commercial Clothes Washers and Residential Dishwashers, Dehumidifiers, and Cooking Products. March 15.

(www.eere.energy.gov/buildings/appliance_standards/residential/dehumidifiers.html)

DOL (2006a). U. S. Department of Labor, Bureau of Labor Statistics, Producer Price Index /finished goods less food and energy, http://data.bls.gov/cgi-bin/surveymost?bls, accessed March 3, 2006.

DOL (2006b). U. S. Department of Labor, Bureau of Labor Statistics, Consumer Price Index/urban consumers/all items less food and energy, http://data.bls.gov/cgi-bin/surveymost?bls, accessed March 3, 2006.

Domanski, P. A., (1988). Recommended Procedure for Rating and Testing Variable Speed Air Source Unitary Air Conditioners and Heat Pumps, NBSIR 88-3781, May.

Dunshee, K., (1995). Design Description and Performance Monitoring of the HydroTech 2000 Variable-Speed Heat With Integrated Water Heating, EPRI TR-104892, Project 2892-22, Final Report, March.

Ellis, D., (2006). Personal communication to Van D. Baxter, April. 
Fanney, A. H., (1993). "Field Monitoring of a Variable-Speed Integrated Heat Pump/Water Heating Appliance,” NIST Building Science Series 171, June.

Gilles, T. C., (1994). “Combining HPWHs with Residential Air Conditioning,” International Energy Agency Heat Pump Centre Newsletter, Vol. 12, No. 3, pp. 24-28.

Goldman, C., R. Scheer, W. Kempton (1995). Information and Telecommunication Technologies: The Next Generation of Utility Residential DSM and Beyond. Presentation at DOE Office of Utility Technologies Program Review, “The Restructuring of the Electric Utility Industry,” December 6.

Hoyt, J. B., (2005). Letter to Andrew Fanara and Mehernaz Polad at EPA. April 5. On line at http://www.energystar.gov/index.cfm?c=revisions.dehumid_spec.

Hutchins, J. W., (2006). Personal communication to C. Keith Rice, September 13.

International Institute of Refrigeration (2005). Technology: Briefs: VRF (Variable Refrigerant Flow),.IIR Newsletter, No. 23, p. 5, July.

Lennox Engineering Data (1997). Innovator Series AquaPlus Water Heating System, RWH21 CB30MWH, Bulletin 210165, February.

Means (2005). Mechanical Cost Data, $28^{\text {th }}$ Annual Edition. RSMeans Construction Publishers \& Consultants.

Miller, W. A., (1988). "Laboratory Capacity Modulation Experiments, Analyses, and Validation," Proceedings of the 2nd DOE/ORNL Heat Pump Conference: Research and Development on Heat Pumps for Space Conditioning Applications, CONF-8804100, April 17-20, 1988, Washington, D.C., April, pp. 7-21.

Murphy, R. W., C. K. Rice, and V. D. Baxter (2007a). Integrated Heat Pump (IHP) System Development; Air-Source IHP Control Strategy, and Specifications and Ground-Source IHP Conceptual Design — FY06 Milestone Report. ORNL/TM-2006/143, May.

Murphy, R. W., C. K. Rice, V. D. Baxter, and W. G. Craddick (2007b). Air Source Integrated Heat Pump for Near Zero Energy Houses: Technology Status Report. ORNL/TM-2007/112, July.

Nordyne Powermiser Installation Certification—Alabama Power Company Heat Pump Training Center

Rice, C.K., (1988). Efficiency Characteristics of Speed Modulated Drives at Predicted Torque Conditions for Air-to-Air Heat Pumps, ASHRAE Transactions, Vol. 94, Part 1, pp.892-921.

Rice, C. K. (1991). The ORNL Modulating Heat Pump Design Tool — User's Guide, ORNL/CON-343.

Rice, C.K., (1992). Benchmark Performance Analysis of an ECM-Modulated Air-to-Air Heat Pump with a Reciprocating Compressor, ASHRAE Transactions, Vol. 98, Part1, 1992 pp.430-50

Rice, C. K., and W. L. Jackson (2002). DOE/ORNL Heat Pump Design Model on the Web, Mark VI Version October. http://www.ornl.gov/ wlj/hpdm/MarkVI.html.

RPC (Research Products Corporation) (2007). Personal communication with Aprilaire humidifier product sales representative, January. 
Rudd, A. F., J. W. Lstiburek, P. Eng, and K. Ueno (2005). Residential Dehumidification Systems Research for Hot Humid Climates. NREL/SR-550-36643, February.

Schoen, P., (2006). Personal communication to Van D. Baxter, May.

Schoen, P., (2007). Personal communication to Van D. Baxter, September.

Solar Energy Laboratory (Univ of WI), TRANSSOLAR Energietechnik, CSTB - Centre Scientifique et Technique du Bâtiment, and TESS - Thermal Energy System Specialists (2006). TRNSYS 16: a TRaNsient SYstem Simulation program, Version 16.01.0000.

Southern California Edison (2005). DEER Residential SEER-Rated Units Performance Maps Phase 2 Report: Performance Maps and Methodology Development. February.

Spencer, J., (2006). NREL, e-mail communication with Van D. Baxter of ORNL, September.

Thorne, J., (1998). “Integrated Space Conditioning and Water Heating Systems: One System Is Often Better than Two,” Report Number A982, American Council for an Energy-Efficient Economy, December.

Tomlinson, J. J., C. K. Rice, R. W. Murphy, and Z. Gao (2005). Assessment and Initial Development of a Small, High-Efficiency Heat Pump System for NZEH — FY05 Milestone Report, September 29.

United States Code of Federal Regulations (2007). "Uniform Test Method for Measuring the Energy Consumption of Water Heaters,” 10 CFR Chapter II, Part 430, Subpart B, Appendix E, 11-07 Edition.

U. S. Patent (1991a). No. 5,050,394, "Controllable Variable Speed Heat Pump for Combined Water Heating and Space Cooling,” September 24.

U. S. Patent (1991b). No.5,052,186, "Control of Outdoor Air Source Water Heating Using Variable-Speed Heat Pump,” October 1.

U. S. Patent (1992). No. 5,081,846, "Control of Space Heating and Water Heating Using Variable Speed Heat Pump,” January 21.

U S. Patent (1994). No. 5,305,614; Ancillary Heat Pump Apparatus for Producing Domestic Hot Water, April 26.

Witte, M. J., and R. H. Henninger (2006). ASHRAE 1254-RP, Evaluating the Ability of Unitary Equipment to Maintain Adequate Space Humidity Levels, Phase II - Final Report-Appendices. American Society of Heating, Refrigerating, and Air-Conditioning Engineers, Atlanta, GA, May 31. 